
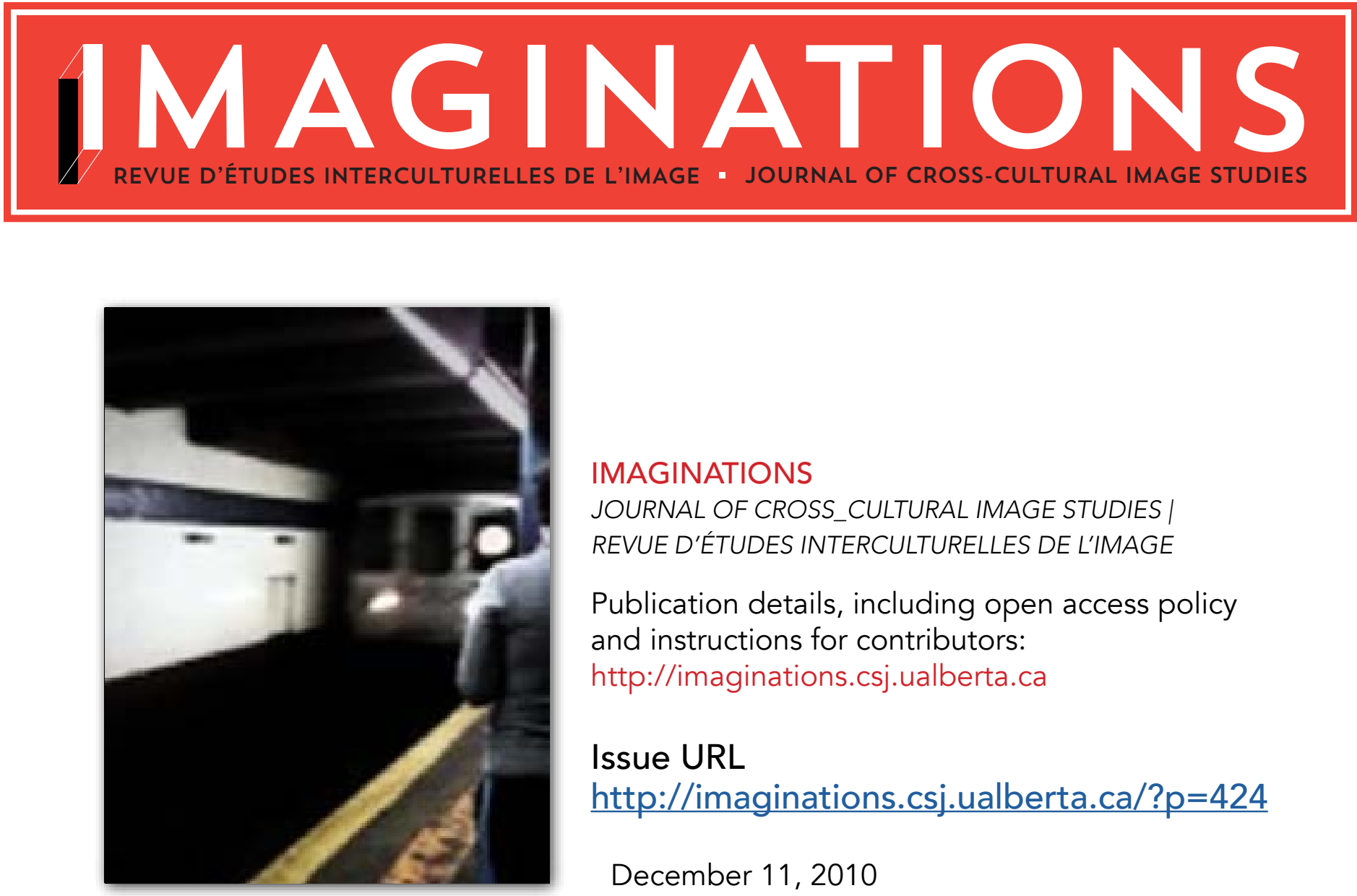

IMAGINATIONS

JOURNAL OF CROSS_CULTURAL IMAGE STUDIES |

REVUE D'ÉTUDES INTERCULTURELLES DE L'IMAGE

Publication details, including open access policy

and instructions for contributors:

http://imaginations.csj.ualberta.ca

Issue URL

http://imaginations.csj.ualberta.ca/?p=424

December 11, 2010

To link to this issue:

http://dx.doi.org/10.17742/IMAGE.inaugural.1-1

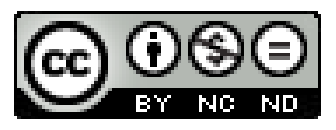

The copyright for each article belongs to the author and has been published in this journal under a Creative Commons Attribution NonCommercial NoDerivatives 3.0 license that allows others to share for non-commercial purposes the work with an acknowledgement of the work's authorship and initial publication in this journal. The content of this article represents the author's original work and any third-party content, either image or text, has been included under the Fair Dealing exception in the Canadian Copyright Act, or the author has provided the required publication permissions. 


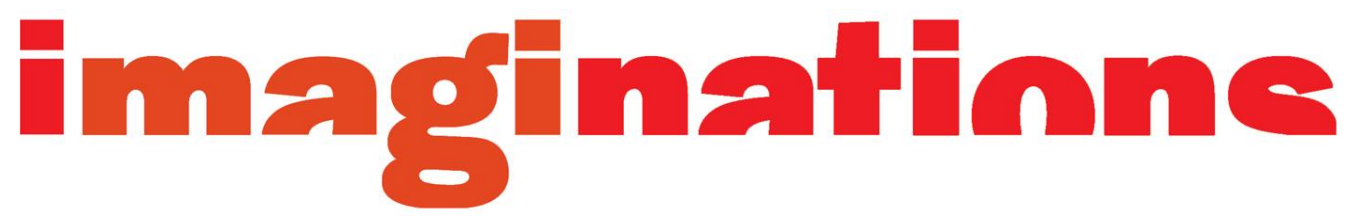

\section{After Imagining: Imaginations}

WE WELCOME YOU to Imaginations: Journal of Cross-Cultural Image Studies / Revue d'études interculturelles de l'image, an open-access online peer-reviewed journal born out of research and developments in cross-cultural and intersecting epistemological fields that have at their root a determined focus on the role and power of the image in contemporary culture and in cultural communications.

As Semiotics reinvested the notion of "sign" with new meaning, or as Cultural Studies expanded "text" beyond literary boundaries, Image Studies repositions "image" within ongoing critical discourses. Image Studies proposes a critical dialogue within an increasingly de-politicized public sphere, where the culture of the image in its capitalistic, impressionistic variance, filters and eliminates political and critical practices from the social realm. For Image Studies, "image" is more than just a visual imprint or-its other common notion-a reputation. With Image Studies, image, of course, can refer to visual art and persona (of an individual or group), but critically investigating the image is also a dialectical process of reclaiming subjectivity.

The range of possibilities offered here form mere starting points. While the fields of film studies, media studies, new media, and digital studies, to name a few, have challenged the academic filtering of the non-literary, the popular, and the technological, these fields can do a better job of speaking to not only one another, but also to older, more established disciplines.

With this in mind, Imaginations positions itself beyond nationalistic, cultural, and linguistic boundaries that pertain to the ongoing crisis of the nation-state in the West. Within this framework, culture can be understood as a nationally, politically, or economically determined space, but also more fluidly as a set of exclusionary social and linguistic practices. Cross-cultural exchanges allow for the recontextualization of images, which, in turn, can be read in terms of their 
displacement from their original context or their detachment from their new context. To this end, the journal auspicates the critically engaged participation of writers, readers, and forgers of the image, who find in Imaginations a venue for engaging in a continuous exchange of ideas and discourse practices. This dynamic will resituate the image beyond agent and object of spectacularization, consumption, and commodifying agency. This poly-framing of the image encourages the interrogation of image-bound and image-relevant narratives of social, political, aesthetic, and ethical discourses. Imaginations aims to foster interdisciplinary work that exceeds the boundaries of film studies, media studies, new technologies, communicative environments, and communities of practice, while also placing these in conversation with one another, and all the while focusing on how images act as cultural production and currency in and up to the present moment, across cultures and languages, in the age of instant access and diffusion in a globalized world.

We have chosen to utilize the open source format for the journal's dissemination to allow for a democratic diffusion of critical knowledge that will promote dialogue among a local and global readership. It is one of our goals to begin a multifaceted conversation amongst the academic discourses of analysis and the artistic communities of practice, and whatever configurations of those communities that might overlap, intersect with, or run parallel to one another.

The contributions in this inaugural issue have been specifically invited to begin such a conversation; in the articles, images, clips, dialogue, and book review essay, the authors and invited artist probe the image and its communicative power within a variety of cultural contexts determined by nation, language, and history, but also medium, spectatorship, discourse, and practice. This issue features a dialogue between artist and academic, five articles, and a comparative book review essay, all subject to a double-blind peer-review process. Parallel to Imaginations is the dynamic "On the Edge" review section, where it will be possible to read about developments in the field of image studies: reviews of publications in any language that address the image, and reviews of installations, performances, exhibits, architecture, etc. transpiring internationally (www.csj.ualberta.ca/imaginations). Read collectively, the journal and the review forum present heterogeneous crossnational perspectives on the role of the image in specific fields, cultural and linguistic contexts, and historical junctures. Moreover, the articles focus on a variety of image-making practices, theories, and media.

Central to each issue of Imaginations will be the presentation of new creative pieces by a guest artist, as well as a dialogue on the image proper and the featured work. This issue showcases three short videos, "Vidoodles," created by our invited feature artist Midi Onodera. These shorts are entitled Animal Crossing Underground, 
Blame Warhol, and If Wishes Came True, and they provide a point of entry for the critical exchange between communities of interrogations and practice. Herein, Sheena Wilson and moving image artist Midi Onodera converse in "Dialoguing on Miniature Cinema as New Art." Together, they discuss the dynamics of changing formats with regards to the image, given the various technological developments that have contributed to the dissemination of the image, and the context(s) that sustain these processes.

William Straw's article, "Cross-border Visualities and the Canadian Image," problematizes the use of determined images linked to Canadian spaces and identities, and analyzes how these specific images are translated and appropriated within American and international iconic codes. Marc Silberman's article, "Soundless Speech / Wordless Writing: Language and German Silent Cinema," discusses German expressionist film as a response to the crisis of modernism played out in the relationship between language and image. Bertrand Gervais' article, "The Vanished Child. An inquiry into Figures and their Modes of Apparition," drawing inspiration from Charles Sanders Peirce's semiotics, offers a fresh perspective on the concept of figure with a reading of French artist Sophie Calle's Disparitions. Fabrizio Scrivano's article, "On the Undecidability of Images," discusses the ambivalent role played by images in systems of communication, whereby they illustrate things and articulate meaning. Davide Sparti's article, "Images of a Sound: Portraits and Pictures of Jazz," analyzes the role of album covers in jazz music, from a socio-political perspective. Russell Cobb's comparative book review essay entitled "Publish and Anguish: Reconsidering the Never-Ending Crisis of the Humanities," examines three recent texts discussing the problematic state of the Humanities in the twenty-first century: Michael Bérubé's The Left at War (2009), Stanley Fish's Save the World on Your Own Time (2008), and Louis Menand's The Marketplace of Ideas: Reform and Reaction in the American (2010). Cobb's essay extends Image Studies into the larger framework of debates on disciplinarity, professionalism, and academia. All these articles present a spectrum of positions and readings that-together with the feature artists' contributions and the interview-demonstrate the scope that this journal proposes.

While the two primary languages of communication for the journal are English and French, the journal will foster cross-linguistic/cultural insemination and dissemination, problematizing specific ideological premises so as to encourage a critical and political debate beyond globalized and spent dominant discourses. Given Canada's intellectual polycultural background, the immediacy of such a project is sustained by its transcultural disposition. 
Thank you for participating in the inaugural issue of Imaginations: Journal of CrossCultural Image Studies / Revue d'etudes interculturelles de l'image. We look forward to the oncoming discursive and practicing communities that will find contemplative pause in this dynamic space, before imagining furthermore.

\section{Acknowledgments}

Imaginations: Journal of Cross-Cultural Image Studies was conceived during a series of conversations on the role of "the image" in contemporary society and the necessity for informed cross-cultural and cross-linguistic dialogues on related issues, which started between (in alphabetical order) William Anselmi, Daniel Laforest, Carrie Smith-Prei, and Sheena Wilson in the fall of 2008.

The editors would like to thank the following people for their skills and technical assistance in getting this inaugural issue online: Leah Vanderjagt, Maria Kutuzov, and Brian Neeland for their technical skills in navigating Open Journal Systems and for Web design; Ardelle Bakker for copyediting; Alberto Montanucci for the development of the graphic lettering of Imaginations; and Amanda Tillstrom for providing the site's background photograph. This journal has also required the support of expert translators: Lise Hogan for translating from Italian into English and French, and Genia Boivin and Samantha Cook for translating numerous texts into French. We would like to extend a special thank you to our invited feature artist and all the contributors including members of our editorial advisory board, our growing network of peer-reviewers, and readers.

Journal of Crass Cultural Image Studies - Revue d'Études Interculturelles de l'Image

Imaginations, I-I, 2010 Copyright (2. Open Journal Systems. ISSN - 1918-8439. 


\section{Après l'imaginer : Imaginations [тRa. SAuнurrin Conk]}

Nous vous SOUHAITONS LA BIENVENUE à Imaginations: Journal of Cross-Cultural Image Studies / Revue d'études interculturelles de l'image, un journal en ligne à accès libre dont les contributions sont préalablement soumises à un comité de révision par les pairs. Cette publication est le fruit d'un vif intérêt pour la recherche et la pratique au croisement de multiples champs épistémologiques et interculturels autour du rôle et de la puissance de l'image dans la société et les média contemporains.

À l'instar de la sémiotique ayant réinvesti d'une nouvelle signification la notion du « signe », comme des études culturelles ayant élargi le sens du « texte » au-delà des frontières littéraires, les études de l'image proposent un dialogue critique à l'intérieur d'une sphère publique de plus en plus dépolitisée, dans laquelle la culture de l'image, dans sa variante capitaliste et impressionniste, filtre et élimine les pratiques politiques et critiques du milieu social. Dans ce contexte, "image » ne renvoie pas qu'à l'empreinte visuelle. Elle peut évidemment se référer à l'art visuel et aux personnages (individus et groupes), mais l'investigation de l'image est également un processus dialectique dans lequel peut se redéployer la subjectivité.

L'éventail des possibilités évoquées dans le présent numéro n'est qu'un point de départ. Les domaines du cinéma, des nouveaux médias et des technologies digitales ont permis la remise en question du filtrage savant du non-littéraire, du populaire, et du technologique; ils ont du coup établi des niveaux différents de communication avec les disciplines plus traditionnelles.

En tenant compte de cela, Imaginations souhaite se positionner au-delà des frontières nationales, culturelles et linguistiques liées à la crise de l'état-nation qui a cours en Occident. Ces limites maintiennent la culture dans un espace déterminé selon des critères nationaux, politiques ou économiques, mais aussi par l'idée plus vaste d'un regroupement de pratiques sociales et linguistiques fermées, au sein desquelles sont les images circulent et sont interprétées. Nous croyons que les échanges et les ponts interculturels permettent pour leur part une recontextualisation salutaire des images. C'est pourquoi le journal invite la participation critique et engagée des auteurs, lecteurs et praticiens de l'image qui trouveront dans Imaginations un lieu pour l'engagement dans un échange continu d'idées et de pratiques discursives. Nous espérons que cette dynamique permettra de déplacer les images au-delà de la spectacularisation, de la consommation ou la chosification, cela afin d'inciter au questionnement des discours liés à l'image dans les sphères sociales, politiques, esthétiques et éthiques. Imaginations vise la promotion d'un travail interdisciplinaire qui ne se cantonne pas aux limites du

Journal of Crass Cultural Image Studies - Revue d'Études Interculturelles de l'Image

Imaginations, I-I, 20I0 Copyright @. Open Journal Systems. ISSN - 1918-8439. 
cinéma, des études médiatiques, des nouvelles technologies et des milieux de la communication; il souhaite plutôt engager ces disciplines dans un dialogue ininterrompu.

Nous avons choisi le format en accès libre pour la circulation du journal afin de permettre la démocratisation de la diffusion des savoirs critiques, ce qui encouragera le dialogue parmi un lectorat aussi bien régional que national ou mondial. Un de nos objectifs principaux est de maintenir le dialogue entre les discours savants et les communautés de la pratique artistique, en mettant l'accent sur les moments où ces deux approches se recouvrent partiellement, s'entrecroisent ou créent des parallèles insoupçonnés.

Les contributions qui forment ce numéro inaugural ont été sélectionnées spécifiquement afin d'initier un tel dialogue. Chacun des auteurs, en plus de l'artiste invitée, interroge les images en relation avec des contextes culturels, nationaux et historiques variés, ainsi que selon des champs disciplinaires résolument hétérogènes. On trouvera ici un dialogue entre une artiste et une chercheure universitaire, de même que cinq articles et un essai critique. De son côté la section "On the Edge" examinera des développements dans le domaine des études de l'image au niveau international : comptes-rendus de publications; d'installations artistiques, de spectacles, d'exhibitions, d'œuvres architecturales, etc. (www.csj.ualberta.ca/imaginations).

Chaque numéro de Imaginations comprendra des oeuvres inédites d'un artiste invité, ainsi qu'un dialogue avec ce dernier à propos de sa démarche et de sa conception de l'image. Le présent numéro offre trois vidéos, des «vidoodles", réalisés par notre artiste invitée Midi Onodera, intitulés Animal Crossing Underground, Blame Warbol et If Wishes Came True, et à propos desquels Sheena Wilson et l'auteure dialoguent dans "Dialoguing on Miniature Cinema as New Art". Ensemble, elles discutent des de la format de format face aux divers développements technologiques qui ont contribué à la dissémination de l'image.

L'article de William Straw, intitulé "Cross-border Visualities and the Canadian Image", problématise l'emploi d'une série d'images liées aux espaces et identités canadiennes et analyse la traduction et l'appropriation de ces images spécifiques à l'intérieur des codes iconiques américains et internationaux. L'article de Marc Silberman, "Soundless Speech/ Wordless Writing: Language and German Silent Cinema", aborde le cinéma expressionniste allemand comme une réponse à la crise du modernisme. L'article de Bertrand Gervais, "The Vanished Child. An Inquiry into Figures and their Modes of Apparition", puise une part de son inspiration dans la sémiotique de Charles Sanders Pierce ainsi que chez l'artiste française Sophie Calle afin d'offrir une perspective originale quant au concept de figure. Dans "On the Undecidability of Images", Fabrizio Scrivano interroge le rôle 
ambivalent joué par les images dans les systèmes de communication, à l'intérieur desquels elles illustrent des choses et des concepts en plus d'articuler des significations. Dans "Images of a Sound: Portraits and Pictures of Jazz", David Sparti analyse pour sa part le rôle des pochettes d'albums dans la musique jazz d'un point de vue interculturel. Enfin l'essai critique de Russell Cobb, intitulé "Publish and Anguish: Reconsidering the Never-Ending Crisis of the Humanities", examine trois textes récents qui portent sur la crise des sciences humaines à l'aube du XIXe siècle : The Left at War (2009) de Michael Bérubé, Save the World on Your own Time (2008) de Stanley Fish et The Marketplace of Ideas: Reform and Reaction in the American (2010) de Louis Menand.

Bien que les deux langues de communication principales de la revue soient l'anglais et le français, nous encouragerons l'insémination et la dissémination à travers langues et cultures afin d'inciter un débat critique et politique qui dépasse les discours dominants de la mondialisation.

Nous remercions les contributeurs et les lecteurs du numéro inaugural d'Imaginations: Journal of Cross-Cultural Image Studies/ Revue d'etudes interculturelles de l'image. Nous saluons à l'avance les communautés discursives et les pratiques créatives qui trouveront ici un espace de réflexion que nous espérons salutaire.

\section{Remerciements}

Imaginations: Journal of Cross-Cultural Image Studies / Revue d'etudes interculturelles de l'image a été conçu au cours d'une série de discussions sur le rôle de "l'image» dans la société contemporaine et sur l'importance des dialogues transculturels et translinguistiques concernant les questions liées à cet enjeu. Ces discussions ont lieu entre (en ordre alphabétique) William Anselmi, Daniel Laforest, Carrie SmithPrei et Sheena Wilson depuis l'automne 2008.

Les rédacteurs tiennent à remercier les personnes suivantes pour le partage de leurs connaissances techniques et de leurs compétences ayant permis la création de ce numéro inaugural en ligne : Leah Vanderjagt, Maria Kutuzov et Brian Neeland pour leurs connaissances techniques concernant la navigation de Open Journal Systems et le design du site Web ; Alberto Montanucci pour son développement du lettrage graphique de Imaginations ; Amanda Tillstrom pour la photo d'arrièreplan du site. Le journal a aussi bénéficié de l'appui expert des traductrices suivantes : Lise Hogan pour la traduction de l'italien au français et à l'anglais, et Genia Boivin et Samantha Cook pour la traduction de nombreux documents en français. Nous tenons particulièrement à remercier notre artiste invitée, Midi Onodera, et tous les contributeurs, en plus des membres de notre commission consultative de rédaction et de notre réseau de critiques, réviseurs et lecteurs. 


\section{imaginatinne}

\section{Maving Image Artist Midi Dnodera's Vidaodles}

Guest artist Midi Onodera has contributed three Vidaodles video shorts designed far miniature cinema - to this inaugural issue of /maginations. Неге аге her reflections on the pieces she has contributed:

FOR THE INAUGURAL ISSUE of Imaginations I created three Vidoodles ideally for consumption on a handheld portable device.

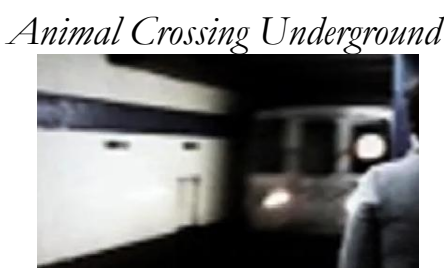

play

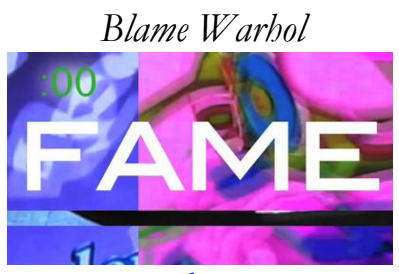

play

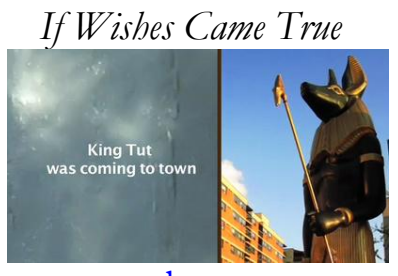

play

These shorts are designed for an audience on the go rather than a stationary viewer inside a dark theatre. For many urban dwellers much of one's daily life focuses on traveling from one place to another. Most of the time, we're too occupied with our own thoughts, conversations and distractions to take in our surroundings. Everything simply seems to blend together into a meaningless landscape of advertisements, continuous building construction, potholes and other pedestrians.

These video shorts are an attempt to pull the urban street life into sharp focus and

Jaurnal of Crass Cultural Image Studies - Revue d'Études Interculturelles de I'Image

Imaginations, I-I, 2010 Copyright (2). Open Journal Systems. ISSN - I9I8-8439. 
apply context and meaning to the blurry sensations swirling around like city jettison. Animal Crossing Underground and Blame Warhol represent typical Manhattan street life: the former, a staccato MTA subway ride and the latter, the overwhelming visual assault of Times Square. If Wishes Came True was filmed in Toronto, in front of the Art Gallery of Ontario during the recent King Tut exhibition. All three shorts were shot with amateur formats ranging from an iPhone to a "point and shoot" digital camera. I chose to work in these formats because of their ease of use and raw aesthetic. I am interested in peeling back another layer in our lives, showcasing scenes that we might overlook and defining the intangible.

\section{-Midi Onodera}

If you are interested in further information about these Vidoodles, please read the interview-dialogue between the artist in this same volume of Imaginations. For further details on Midi Onodera and her body of work, consult her website(http:/ / www. midionodera.com), her filmography, or contact her here. ADVD collection of her work from 1981 -2008 is also available is available for purchase through Art Metropole. Her films and videos can be rented from the CFMDC or $\mathrm{V}$ tape. 


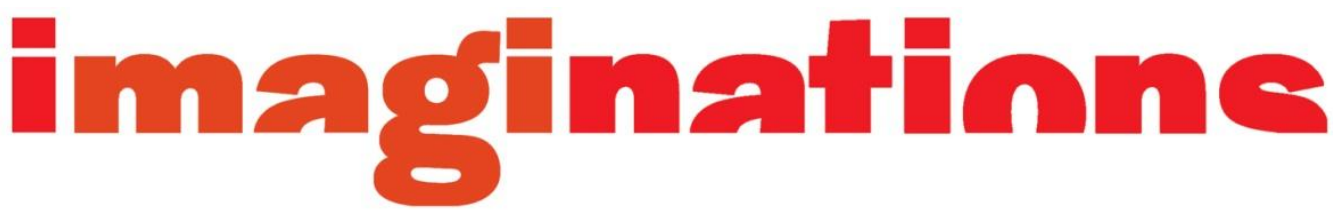

\section{Dialoguing on Miniature Cinema as New Art: Sheena Wilsan with Midi Znodera}

Sheena Wilson

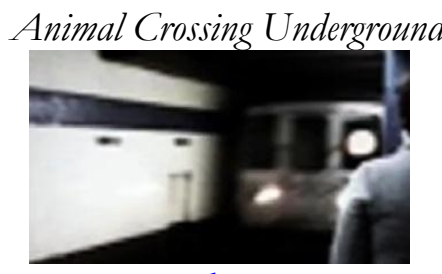

play

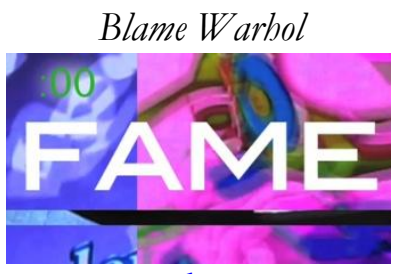

play

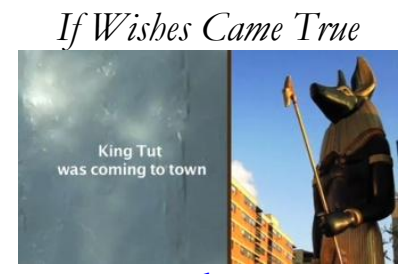

play

Backgraund information on Midi Onodera

Midi OnODERA IS A WeLL-RECOGNIZED Canadian filmmaker with more than thirty years of filmmaking experience. She has had screenings internationally at such prestigious venues as the Andy Warhol Museum, the International Festival of Documentary and Short Films, Bilbao, Spain, the Rotterdam International Film Festival, the Berlin International Film Festival, the National Gallery of Canada, and the Toronto International Film Festival. Her first film, a seven-minute short film entitled Reality-Illusion that she shot on Super Eight, appeared in 1979, while she was still in high school. She now has twenty-four films, two television writing credits, two commissioned artist profiles, two feature length works, two interactive DVDs, 434 short videos, and a total of 467 films and videos to her name.

Starting in November 2006 and continuing for one year, Onodera worked on the A Movie a Day project, and an article on this project was featured in CineAction in $2008 .^{12}$ As part of that project, she created one 30-45 second video per day for 
Imaginations / Wilsan II

365 days. These films explore a variety of issues and social situations from a variety of perspectives that are occasionally specific to Onodera's own life and viewpoint but also include the perspective of fictional characters. In the article mentioned above, published as "Mini-Camera: A Digital Diary for iPod," Catherine Russell has argued the following:

The 365 videos rigorously interrogate the nature of the "image" as an object. The techniques Onodera uses include a play with framing in which the image size and shape is consistently varied, a dynamic use of saturated colours, and special effects that alter space and time. An extensive palette of designer colours are used to frame the videos, making interesting contrasts with the many striking images of nature. The rich colours contribute to the object-like nature of the image. (3-4)

As an acknowledgement of Onodera's long and productive career as a Canadian artist and filmmaker who has consistently demonstrated critical engagement with her subjects and her chosen media, we have invited Onodera to be the guest artistfilmmaker for the inaugural issue of Imaginations: Journal of Cross-Cultural Image Studies.

\section{In Dialogue}

Sheena Wilson: Hello, Midi. I would like to thank you for accepting the invitation to be the guest artist-filmmaker for the inaugural issue of Imaginations, and for agreeing to participate in this dialogue. ${ }^{3}$ As you know, the vision that the editorial board has for this journal is to use it as a vehicle to transcend some of the traditional boundary lines between academia and the critics, and artists and filmmakers working with images. One of our goals is to create an ongoing conversation between various communities that intersect because of a shared interest in the role of the image in the current image-dominated culturalmediascape; our conversation is the beginning of that process. You were invited as the guest artist for many reasons, including the fact that your work deals with cross-cultural aesthetics and images, as well as the fact that you are working in the cutting edge area of miniature cinema.

I am drawing attention to 365 because the video-shorts that you have created specifically for this inaugural journal issue are in the same vein as those created for that project. Also, your use of images, or image as object, as Catherine Russell refers to it, aligns well with the focus of this inaugural issue, devoted to defining theoretical frameworks for image studies through variegated approaches to manifestations of the image as it is informed by different cultures, national histories and linguistic traditions. I hope that we can address most of these issues during the course of our dialogue.

Journal of Crass Cultural Image Studies - Revue d'Études Interculturelles de l'Image

Imaginations, I-I, 2010 Copyright (2. Open Journal Systems. ISSN - 1918-8439. 
Perhaps the best way to do this is to begin our discussions of these issues by addressing the three feature videos that you created specifically for Imaginations. I must say that I appreciate how you have created three dramatically different videos: Animal Crossing Underground, Blame Warhol, and If Wishes Came True. Do you think you could comment on how each of these videos was inspired by the Call For Papers and the focus of Imaginations and how each of these miniature films is, as you see it, a commentary on the relationship of the image to our contemporary lives?

Midi Onodera: First of all, Sheena, thank you very much for the honour of being involved with the inaugural issue of Imaginations. I welcome a forum that encourages dialogue between academia and artists and a journal that utilizes the tools of digital publication. In some way, the three shorts that I've made are ideally suited for your intended audience and form of dissemination.

As you've mentioned, these shorts have their roots in the A Movie a Day project, as well as the Movie of the Week project. For four years now I have been making short videos for personal viewing: either online or for portable viewing devices such as the iPod, etc. I see these movies as a form of miniature cinema: intimate, temporal, and spontaneous. These tiny movies or, as I call them, "Vidoodles," have a very different relationship with the viewer than larger screen movies. Unlike conventional cinema that draws on techniques and a visual/auditory vocabulary of over one hundred years, tiny cinema's history is only five years old, marked by Apple's introduction of their fifth generation iPod with video playback capability. There are vast unexplored and unexploited opportunities for visual and audio manipulation in this new format, and even after making over four hundred titles, I know that I am only superficially scratching the surface. Therefore I am very interested in participating in this dialogue to both further my understanding of this unique viewing format and to begin forming a critical framework in which to examine these wireless, portable artist-produced works.

I call these shorts "Vidoodles" because like a doodle these videos are meant to be an almost unconscious form of expression. I wanted to challenge myself to create an everyday amusement, a thought or quote for the day but in the form of moving images. Obsessively-crafted within a limited timeframe, I sometimes think these Vidoodles have a stronger relationship to folk art than cinema. My Vidoodles are similar to many personal YouTube postings: these videos reflect the passionate interests of the maker, whether it be an amateur glee club or a makeup demonstration. These movies are designed to attract an audience of like-minded individuals, a social network. This is an audience that makes public comments, creates mash-ups and reworks posted videos to create their own personal statements. This is the context for online videos, it is dominated by the personal and the DIY culture. In some ways, it is the contemporary version of the soapbox in the park.

Journal of Crass Cultural Image Studies - Revue d'Études Interculturelles de l'Image

Imaginations, I-I, 2010 Copyright (2). Open Jaurnal Systems. ISSN - 1918-8439. 
But I am not naïve or idealistic enough to believe that there are vast numbers of like-minded souls devouring videos in the privacy of their homes. In reality I think that unless a video has gone "viral," then the chances are quite high that one's audience is made up of friends, family, and a few strangers who happen to stumble upon your posting. This is the flip side of online viewing: what if no one is watching? For me, the practice of online video-making is a constant rebalancing of the desire for anonymity and pull for increased audience numbers, although I think that I am more weighted to the anonymous side.

The shorts that I made for Imaginations are very much tied to different forms of digital communication. My world has always included a screen. Although I am old enough to remember black and white television, I have become a game addict with a number of gaming consoles, a collector of digital toy cameras, and an incessant computer and iPhone user. I tweet, text, and automatically refresh my email every minute. (But oddly my presence on Facebook is more of a lurking ghostly inhabitant than active participant). This is the context in which I make these Vidoodles.

Specifically these forms of insta-communication have provided me with more toys to play with in the digital sandbox. For instance, both Animal Crossing Underground and Blame Warhol use manipulated Nintendo DS scores. These tinny sounding MIDI soundtracks are ideal for the earbud generation. The metallic taste of these tracks is both soothingly familiar and abrasive. The soundtrack for Blame $W$ arbol is from SonicRush Adventure, a SEGA produced title, featuring Sonic the Hedgehog. This endlessly climaxing, relentless soundtrack evokes a hypertensive feeling, a sense that one is on the brink of fame, within reach of conquering the villain or winning the game. In contrast, Animal Crossing Underground utilizes the ambient tones of the passive almost non-game Nintendo title, Animal Crossing Wild $W$ orld. This movie also employs an unconventional frame format or screen size, something which at this point can only be achieved using software programs such as QuickTime. Further, this short is an animation, made up of one hundred-plus stills taken with my iPhone using the QuadCamera App.

I have always been interested in how we see the world through visual technologies. Having cut my teeth on the Structuralist films of the 1970s, I challenged myself to examine the fundamental qualities inherent in film: grain, composition, superimposition/dissolves. Now, several decades later, I find myself playing with similar formal concerns, except now the palette is not limited to film stock, the camera, film processing, and editing but it encompasses a diverse range of different image and sound creating equipment. But just as our storage shed of image-making tools has expanded, our narrative sense of storytelling has also shifted. More and more ideas, concepts, and conversations can be distilled into 140 characters, slogans, branding devices, and catch phrases.

In the end, however, there is still the relationship between the viewer or user (in the case of participatory works) and the moving image. Do you see these miniature movies differently than you do theatrical or gallery-situated works? In

Journal of Crass Cultural Image Studies - Revue d'Études Interculturelles de l'Image

Imaginations, I-I, 2010 Copyright (2. Open Journal Systems. ISSN - 1918-8439. 
what ways do we experience contemporary moving images that are similar/dissimilar to the past? As an academic, how do you frame discussions in "cross-cultural image studies" within the ever-evolving state of both political globalization and technological advancement?

Sheena Wilson: I'll answer your last question first and then go back to your other questions about delivery format and reception: big screen versus miniature screens. Your question regarding how I frame discussions in cross-cultural image studies within the ever-evolving state of both political globalization and technological advancement, speaks to the focus of Imaginations. The short answer to this question is that I frame the discussion of any image in relationship to the context out of which it originates and the reverberations it has in the culture or cultures of its reception at one or more historical moments. Some images can communicate a consistent message across time and culture and others cannot. Some images are recuperated over time, transforming the original message. This, in fact, is the theme of the next issue of the journal: "Stealing the Image."

However, the use of the term "cross-cultural image studies" as it appears in the journal title refers more specifically to our desire to address images from a diversity of cultural contexts, and not specifically to discuss images that do, or do not, transcend cultural borders, however porous they are rendered by technological advancements in global communication.

Now, to answer your question about whether I see miniature movies differently than theatrical or gallery-situated works, the answer is yes. I do agree with you that the big screen and the miniature screen function very differently. You made specific reference to the different technical tools and applications used in the production of these different film formats. I'd add to that the fact that gallery-situated film is typically constructed according to more classical notions of narration and storytelling, even experimental film is in dialogue with those expectations. The subjects of gallery films, regardless of the specific genre, are generally developed over a long period of time, require significant funding-which comes with its own implications - and the message often makes social or political commentary, either implicitly or explicitly. Stories, after all, are how we understand ourselves, our world, and our place in it. Viewers take time to watch and to consider the message of such a film, often in a communal setting. When viewed in a movie theatre, the venue requires a certain amount of social interaction and it is received as a shared experience. Beyond that, gallery films usually receive at least some attention from film critics.

Transformations are now taking place in the world of moving images - movies and videos - that can be compared to what happened decades ago in the music industry; historically music was performed live and it was a communal experience. Then, the advent of vinyl LPs allowed music to be recorded and played on a gramophone or stereo; later technological developments resulted in the 8-track, the cassette, the CD player, and then the Minidisc (to lesser commercial success),

Journal of Crass Cultural Image Studies - Revue d'Études Interculturelles de l'Image

Imaginations, I-I, 2010 Copyright (2). Open Journal Systems. ISSN - 1918-8439. 
and we now play music stored on computer files. The similarities that I see between earlier developments in sound technology and more recent transformations in movie-image delivery devices are largely in people's reactions to the notion of individual or private experiences as replacing the communal viewing experience. People once balked at the notion of recording music and listening to it in a private space. In fact, the Walkman was originally designed to have two headsets because the belief was that no one would want to listen to music alone. Ultimately, market trials proved that this was not to be the case. Moreover, we know that sound recordings did not, as some feared, separate the individual from the larger cultural experience. Neither will this occur with the increased popularity of individual viewing experiences. The concept of watching a movie alone or in a private space using a VCR or DVD attached to the home television has long been accepted. However, as you know, since the release of the iPod, film/ video/moving image technology has become as portable as sound (music) technology, and this is having ramifications not only on how we receive visual messages but on the form those moving image messages are taking. Now, we are not simply watching feature length movies on the go or catching the latest episode of our favourite TV drama while riding the bus; the iPod has inspired a new genre of miniature-cinema that is responding to this new medium.

These miniature movies are for consumption on a dynamic individual basis, and as such, they are filmed with technology that corresponds to the small screen. Unlike some shows where visual clues might be provided in the background as you watch, the miniature screen does not allow for this kind of visual detail. Also, it is very significant that miniature films are not only smaller but shorter. These visual messages are conveyed as an "image-bite" (sound-byte) and received more like the way in which one would view a commercial. The amount of time that certain viewers or communities of viewers spend watching the film may be proportionate to the time he/she spends reflecting on the issue; given, there are engaged viewers who fall outside these categories. Paul Virilio saw speed as an innately transformative agent of contemporary civilization. Therefore, I'm very interested to discuss further with you your perspective on the short delivery format of miniaturecinema given that you are a pioneer in the exploration of miniature-cinema.

However, you had asked, "In what ways do we experience contemporary moving images that are similar/dissimilar to the past?" and my answer to you would be that the general viewer, both past and present, to varying degrees, is looking for the message being communicated via the images, with an eye to the way they are combined and juxtaposed in order to create meaning. People are always seeking meaning, and certain communities of critical viewers even more so. Earlier, you drew a parallel between your "Vidoodles" and the soapbox in the park. The metaphor of the soapbox, of course, makes recourse to political speech and action. Therefore, my next question to you would be whether you see

Journal of Crass Cultural Image Studies - Revue d'Études Interculturelles de l'Image

Imaginations, I-I, 2010 Copyright (2. Open Journal Systems. ISSN - 1918-8439. 
"Vidoodles" as having a political message? What is the transformative power of miniature-cinema as an art form?

Midi Onodera: You've touched upon many different aspects of image making and the varied relationships between the viewer and the image: communal and individual. How one sees the work plays a very big role in how one interprets the content of the movie. Stepping back further to the conceptual stage, it's important to discuss why one would choose to create movies within the framework of the small screen in the first place. Over the years filmmaking has morphed into videomaking. Today, there is very little distinction between the two. Film festivals now show videos or digital copies rather than celluloid film prints. Production costs have diminished, allowing more people to make movies. People without formal filmmaking educations can now create their feature length masterpieces and post the work online for the public to view. But is the possibility for widespread distribution the only reason one would choose to produce work for the small, portable screen?

For myself, distribution is one factor, but it was more an afterthought than the main reason I became interested in this format. After making Skin Deep (1995) I became disillusioned with the politics of traditional filmmaking. I spent so many years trying to raise the funds to produce that theatrical feature that I lost sight of what was important to me. I found myself making compromise after compromise, and gradually the content of the film became less important than getting it made. For five years following Skin Deep, I struggled with the idea of ever making another film again. Instead I worked in watercolours and carved large wood "paintings" and kept it all locked away in my studio. But around that time, electronic toy manufacturers began to produce toy cameras for children.

Back in 1987 when the Fisher Price PixelVision camera (PXL-2000) came out, I was a starving artist unable to buy the precious device that recorded fuzzy black and white images onto cassette tape. I vowed I would never let another toy camera slip through my fingers and eagerly purchased the latest gadgets for children. At first I had no idea how to work with this new format. The fixed lens and camera bodies were made from cheap plastic, and the recording capacity limited to a few minutes. The resolution of these recordings was so low that it would make it extremely difficult to show in a theatrical setting, never mind ever conforming to broadcast standards. But since I had turned my back on large budget productions, these limitations were exactly why this form appealed to me. Working with toy cameras made creating moving images fun again.

As I mentioned before, the birth of portable cinema really began with the first iPod capable of video playback. With this innovation, my toy camera-produced works finally had a distribution platform. Although iTunes began to sell feature length movies reformatted for the iPod, this reduced version of a theatrical experience did not appeal to me. Beautifully composed wide shots that were breathtaking on the large screen were reduced to tiny landscapes for ant-sized

Journal of Crass Cultural Image Studies - Revue d'Études Interculturelles de l'Image

Imaginations, I-I, 2010 Copyright (2. Open Journal Systems. ISSN - 1918-8439. 
characters. The loss of so much visual detail and the isolated viewing experience created a clear distinction between the large screen and the tiny screen.

I began to experiment with what kinds of images "worked," the use of audio heard not through speakers but headphones, the use of text-the font size, placement, and style. I discovered the subtle visual differences between the digital VCamNow and the Mattel Vidster versus analogue toys such as the Barbie Camera and TrendMaster video camera. I worked with aspect ratios and video compressions and allowed myself the freedom to manipulate the footage in postproduction.

I never saw these miniature movies as "calling cards" for a traditional career in filmmaking. These are not movies that can be easily translated to the large screen; they are specifically made to hold in the palm of your hand. But because of the portability of this format, the viewing context in which one can watch miniature movies is incredibly varied. We are no longer restricted to special locations such as movie theatres or galleries, living rooms, etc. in order to view moving images. The video screen now dominates public spaces from monitors showcasing the baggage claim network in airports, to elevators, washroom stalls, and of course electronic billboards.

Obviously these public screens are different from the personal screens we carry in our pocket, but they are linked through an urban context. I imagine that the typical urban iPod video audience is on the go, traveling to and from work on public transportation. In order to make the trip more bearable the portable viewer distances him/herself from the reality in front of his/her eyes. In a way, the iPod screen becomes dominant, and reality falls into the peripheral.

The Vidoodles that I made for Imaginations and most of my other small format shorts are shot spontaneously. While going about my daily life, I happen upon moments or locations that I find compelling. It could be an unusual interaction, an odd juxtaposition, or simply a moment in time. Most of these shots eventually evolve into tiny narratives. Because these Vidoodles are produced very quickly I've learned how to carefully narrow my production parameters and therefore my shooting ratio is very small. I carve these narratives out of material found littered in the street, from a direct experience of the reality in front of me. This relationship that I have with the images is almost in direct opposition to the escapist desires of the urban iPod audience. I am trying to call attention to the moments we may have overlooked or want to avoid.

For instance, Blame $W$ arhol can be viewed in the location where it was filmedTime Square, NYC. Watching the Vidoodle in situ amplifies the viewer's relationship to the visible bombardment of commercialism dominating this physical location. But is it simply a reinforcement of this physical reality or does it make the viewer conscious of our growing obsession with celebrity and consumption? I would hope that Blame $W$ arhol reawakens how we perceive the reality in front of us, reclaims the peripheral experience and forces it into focus.

Journal of Crass Cultural Image Studies - Revue d'Études Interculturelles de l'Image

Imaginations, I-I, 2010 Copyright (2. Open Journal Systems. ISSN - 1918-8439. 
Animal Crossing Underground could work similarly, challenging the audience to reexamine a mundane subway ride.

If wishes came true works on another level: it is a reflection of urban reality, but the narrative also evokes childhood memory, desire, and imagination. The split screen device works to separate and contrast these two worlds. Yet the overall connection with present-day reality is still visible through the imagery of the Egyptian god Anubis set against a downtown cityscape.

Looking back at what I've written, I realize that I have only provided partial answers to some of your questions and perhaps I have just complicated our discussion even further. I'm not sure if I could answer the question, "[W] hat is the transformative power of miniature-cinema as an art form?" That seems to be a never-ending discussion in itself. I feel the same way about the question of whether my Vidoodles have a political message. To answer this I think we would need to define what a moving-image "political message" is in the landscape of media consumerism and consumption. How does one differentiate between a political message and a "Just Do It" Nike advertisement, or is this distinction even important?

Sheena Wilson: It is true that current communicative technologies and the associated communicative environments have created a specific fluidity regarding the political spectrum, a fluidity that allows for a plurality of simultaneous messages, contradictory, paradoxical, and/or evanescent, to instantly diffuse via the networks of communication. However, in the age of instancy or immediacy gratification, this post-political climate risks merely creating a noncommittal/ethical political action-post-political participaction - that reinforces the dominant discourses, however masked they might be by the communicative environments. ${ }^{45}$ And, in order to define what a political message entails in the context of current communicative environments is to first acknowledge that in the present situation the image is instantly diffused in such ways that the contexts of production, the contexts of diffusion, and the contexts of critical engagement are no longer knowable, in many/most cases: neither to the artist, nor to different communities of viewers respectively. Current communicative technologies thus result in an erasure of contexts, both of production and of reception. The image might still have, when necessary to strict ideological enterprises, some possible political message, but it depends on how it is created, used, consumed, distributed, filtered, recontextualized, re-invented, re-circulated, etc.

In any case, your responses have given your viewers (and our readers) some insight into your changing relationship to the moving image by indicating how toy cameras and miniature cinema have, in fact, inspired you anew to use video- the moving image - as your medium of expression. However, I'd like to ask more specifically how you see yourself in relationship to the camera. Are you a filmmaker, an artist, a collector of images, a narrator of contemporary life, all of the above, or none of the above?

Journal of Crass Cultural Image Studies - Revue d'Études Interculturelles de l'Image

Imaginations, I-I, 2010 Copyright (2). Open Journal Systems. ISSN - 1918-8439. 
On a related note, regarding how you identify as an artist, I cannot end this conversation without touching on the ethno-cultural influences in your filmmaking. I am most familiar with your film The Displaced View-a film that I have called your ethnic coming out film, since your films prior to that did not directly address your Japanese Canadian heritage-and a film that makes use of Japanese literary motifs, visual symbols, and images. Related to that, I've always been intrigued by your use of fairytale and poetry in your film/videomaking. Poetry and elements of classic stories and storytelling techniques are present in many of your earlier experimental films, including The Displaced View, and your Vidoodles. These narrative techniques also seem linked to the use of the split screen that you just referred to as a way to represent multiple realities at once. Could you comment on the role of poetry, fairytales, classic storytelling techniques, and the more technical elements of visual communication such as colour, split screens, graphics, collage, etc., in constructing your films and Vidoodles? Simply stated, how do you self identify and how does this impact your artistic vision and your artistic production?

Midi Onodera: It's funny that you ask if I consider myself to be a collector and a filmmaker. The latter is a term that I have been wondering if I can continue to use to describe what I do. From the beginning of my career I have made a clear distinction between film and video. Back in the 1980s the terms filmmaker or artist filmmaker connoted a specific practice in the context of art production: experimental, non-industry, and non-traditional. Similarly, video artists had their own history based more on alternative narrative structures and the aesthetics of analogue video. Today, however, I see myself more as a moving image artist: someone who is working in different areas of media production, discovering the inherent qualities of each medium and exploring these through an alternative story-telling framework. I would say I see film, video, and moving images as a continuum rather than separate disciplines such as experimental film, artist videos, and new media. Over the years I have become a collector of images, and through the collection process I adapt, shift, and question those images and how we process them.

An example of this would be my video I have no memory of my direction (2005). This piece was an informal follow-up to The Displaced View (1988). I have no memory of my direction was shot in Japan over five months between the early spring and late fall of 2003. Rather than approach the video as I had previously done with my other scripted work, I decided to shift my approach and tackle the work in a more freeform way. Having never been to Japan, I was unsure of what I might discover there. The only elements I had to work with before I arrived were vague family histories and pop culture references flavoured with fairy tales and contemporary myths. The one constant framework was Chris Marker's film Sans Soleil (1983). This essay film masterwork deeply influenced my approach to image making, and I wanted to pay homage to Marker while constructing counterpoints from the

Journal of Crass Cultural Image Studies - Revue d'Études Interculturelles de l'Image

Imaginations, I-I, 2010 Copyright (2). Open Jaurnal Systems. ISSN - 1918-8439. 
perspective of a woman of Japanese descent. Arriving in Japan, a few days after the 2003 invasion of Iraq, I armed myself with various cameras (toy, traditional video, and still cameras) and dove into the culture. My agenda consisted of visiting different locations that were in Sans Soleil and locating my relationship with those spaces.

Each day I would leave my apartment before the overwhelming Tokyo rush hour and head off to a few places I tracked down from the film. I would observe the area and try to imagine what Marker might have seen twenty years earlier. What had changed? How did I view the scene differently? What did this place mean to me? I would unpack my gear and film images that captured my attention. From these original Sans Soleil locations, I discovered links to other places and connections with family back in Canada and a family I had never met in Japan. Every night I would return to home, log my shots, and jot down my impressions of the day.

My first trip lasted about three months. Returning home, I mulled over the footage and

watched my father struggle with Alzheimer's. I became obsessed with memory: familial, personal, and cultural. I chose the framework of a dream because I didn't want to be limited to a documentary perspective; I wanted to create a fantasy that flowed in and out of the crevices of reality, a form that might resemble a shifting memory or a dream. I returned to Japan in the fall and picked up the missing shots that I needed to shape the dreamscape. The Japanese title of the video is Yume Oi, which roughly translates to "chasing the dream."

Making this video in this non-scripted manner was particularly challenging, and through the process I honed my skills of quiet observation that later became essential in creating my Vidoodles. Living on an overpopulated island with people who physically looked like me was an experience I had never had. Although I had always self-identified as a Japanese Canadian, I realized that I had to a certain extent been mythologizing my Japaneseness. On many levels this created ethnic mythology has shaped my work. However, I do not see this in isolation to the other aspects of my identity. I cannot separate my ethnicity from my sexuality from my gender identity. They are all intrinsically linked and sometimes in conflict with each other.

The visual manifestation of this shaded identity could be subconsciously tied to my multi-screen devices that seem to permeate the Vidoodles. Obviously the use of multiple screens has invaded our visual landscape through advertising and the omnipresence of public and private screens. How we now digest these multiple moving image screens is vastly different today from just a few decades ago. I remember, as a five year-old child, attending Expo 1967 in Montreal and visiting the Ontario Pavilion. Christopher Chapman created A Place To Stand, a fifteen-screen portrait of the province with six-channel surround sound. Engulfed by the orchestral soundtrack, I felt transported to another world, not one that actually existed but one that was locked away in my mind's eye. The sheer diversity

Journal of Crass Cultural Image Studies - Revue d'Études Interculturelles de l'Image

Imaginations, I-I, 2010 Copyright (2). Open Jaurnal Systems. ISSN - 1918-8439. 
of the multiple images was inspirationally irresistible, and I think I must have childishly come to the decision that making images was what I wanted to do, but it wasn't until I picked up my first Super 8 camera in high school that I had the opportunity to pursue my dream.

Being involved with this dialogue for Imaginations has forced me to consider the trajectory of my practice and has demanded that I examine, evaluate, and articulate what that means. It's not an easy process to go through. To a certain extent, I want to hide behind the traditional artist's mask and tell you that it is up to your interpretation, as a viewer, an academic, someone who is forging a path or paths between the audience and the maker. But that would be the easy way out, less challenging and less threatening. By agreeing to this process I have exposed fragments of myself that I have kept private. These fragments, to some degree, are the shards that I use to piece together a facsimile of a screen identity, characters that become woven into imaginary landscapes that confront or avoid the complexities of that space.

In 1990, I was invited to create an artist profile on David Cronenberg for the Toronto Arts Awards. During the interview he spoke a bit about the "surgical impulses" of an artist: the desire to "cut open the surface skin, and then once beyond that, to make sense of what lies beneath it." He spoke about how art can be dangerous to the artist: the drive to push oneself over the edge, into the abyss of the unknown. I would add that there is nothing more exhilarating and melancholic than completing a work. The dizzying intoxication one feels when absorbed in creating something is highly addictive.

But there's nothing like that first time, and one is always searching to recapture that extraordinary experience again and again. For some, however, the process of analyzing the artistic cocktail endangers the magic and destroys the high. I like to think of myself as a cultural mixologist: just as I need to keep increasing the potency of my own work, I also want to understand the ingredients better in order to reach that next level (of scrumptiousness).

If you are interested in further information about these Vidoodles, please read the interviewdialogue between the artist in this same volume of Imaginations. For further details on Midi Onodera and her body of work, consult her website(http:// www.midionodera.com), her filmography, or contact her bere. A DVD collection of her work from $1981-2008$ is also available is available for purchase through Art Metropole. Her films and videos can be rented from the CFMDC or $\underline{V \text { tape }}$.

\section{References}

Anselmi, W. and Sheena Wilson. "Performative Radicalism in contemporary

Canadian documentary film." Film International \# 37. 7.1 ( 2009): 44-53. Atypon. Web. http://www.atypon-link.com/INT/doi/pdf/10.1386/fiin.7.1.44

Jaurnal of Crass Cultural Image Studies - Revue d'Études Interculturelles de l'Image Imaginations, I-I, 2010 Copyright (2). Open Jaurnal Systems. ISSN - 1918-8439. 
Anselmi, W. and Sheena Wilson. "Technologies of Memory, Identity and Oblivion in Persepolis (2007) and Waltz with Bashir (2009)." Representation of the Self in Iranian Literature, Art, and Film. Ed. Manijeh Manani. Athabasca UP. Forthcoming 2011. Print.

\section{Endnotes}

${ }^{1}$ This project is referred to as both "A Movie a Day" or "365."

2 Russell, Catherine. "Mini-Camera: A Digital Diary for iPod." CineAction. Toronto. Issue 73/74 2008.

3 This dialogue took place in written format, via e-mail correspondence.

4 These terms come from an article co-authored with Dr. William Anselmi entitled "Technologies of Memory, Identity and Oblivion in Persepolis (2007) and Waltr. with Bashir (2009)," forthcoming in 2011 with Athabasca University Press. In that article we explain the following: "These two terms refer to the current sociocultural condition created by technology. On the one hand, we can be in multiple spaces simultaneously and, on the other, the grand narrative of postmodernism has transformed History into a plethora of diluted/deluded narcissistic performances/stories for commercial use."

5 The term "post-political" comes from previous and ongoing collaborative work with William Anselmi where we refer to the post-political as a current reality where the historically understood political spectrum has been mutated, such that it has merely become a rhetorical reference in a post-political reality where all positions on the spectrum can simultaneously be attributed to one individual or action in a media frenzy where there is no responsibility to history and its references. Likewise, all perspectives on the political spectrum can simultaneously exist and find viewership without having to acknowledge or be acknowledged through critical debate, thus eliminating dialectical processes

Journal of Crass Cultural Image Studies - Revue d'Études Interculturelles de l'Image

Imaginations, I-I, 2010 Copyright (2. Dpen Journal Systems. ISSN - 1918-8439. 


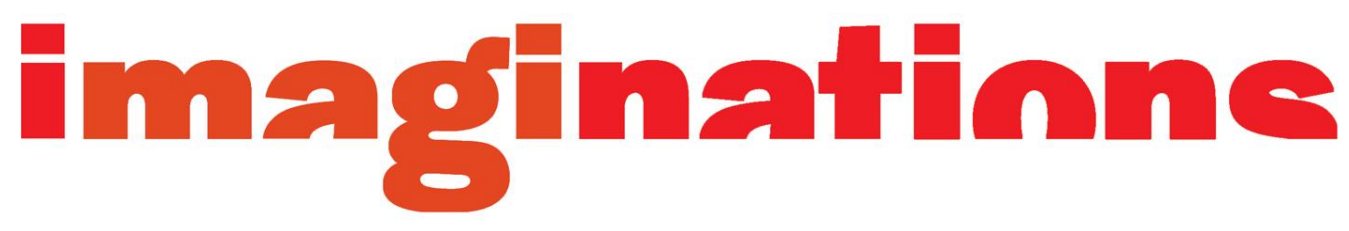

\title{
Cross-Barder Visualities and the Canadian Image
}

\author{
Will Straw
}

In THE COURTROOM SCENE of the 2002 film Chicago (dir. Robert Marshall), Roxie Hart (Renée Zelwegger) is being tried for the murder of her abusive boyfriend. Shot in Toronto, and featuring a number of Canadian performers, this scene condenses, I will argue, common patterns by which Canadian cultural materials share visual space with others originating in the United States. I begin with this scene as a way of raising a set of questions having to do with popular visuality in Canada. In what ways do images produced in Canada betray some of the broader features of Canada's relationship to a variety of cultural elsewheres and, most notably, to the United States? If we are rightfully suspicious of attempts to isolate visual forms that are coherently or exclusively Canadian, might we speak, nevertheless, of characteristically Canadian inflections of the image?

My intention here is not that of rushing to develop a Canadian version of the "pictorial turn" that has been observable across the humanities over the last decade (Curtis 95). Given the rich traditions of art-historical thinking already concerned with image-making in Canada, this could only be both belated and presumptuous. (See, among many examples of important work, Nelson; O'Brien and White). By treating several images in terms of the ways in which they stage some of the predicaments of Canadian cultural expression, however, I hope to contribute in a speculative fashion to the study of Canadian popular visuality. Some of the images to be examined here are photographs and paintings; others are 
sequences from films. These are not all "pictures" in the same way, of course, and those that form part of narrative feature films invite readings that would acknowledge their larger textual surroundings. Nevertheless, the audiovisual excerpts discussed here function as relatively circumscribed tableaux that allow me to detach them, for the purposes of analysis, from the larger narrative structures to which they belong.

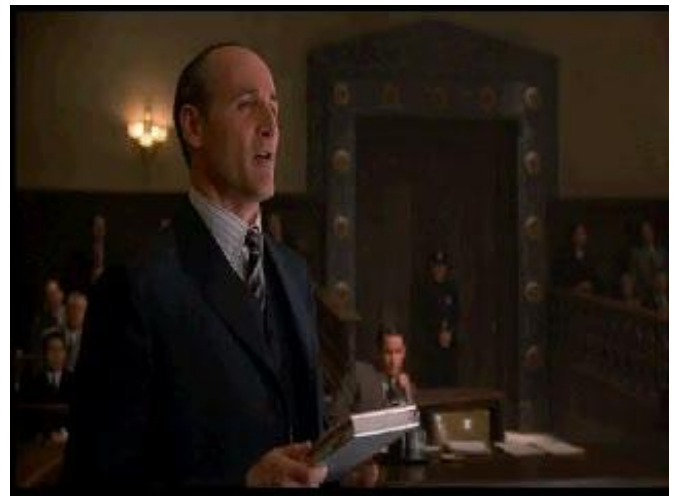

Figure One. Colm Feore in Chicago.

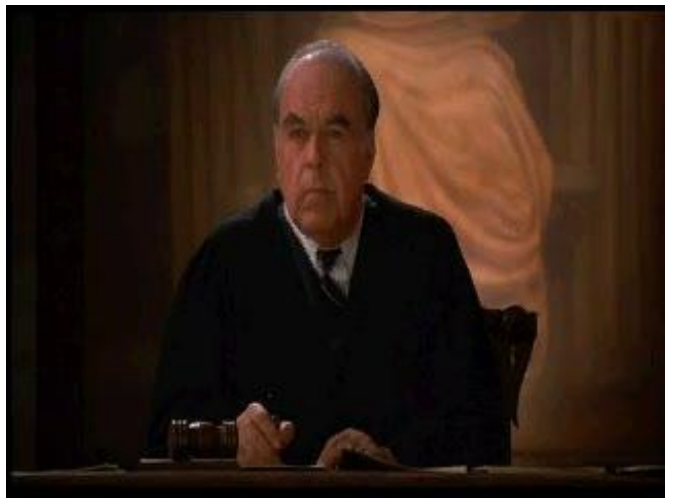

Figure Two. Sean McCann in Chicago.

\section{Economies of passion}

In the courtroom scene that serves as the climax of Chicago, secondary roles embodying stuffy legal authority are played by Canadian actors. Colm Feore plays Harrison, the prosecuting attorney (Figure One); Canadian character actor Sean McCann is the presiding judge (Figure Two). Their appearance in such roles resonates, at least slightly, with longstanding stereotypes about Anglo-Canadian character and its legendary investment in notions of order and propriety. Both of these actors are perhaps best known for having played Canadian Prime Ministers in television miniseries (Feore in the 2002 series Trudeau, McCann in the 1988 series The King Chronicle.) Neither has more than a few lines of dialogue in Chicago, however, and McCann, in particular, is listed far down in the film's credits. To Canadian viewers of Chicago, memories of Feore and McCann in these earlier roles can only enhance their associations with authority, even as the same memories make their diminished screen time in Chicago seem all the more humiliating. The well-known Canadian character actress Jayne Eastwood (Goin' Down the Road, King of Kensington) appears for a few seconds early in the courtroom scene, shrunk by the magnitude of this large-scale Hollywood production to the status of a bit player. 
I treat this scene as hieroglyphic for the ways in which it offers an image of materials (people, spaces, objects) overlaid within a distinctive arrangement that condenses a broader set of relationships. The courtroom scene in Chicago becomes a visual surface on which are laid bare some of the economic and cultural arrangements that structured the making of the film. The scene exposes these relationships, not by somehow elaborating a meta-language with which to speak of them, but by visually staging patterns of subservience and stereotypification that have longer histories. Chicago does this, in particular, through a telescoping that is typical of Hollywood films shot wholly or in part in other countries. In such productions, usually, performers who are prominent in national entertainment industries outside the U.S. appear with diminished presence relative to the U.S. stars who surround them.

More is involved here, however, than the predictable consignment of Canadian performers to roles of secondary status. The relationship between international stars and Canadian performers in films like Chicago regularly expresses what Marta Savigliano, writing about the global circulation of musical forms, once called the "political economy of passion" (Savigliano 1). This economy takes the form, Savigliano suggests, of a "trackable trafficking in emotions and affects" (Savigliano 1). The version of this trafficking to be discussed here is minor both in its scale and in the levels of inequity it presumes and reinforces. Nevertheless, a distribution of emotional intensities is one effect of transnational co-production arrangements that set charismatic stars from the U.S. industry at the centre of dramatic narratives, then fill the backgrounds of these narratives with performers, hired locally, whose bodies function as social texture.

As is so often the case with U.S. films shot in Canada, the most prominent Canadian actors used in Chicago appear as fleeting figures of judicial or bureaucratic authority. The appearance of Feore and McCann in Chicago's courtroom scene exposes the limited exportability of English-Canadian "stardom," but it also repeats a pattern whereby locally-hired performers occupy the roles of passionless enforcers of social or legal discipline. (As a result, and not incidentally, these locally-hired performers tend to be overwhelmingly white, middle-aged and male.) This is all the more strikingly the case in Chicago, whose star performers (Richard Gere and Renee Zelwegger) express themselves in libidinous musical fantasy numbers that are interspersed throughout the courtroom scene and make use of its space. Neither Feore or McCann participate in these numbers, figuring, as they do so clearly, on the side of a reality principle to which these musical sequences are opposed.

As has been noted by others, Canada was once the source of exotic, picturesque landscapes that filmmakers employed as decorative backdrops (Gittings). Now, 
arguably, Canada's status as a source of cinematic raw materials has been transformed. Our cities, touted as being virtually indistinguishable from those of the United States, are now more likely than our natural landscapes to serve as the settings for American films. Increasingly, the recognizably Canadian elements in present-day Hollywood films shot in Canada (or in U.S.-Canadian coproductions) are human figures whose function, within urban narratives, is that of the emotionally flat, functional narrative detail. At the same time, the narratological function of such characters usually requires that they serve as momentary, frustrating impediments to the central characters' trajectories of triumph or selfrealization. Like the detention-dispensing geography teacher played by Canadian actress Jayne Eastwood in the 2007 film Hairspray (shot, in part, in Hamilton, Ontario), Canadian performers in Chicago often populate a dramatic background of institutional and moralistic forces against which the lead actors must struggle. (Eastwood herself turns up first in Chicago as a snoopy landlady delaying the sexual liaison between Roxie Hart and her boyfriend.) Other cases of such uses of Canadian performers in Hollywood films shot in Canada, among hundreds of possible examples, include John Boylan as "Officer Brucks" in Harold and Kumar Go to White Castle (dir. Danny Leiner, 2004), Andrew Gillies as "Principal Woodhouse" in The Virgin Suicides (dir. Sofia Coppola, 1999), Kenneth Welsh as "Vice President Becker" in The Day After Tomorrow (dir. Roland Emmerich, 2004), and Quebec actor Al Dubois as "Pan Am Executive No. 1" in The Aviator (dir. Martin Scorcese, 2004).

The dramatic "thinness" of these roles contrasts sharply with the psychological complexity and affective expansiveness of the leading roles played by Hollywood stars. This distribution of Canadian performers, as backgrounds and blockages to the pleasure-seeking trajectories of popular narratives, cannot help but invoke (and nourish) longstanding ideas about Canada's place within broader moral and emotional geographies. Among other responses, it invites us to consider Kieran Keohane's claim that a prominent feature of Canadian experience is the sense of our own enjoyment having been stolen from us (32.) Arguably, as well, the functions typically assigned to Canadian performers--those of narrative interruption and irritation-somehow resonate with these performers' industrial status, as local resources bureaucratically imposed upon a film's producers by union regulations and co-production agreements.

\section{Staging the nation}

We might, through the familiar methodological protocols of cultural studies, want to treat the courtroom scene from Chicago as material inviting a resistant reading. Certainly, it is easy to imagine a relationship to this image which reclaims it as fundamentally "Canadian," by noting how the presence of Feore and McCann 
reorders, for Canadian viewers familiar with these actors, the relationships of foreground to background presumed by the film's makers. This seems less useful to me, however, than a consideration of the labour done by these images themselves, as they gather up and arrange the constituent features of a complex transnational relationship. This work takes place across series of images that works to establish and stabilize certain regularities, producing a national version of what Mirzoeff has called "intervisuality," the effect of culturally specific "interacting and interdependent modes of visuality" (Mirzoeff 7). As Canadian performers circulate through the backgrounds of American audiovisual texts, their hazy familiarity as actors or actresses (often derived from their television appearances) underpins the slightly reassuring (and quickly communicated) elements of social control or moral convention that the roles they play are so often meant to enforce. This experience of vaguely recognizable faces thickening the social structures within (and against) which charismatic lead performers pursue their destinies is a persistent, if generally unacknowledged, feature of the intervisuality of English Canadian audiovisual culture.

Treatments of visual imagery in the United States have often been concerned with the capacity of pictures to gather up the constituent features of national belonging and, in Jack Hogan's phrase, "stage the nation" (100). The concern of such studies is normally with the work of images in crystallizing a coherent, collective sense of purpose and identity. Writing about iconic examples of American photography (like the image of the flag-raising at Iwo Jima), Hariman and Lucaites suggest "that photojournalism provides resources for thought and feeling that are necessary for constituting people as citizens and motivating identification with and participation in specific forms of collective life" (13). The process suggested here is one by which fragmentary features of a collective imaginary are molded together within a "visual eloquence" that gives expressive fullness to scattered, inchoate sentiments (3). Clément Chéroux' book-length analysis of press images of the events of 11 September 2001 shows how iconic photographs of the twin towers in flames were displaced quite quickly, in the days following those events, by other images (most notably, those of New York firefighters holding a flag) that resonated more forcefully with imagistic traditions expressive of national cohesion (and with the Iwo Jima photographs, in particular).

In contrast, the "visual eloquence" of images circulating in Anglo Canada is regularly seen to be undermined by the collective suspicion that such images are too blatantly imitative of models from elsewhere (usually the United States), or that their circulation within public life is intended to fulfill civic purposes whose contrived and official character is only too obvious. Some of the most interesting analyses of Canadian visuality have dealt with the projects of national cohesion embedded within canonical or institutionally cherished cases of image production. 
As Anne Whitelaw has shown, in her influential study of Canadian art museums, the consolidation of a national painterly tradition, with the Group of Seven painters at its centre, was inseparable from the designation of empty landscapes as core features of a collective national experience (Whitelaw). In her analysis of the Heritage Minutes short films (1991-) and CBC documentary series Canada: A People's History (2000-2001), Emily West traces the manner by which disparate features of national history and collective memory were assembled within representations that treated Canadians as eternally multicultural and tolerant (West). All of these projects were directed at "staging the nation," by offering visual resources for the nourishment of civic cohesion and virtue. Each, to different degrees, floundered when the images around which they turned failed to resonate fully with more quotidian experiences of place, identity, and social cohesion.

My own interest here is less with such instances of Canadian visuality, which seek to "stage the nation," than with images that stage fleeting instances of co-presence between elements we may recognize as in some way Canadian and others that come, just as clearly, from somewhere else. A key analytic question posed by images in general is the manner in which the spatial proximity of elements visible within them offers itself up as emblematic of social or political forms of intimacy and estrangement. In her sharp analysis of documentary film, Marion Froger suggests ways in which particular formal devices characteristic of documentary may be deployed to convey the sense of a social bond (Froger). The extended travelling shot that moves past a city's inhabitants, for example, may reveal, in the reactions of human figures encountered in its movement, a resistance to being filmed, but in seeking out the consent of these figures the same shot may manifest a concern for linkage "[le souci du lien]" that expresses something of the film's ethical project (Froger). Conversely, modes of scene construction in Chicago that regularly exclude Canadian actors from moments of affective charge express a relationship between primary and secondary characters that is expected in complex narratives, but that need not inevitably reproduce a transnational division of labor. More broadly, we find enacted, within Canadian popular imagery, ways of being together that stand as implicit propositions about the relative claims of different figures-human or non-human—on social spaces and the relationships such spaces may enable.

As I have argued elsewhere, drawing on the ideas of Ira Wagman, the Canadian cultural artefact is almost invariably marked by a particular ratio of imported to domestic materials (Wagman; Straw, 188). In narrative forms, like the novel or the feature film script, this interweaving of elements is the object of a labour of articulation that works between textual levels and materials to endow this ratio of materials with a sense of seamless intelligibility. In contrast, the image (the 
photograph, painting, or film segment) is more likely to give us an overlaying of motifs and influences which flattens them upon a shared material base (the canvas or photo-chemical surface, for example), such that clues as to their differential provenance are elusive. This flattening problematizes any easy distinction between language and metalanguage, between those elements, which come from various kinds of cultural elsewhere, and a narrative or authorial voice that would work to reframe them within national or other frameworks of collective understanding.

In this respect, commercial and culturally mainstream Canadian images provide weak cases for the application of compelling concepts developed in recent work on the transnational traffic in images. In her work on diasporic visuality, Kate McFarlane writes of the "syncretic visuality" of images produced under conditions of postcolonial displacement and emigration-images marked by the "intercultural mixing of visual regimes" (McFarlane 177). Within such images, she suggests, we may observe the frequent clash or collusion of culturally distinct visual traditions and practices of looking. This same stitching together of visual regimes clearly characterizes innumerable images produced within the vernacular and artistic spaces of Canadian diaspora (see, for several accounts, Li). At the level of the widely-circulating Canadian image of commercial or official provenance, however, the evidence of syncretism will be weak. With their styles and themes formed, most of the time, in an unending cultural traffic with the United States, mainstream Canadian images are unlikely to manifest a significant interweaving of distinct visual systems. The national character of Canadian images is more likely to reveal itself in the minor ways in which their various iconographic elements are ordered and set in relationship to each other within homogeneously legible visual fields.

In his analysis of photographs, Pierre Bourdieu suggests that one of their key functions is that of offering the image of a group's integration. Bourdieu is speaking here primarily of the family photograph, and of its variable capacity to convey a sense of untroubled familial harmony (Bourdieu 39). Nevertheless, we might extend this analysis to the range of phenomena that images gather up within themselves. Photographs regularly pose the question of the image's capacity to make spatial proximity an affirmation of cohesion or a staging of its failures. If, in Philippe Bonnin's words, the photograph serves as the consecration des liens (228), the bonds or linkages that photographic images propose and reinforce are not inevitably those of comfortable affinity. Pictures that place the recognizably Canadian and the obviously non-Canadian in spatial proximity almost inevitably risk exposing the discrepant levels of legibility, charisma, historical pedigree, or cultural power possessed by the various elements these pictures bring together.

Journal of Crass Cultural Image Studies - Revue d'Études Interculturelles de I'Image

Imaginations, I-I, 2 DI0 Copyright (2. Open Journal Systems. ISSN - 1918-8439. 


\section{Proximity and difference}

We may explore versions of these discrepancies through the brief consideration of two very different kinds of images. The first (Figure Three) is one of the widelycirculated photographs of Brian and Mila Mulroney posing with Ronald and Nancy Reagan on the occasion of the U.S. President's visit to Canada in 1985. This was the visit marked by the "Shamrock Summit" in Quebec City. (The photograph shown here is held at the Ronald Reagan Presidential Library, in Slim Valley California, and available on its website.) Framed in the conventional fashion of the diplomatic photograph, this picture cannot help but let slip, I suggest, the uneven investments of these Canadian and American figures in the "special" quality of their relationship, the ceremonial significance of the occasion, and the common Irish ancestry of Reagan and Mulroney. Mulroney's gaze, turned towards Ronald Reagan in an attitude that conveys both devotion and a slight anxiety, works against the image of shared and controlled satisfaction that is a usual requirement of this photographic genre. If Mulroney's solicitousness and possible unease may be qualities of his relationship to Reagan (and not simply formal features of the photograph) these nevertheless function in more formal terms to bring a surplus of animated emotion to a genre of photograph normally marked by ceremonial flatness.

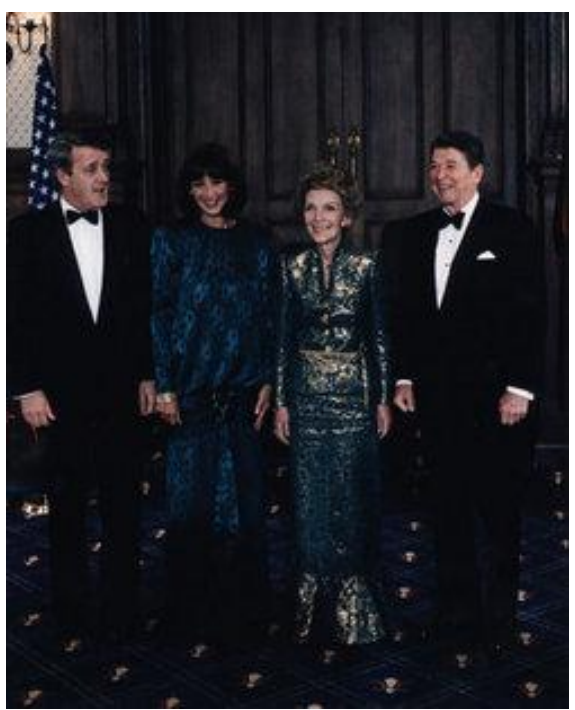

Figure Three. Brian and Mila Mulroney with Nancy and Ronald Reagan, 1985. 
While, from one perspective, this picture offers a coherent image of Canadian subservience to American power, I am more interested in the ways in which that subservience is made manifest in the image's instability, in its incapacity to hold these four people in a pose of equally distributed respect and comfort. Like the minor forms of estrangement that may reveal themselves in the family photograph, the slight turn of Brian Mulroney's head suggests an inability to comfortably inhabit the formal space of the diplomatic image. It may simply be that the Madame Tussaudish poses of Ronald and Nancy Reagan are naturalized through the intervisuality in which they participate-through our familiarity with hundreds of other widely circulated photographs of the couple. As a result of this familiarity, the Reagans' stance here seems self-sufficient and detachable, repeated from innumerable similar events involving other political leaders and thus conveying little investment in the harmony or significance of this specific group and occasion.

The textual and media forms that disseminate images in Canada are differentiated, for the most part, along linguistic lines. This remains the case even as linguistic lines might seem to recede as forces structuring identity in Canada, and as linguistic communities themselves are more obviously lived as shifting coalitions criss-crossed by multiple other forms of diversity. Nevertheless, the dominant examples of cinema, television, and print culture in Canada are usually in the French or English languages, so that even when images are not linguistically marked or annotated, the circulatory matrices within which they travel typically follow the lines of linguistic division. On either side of this division, one finds very different systems of mutual reference, of the intervisuality referred to earlier. Almost paradoxically, the domain of images is one in which the distinctiveness of Francophone and Anglophone cultural life is expressed most starkly, even if images themselves are not "linguistic" in any obvious way. These systems, which bind together series of images on either side of the linguistic divide, are further differentiated by the extent and character of their proximity to models from elsewhere and, in particular, to those that come from the United States.

The Quebec celebrity gossip magazine Echos Vedettes, shown in Figure Four, is notable in at least two ways. Its most obvious feature, to English Canadians, is the extent to which, with one obvious exception, none of the faces displayed in photographs are familiar (I have tested my Montreal-based students in several classes, using this image, and never found an Anglophone able to recognize a single celebrity other than Céline Dion). The Echos Vedettes cover stands as evidence of the well-known self-sustaining character of Quebec show business. Its second and most striking feature, to me, is how coherently it models itself on the U.S. celebrity-oriented supermarket tabloid. The "apartness" of Quebec entertainment culture is such that it may borrow models from elsewhere without 
running the risk that the various elements configured within their local versions will be weakened by this evidence of cultural proximity. Like the Quebecois television variety show, Echos vedettes is more "American" than most of the forms that make up English-Canadian popular culture, even as English-Canadian culture is more frequently criss-crossed by cultural fragments that come from the United States.

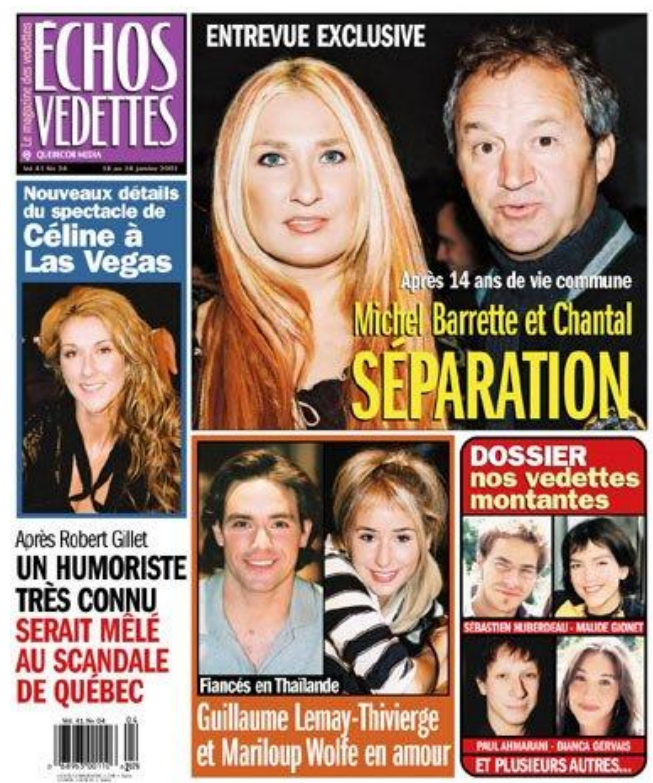

Figure Four. Echos vedettes. January 2003.

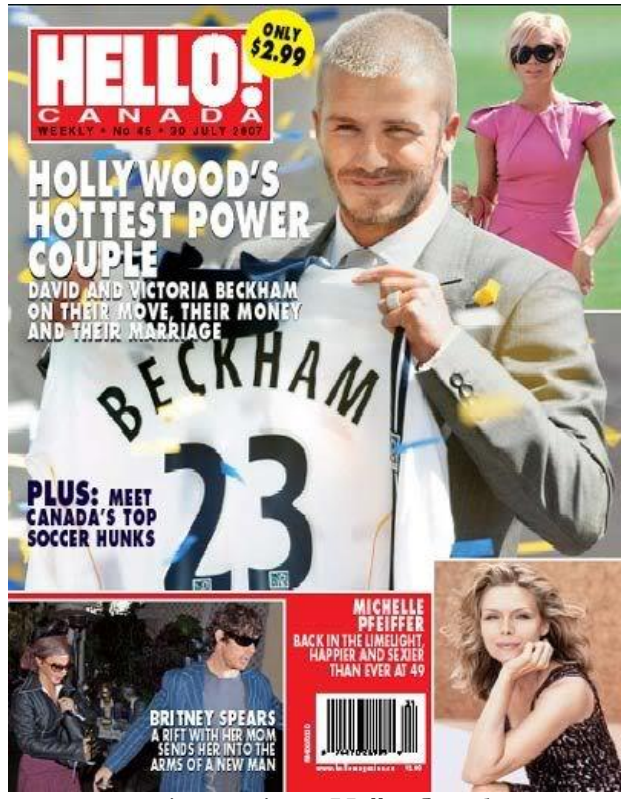

Figure Five. Hello! Canada. July 2007.

In contrast, the English-Canadian entertainment tabloid must contend with the fact that it can neither model itself completely on U.S. models (which would render it redundant relative to such easily available models) nor base its distinctiveness on coverage of Canadian celebrity culture exclusively (since that culture is widely viewed as insufficiently large, sensational, or interesting.) Figure Five shows the cover of a 2007 issue of Hello! Canada, one of the few EnglishCanadian celebrity-oriented magazines to achieve any longevity in several decades. If Echo Vedettes works centrifically, gathering the different components of Quebecois popular culture within a coherent universe of places, names, and sensations, the cover of Hello! Canada shown here does little more than stage the awkward proximity of elements, whose origins and national pertinence are widely 
varied. Based on a British magazine (the original Hello.), Hello! Canada can offer, as the only plausible source of its distinctiveness, the fact that it is neither a blatant copy of a U.S. tabloid, nor as narrowly British in its focus as the U.K. title that serves as its model. While the image shown in Figure Five labours to convey a sense of the convergence of British, American, and Canadian entertainment worlds, the cover's energies seem, in fact, to be centrifugal, scattering viewer attention along multiple and disconnected lines of association.

\section{The overlay of images}

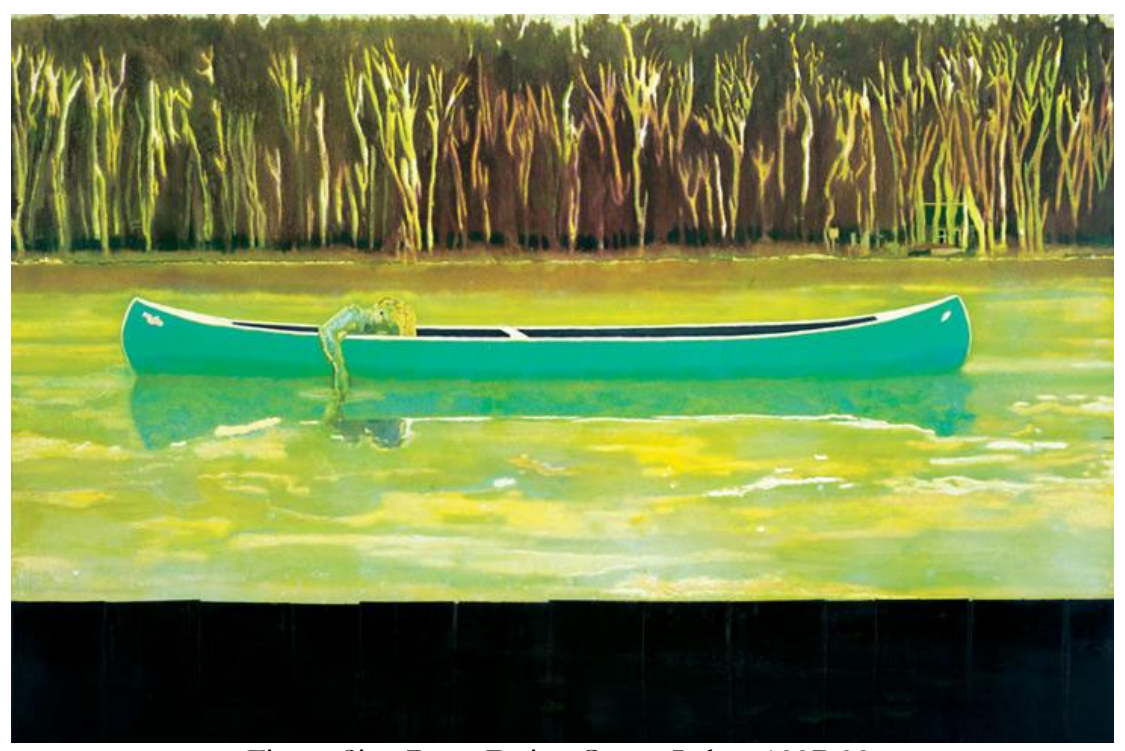

Figure Six. Peter Doig. Canoe Lake. 1997-98.

Figure Six is a very different kind of image: the painting Canoe Lake (1997/1998), by Canadian-British-Trinidadian painter Peter Doig. As the artist has acknowledged, and critics have noted (e.g., Grande), Canoe Lake is one of a series of works by Doig that imbue the canonical Canadian iconography of northern landscapes with a sense of eerie menace borrowed from low-budget American horror films of the early $1980 \mathrm{~s}$, like Friday the $13^{\text {th }}$. It was typical of these films to feature teenagers confronting danger in remote, "natural" locations (like summer camps), and the locus of menace these films offered was that of both an untamed nature and the resurgence of repressed familial trauma. In Doig's painting, the iconographic traditions of Group of Seven painting and the U.S. serial-murder horror film are overlaid upon each other in a way that avoids the marginalization 
of Canadian elements seen in the images discussed so far. In Doig's painting, there is neither the effort to deceive, to disguise a Canadian location as something else, nor the uneasy, stumbling attempt (as in the photo of the Mulroneys and Reagans) to stage a harmonious relationship between elements whose unequal status, in more broadly geopolitical terms, cannot help but betray itself.

The artfulness of Doig's image stems in part from the ways in which it produces a constant reversal of our sense of the primary and the secondary. On the one hand, the wildly successful Hollywood film is overlaid upon the globally "minor" traditions of Canadian painting; on the other, the canonical tradition of Canadian landscape art is made to be haunted by the unsettling constituent features of a debased American film genre. In other words, the Canadian and U.S. elements of this painting function simultaneously (or alternately) as its major and minor features, advancing and receding between foreground and background. The "proximity" of these different elements in Doig's painting does not generate easily decipherable propositions about hierarchical cultural relationships between Canada and the United States. Neither, however, does the painting occlude these relationships. For the noble Canadian landscape tradition to acquire a veneer of terror, it seems, it is necessary to invoke the collective memory of cheaply-made U.S. horror films, to partake of that cross-border trafficking in "emotions and affects" that Savigliano has identified. At the same time, this sense of terror further dignifies the Canadian landscape painting, rescuing it from the merely pastoral or canonical and joining it to older means of representing a terrifying and unsettling nature-means whose art-historical pedigrees are of considerably greater prestige. It is as if, having diagnosed the multiple dynamics that mark cultural traffic between Canada and the United States, Doig devised a work that maintained them all in perpetual motion.

\section{Conclusion: Cultural forms and public spheres}

The sense that national or supranational entities might be distinguished by the preeminence of one cultural form or another has woven its way through analyses of media and culture for a long time. Harold Innis' claims about a culture's "bias" towards time or space presumed the predominance of specific cultural forms over others (Heyer and Crowley xvi). This predominance is suggested, at the very least, by Marshall McLuhan's notion of the sensory hierarchies characteristic of particular times and spaces (McLuhan 22). More recently, scholars across a range of fields have made claims about the dominant role of post-literary cultural forms in the consolidation of new sorts of public spheres. Michael Warner has suggested that, as the contemporary public sphere (in the United States, at least) has come to be oriented more and more towards electronic, audiovisual media, it has made "the bodies and expressive lives of politicians and citizens"-phenomena which 
circulate primarily through visual representation-more important than the abstracted subjectivity characteristic of a public life organized around print media (Warner 102).

Scholars working within Latin American cultural studies have offered new accounts of national or regional public spheres that are no longer organized around the cultural expression of a literary elite, around the "lettered city" conceptualized by Angel Rama in an influential work (Rama, 1996). In different ways, Ana Maria Ochoa Gautier and Rosalind Winocur have argued for the aural as a dominant feature of new public spheres in Brazil and Mexico, respectively. Identifying what she calls a "sonic turn" within Latin American identity, Ochoa Gautier suggests that "under the contemporary processes of social globalization and regionalization coupled with the transformations in the technologies of sound, the public sphere is increasingly mediated by the aural" (Gautier 807). In more restricted terms, Winocur has traced the contours of a Mexican sphere of civic engagement organized around the aural and the vocal, through the interconnection of such technologies and cultural forms as the cell phone and the radio call-in program (Winocur, 2002, 2003).

If I resist the temptation to characterize the public culture of Canada in terms of any dominant sense, medium, or cultural form, I would nevertheless argue that still or moving images express, in distinctly revealing ways, the varieties of our relationship to the United States and its commercial, popular culture. This is, in part, because images have become the principal token in the cultural traffic between these two countries, but that is almost incidental. Rather, as I have suggested, images stage the proximity of things, people, and places and, in doing so, pose the question of their equitable coexistence. Most of the time, the proximity of elements appearing within an image is at least partially naturalized, through the sorts of conventions that mark specific genres, like the family portrait, the diplomatic photograph, or the cinematic courtroom scene.

At the same time, it is part of the work of images to distribute their various elements along the axes of foreground and background, major and minor, the communicatively expansive and the restricted. It is in relation to this distribution that the formal analysis of still images and dramatic audio-visual excerpts may open onto a broader analysis of the transnational cultural traffic in affect, stature, and degrees of imagistic presence. When, as is so often the case, these axes serve to differentiate visual elements that are recognizably American and others we read as Canadian, a transnational relationship has assumed cultural solidity as iconographic convention. 


\section{References}

Bonnin, Philippe. Images habitées: photographie et spatialité. Paris: Creaphis, 2006.

Bourdieu, Pierre ed. Un art moyen: essai sur les usages sociaux de la photographie. Paris: Editions de minuit, 1965.

Chéroux, Clément. Diplopie: L'image photographique à l'ère des médias globalisés : essai sur le 11 septembre 2001. Paris: Le point du jour, 2009.

Curtis, Neal. "'As if: Situating the Pictorial Turn." Culture, Theory \& Critique 51: 23. $95-101$.

Froger, Marion. "Mitoyenneté dans le cinéma urbain de Johan Van der Keuken. » Intermédialités, no. 14, 2010. 127-142.

Gautier, Ana Maria Ochoa. "Sonic Transculturation, Epistemologies of Purification and the Aural Public Sphere in Latin America." Social Identities 12: 6 (2006): 803-825.

Gittings, Chris. "Imaging Canada: The Singing Mountie and Other Commodifications of Nation." Canadian Journal of Communication 23: 4 (1998): 83-97.

Grande, John K. "Peter Doig: Hallucinating Landscapes - Canadian Style.” Border Crossings, 21: 1 (2002): 73-74.

Hariman, Robert and Jean Louis Lucaites. No Caption Needed: Iconic Photographs, Public Culture, and Liberal Democracy. Chicago: University of Chicago Press, 2007.

Heyer, Paul and David Crowley. "Introduction." In Harold Innis. The Bias of Communication. Toronto: The University of Toronto Press, 1995. ix-xxvi.

Hogan, Jack. "Staging The Nation: Gendered and Ethnicized Discourses of National Identity in Olympic Opening Ceremonies." Journal of Sport \& Social Issues, 27: 2 (2003) 100-123.

Keohane, Kieran. Symptoms of Canada: An Essay on the Canadian Identity. Toronto: University of Toronto Press, 1997.

Li, Xiaoping. Voices Rising: Asian Canadian Cultural Activism. Vancouver: University of British Columbia Press, 2007.

McFarlane, Kate. "Diaspora, cultural practice and syncretic visuality." Journal of Intercultural Studies, 25: 2 (2004): 175-184.

McLuhan, Marshall. Understanding Media: The Extensions of Man. Cambridge: MIT Press, 1995.

Mirzoeff, Nicholas. “The Multiple Viewpoint: Diasporic Visual Cultures” In Nicholas Mirzoeff, ed. Diaspora and Visual Culture: Representing Africans and Jews. London and NewYork: Routledge, 2007. 1-18.

Nelson, Charmaine. "Slavery, portraiture and the colonial limits of Canadian art history [Portrait of a Negro Slave]." Canadian Woman Studies, 23: 2 (2004). 22. O'Brien, John and Peter White, ed. Beyond Wilderness: The Group of Seven, Canadian Identity, and Contemporary Art. Montreal: McGill Queen's University Press, 2007. 
Rama, Angel. The Lettered City. Translated and edited by John Charles Chasteen. Durham and London: Duke University Press, 1996.

Savigliano, Marta E. Tango and the Political Economy of Passion. Boulder: Westview Press, 1995.

Straw, Will. "Pathways of Cultural Movement." Accounting for Culture: Thinking Through Cultural Citizenship. Ed. Caroline Andrew, Monica Gattinger, Sharon Jeannotte and Will Straw. Ottawa: University of Ottawa Press, 2005. 183-197.

Wagman, Ira. "Statistics and Narratives of Canadian Cultural Weakness" Paper presented at the annual conference of the Canadian Communications Association, Halifax, Nova Scotia, June 1, 2003.

Warner, Michael. "Zones of Privacy." What's Left of Theory: New Work on the Politics of Literary Theory. Eds. Judith Butler, John Guillory and Kendall Thomas. New York and London: Routledge, 2000. 75-113.

West, Emily. "Selling Canada to Canadians: collective memory, national identity, and popular culture." Critical Studies in Media Communication, 19: 2 (2002): 212 229.

Whitelaw, Anne. "Whiffs of Balsam, Pine and Spruce: Art Museums and the Production of a Canadian Aesthetic." Capital Culture: A Reader on Modernist Legacies, State Institutions and the Value(s) of Art. Ed. Jody Berland and Shelley Hornstein. Montreal: McGill Queens University Press, 2000. 122-136.

Winocur, Rosalia. "Media and Participative Strategies: The Inclusion of Private Necessities in the Public Sphere." Television \& New Media 4: 1 (2003): 25-42.

---. Ciudadanos Mediáticos. La construcción de lo público en la radio. Barcelona: Gedisa, 2002.

\section{Image notes}

Figure One and Figure Two

Colm Feore and Sean McCann in Chicago (2002).

[DVD grab, (c) Miramax Films, 2002]

Figure Three

Brian and Mila Mulroney with Nancy and Ronald Reagan, 1985.

[Courtesy Ronald Reagan Library.

www.reagan.utexas.edu/archives/photographs/large/c27762-8.jpg

Figure Four

Cover, journal Échos-Vedettes, January 2003.

[C TVA Publications, Quebecor Media]

Journal of Crass Cultural Image Studies - Revue d'Études Interculturelles de I'Image

Imaginations, I-I, 2 QII Copyright (2. Dpen Journal Systems. ISSN - 1918-8439. 
Figure Five

Cover, Hello! Canada, July 2007.

[@ Hello LTD]

Figure Six

Peter Doig, Canoe Lake, oil on canvas, 1997-98.

[C The Saatchi Gallery, London UK] 


\title{
imaginatinne
}

\section{Soundless Speech / Wordless Writing: Language and German Silent Cinema}

\author{
Marc Silberman
}

THE MEDIATIZATION OF SEEING, which set in with the invention of the camera obscura in the seventeenth century and reached an initial peak of mechanical perfection in the moving camera at the end of the nineteenth century, enriched the psychophysics of perception. A whole series of ever more sophisticated technological innovations in optical instruments led to new means of representation and concurrently opened up new ways of imagining the self. What came to be called in 1920s Germany "neues Sehen" or new seeing was the shorthand description for an effect of modern industrial society that literally bombarded the eyes with a shower of visual stimuli. We encounter the breakdown of perspectival focus and the introduction of abstraction in the visual arts; modernist literature adapts techniques of narrative montage connected with memory and interiority; and a new kind of spectator evolves who has experienced the spatial rhetoric of rapid movement associated with trains and automobiles as well as the visual fragmentation associated with photography and cinematography. These creative aesthetic responses were probing the limits of representation and perception but at the same time they threatened to displace verbal language as well as the written word. The primacy of writing, which itself had displaced oral culture in the wake of the Renaissance, was challenged by the media shift to visuality. Yet this by no means erased speech or print; rather the flood of images and the fragmentary techniques of representation based on mechanical means of reproduction forced artists and critics to rethink their assumptions about language and communication. The historical oppositions of pictura et subscriptio come into 
especially sharp focus in the visual and textual signifying systems of the German silent cinema.

If language loses its communicative and interpretative functions in direct proportion to the loss of its referential grounding, then the modernist crisis is simultaneously a crisis of its signifying practices. The evolution of the silent cinema in Germany between 1912 and 1930 engaged this crisis on at least three levels. Thematically we find here an inflation of psychological stories about ego destabilization, urban alienation, and claustrophobic family life, populated by fantastical doubles, psychopaths, vampires, robots, and golems. Inscribed in the paranoid narratives of self-loss is the modern experience of dissociation and deracination. Aesthetically the silent cinema was exploring new ways to represent such anxieties of modern subjectivity. These included technical innovations in lighting and cameras that allowed for intensely dynamic, expressive space relations as well as a distinct gestural acting style aimed at translating inner emotions into corporeal intensity. Philosophically the ongoing debates about the nature of the cinema as art and entertainment began to reformulate the image-text relation by questioning the hierarchy of terms. Does the silent cinema sponsor a linguistic theory of images based on the idea of "reading" the pictorial discursively, or does it rest on an image theory of language that claims the image as the ground of language's referentiality?

In this essay I propose to examine the German expressionist cinema as a specific response to the modernist crisis of language in order to describe the diverse cinematic forms of resistance to the word, to articulated speech. I propose to do this from two different directions, even though in practice they were not clearly separate. Some expressionist film makers developed the silence of the silent film into a "gestural language" that dramatized light and movement; others reproduced the silent speech of the film figures by means of graphically stylized intertitles. My thesis is that the expressionist cinema maintained a traditional, idealistic notion of the film as a pure work of art that aimed at a unified composition of all elements: set design, architecture, costumes, make-up, acting, lighting, plot, and even writing. While other avant-garde artistic practices, say, in the theater (Bertolt Brecht, Erwin Piscator), photography (Hannah Höch, John Heartfield), or the fine arts (Max Ernst, George Grosz), integrated the most advanced technical means at their disposal in order to transform traditional art forms and to open up new dimensions of artistic perception, the expressionist film makers missed the opportunity to explore the rich semiotic possibilities of the new technological medium with its hybrid, synergetic forms and provocative force. Hence, the expressionist cinema marks a transition or even the endpoint of a long process of reflection about the communicative possibilities of language that shifted to a

Journal of Crass Cultural Image Studies - Revue d'Études Interculturelles de l'Image

Imaginations, I-I, 2010 Copyright (2. Open Journal Systems. ISSN - 1918-8439. 
fundamentally new level with the invention of sound cinema at the end of the 1920s.

First of all, we need to recognize that the early cinema was not silent in the sense of soundless; sound had always been present in cinema auditoriums. The widespread assumption that written intertitles substituted for the lack of voices must be qualified. First, beginning in 1903 already there were successful experiments with new technologies of sound accompaniment through the mechanical separation of image and sound. In Germany, for example, synchronized wax disk recordings were especially popular for music and opera films, seeking to reproduce the "authenticity" of performance. These "MessterTon-Bilder" (Sound-Images), produced under the brand name of "Biophon," were commercially distributed with some success until 1913. Also, since the beginning of the cinema live film narrators-like the impresarios and entertainers on variété stages - accompanied movies with running commentaries. The narrator, standing in front of or next to the screen, introduced the film, explained the plot, and spoke the dialogues, a tradition that had disappeared entirely only in 1913. ${ }^{1}$ Around 1910 an alternative arose to the film narrator in the form of a small group of actors who behind the screen acoustically illustrated the corresponding visual events, but this proved to be only a short-lived fad (Orosz 136). And, of course, by the early teens other kinds of live musical accompaniment were becoming widespread, be they pianos, organs, small ensembles, or large-scale orchestras for gala openings in the new cinema temples in urban centers. In another sense too the silent cinema was not silent. Actors did speak their parts in front of the camera, and viewers saw them moving their lips, although they did not hear them once the "institution" of the film narrator disappeared. Thus, the silent film does show a communicating world but without audible speech, and as a result viewers developed historically conditioned habits of lending the screen figures their own imaginary voices. The audience provided not only their own "spoken" text of unheard voices but also the sound quality of those voices - timbre, intonation, pitch, tonality, not to speak of other sounds and noises such as whistles, rain hitting the pavement, or screeching car wheels that might be represented in film images. In this sense it is impossible to regard the silence of the silent film as a lack; on the contrary, the absence of audible sound constituted its specific communicative condition, the condition of the viewer's imaginary activity in watching the film.

If the silent cinema was from early on not without sound, the new visual medium of moving images similarly did not forego text in the form of printed words. From its very beginnings conventionalized print forms of communicating information accompanied the cinema in the texts of program booklets and on advertising posters. Printed words could also be seen in the profilmic space of the moving

Journal of Crass Cultural Image Studies - Revue d'Études Interculturelles de l'Image

Imaginations, I-I, 2010 Copyright (2. Open Journal Systems. ISSN - 1918-8439. 
images, for example, a shot might show a factory entrance with the company name inscribed on it, a store front with business signs, a street sign or place name, a streetcar with advertisements. Even before the (technological) invention of the close-up shot cinema viewers apprehended visually such diegetical images of words. Moreover, printed credits at the beginning and end of films existed in the earliest phases of cinematography, although at this point they were not yet technically connected to the raw film stock; rather such titles were projected separately by means of the older laterna magica technology (Hediger 169). It is relatively obvious that the projection of moving images begins in the medium of print, pointing to its precursors in book culture (the covers and title page of the printed volume) and the stage (the theater program). In short, the shift to mechanically produced visual media around 1900 was from the outset tied to technologies of sound and print.

Text-image relations in the silent cinema revolve principally around the use of inserts and intertitles as an integral component of the narrative system. Inserts are functional elements of the narrative fiction; they contain texts of written messages, for example, a letter, a contract, the verse of a poem, the inscription on a memorial, the words on a sign. Often they can be identified by the visual structure of the material on which the text is written (parchment, sheet of paper, page of book) or by the handwriting or typescript. This insert from from Fritz Lang's Dr. Mabuse, der Spieler (Dr. Mabuse, the Gambler, 1922) shows Edgar Hull's calling card, grasped by a finger in the upper right corner, with the handwritten promise to pay a debt;

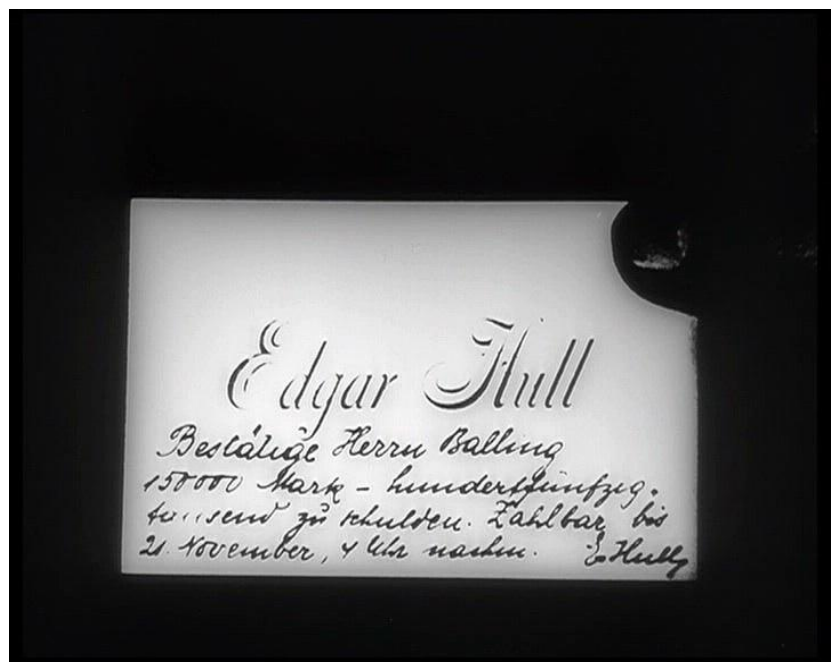

Journal of Crass Cultural Image Studies - Revue d'Études Interculturelles de l'Image Imaginations, I-I, 2010 Copyright (2. Open Journal Systems. ISSN - 1918-8439. 
the next insert shows the other side of the card, now with the finger in the lower right, and the implicit threat "Spiel ist Spiel" underlined ("A game's a game").

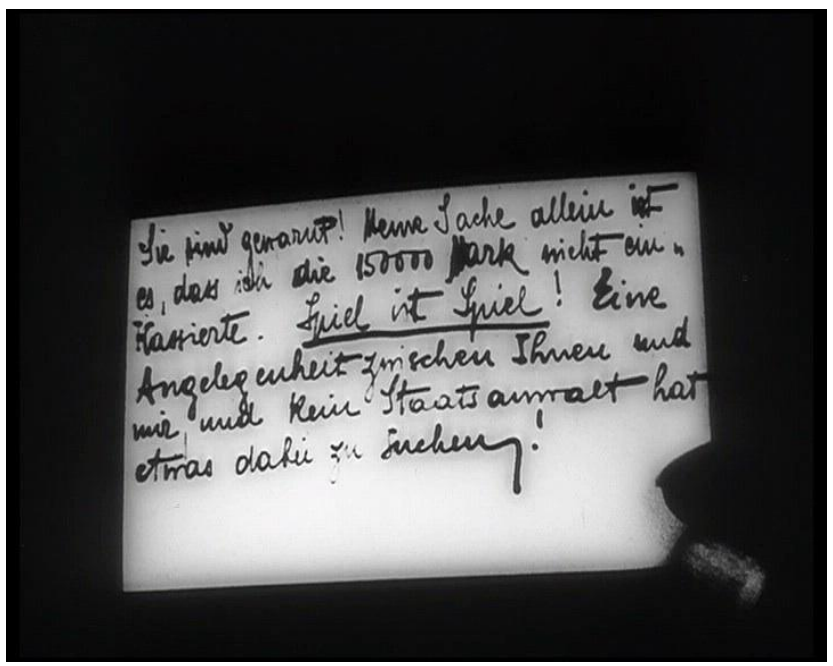

Dialogue titles provide direct speech of the film characters (often with quotation marks), while expository titles explain the plot with details about place and time and/or commentary. This dialogue title, again from Dr. Mabuse, der Spieler, includes quotation marks for the question at the gaming table: "And why aren't you playing?"

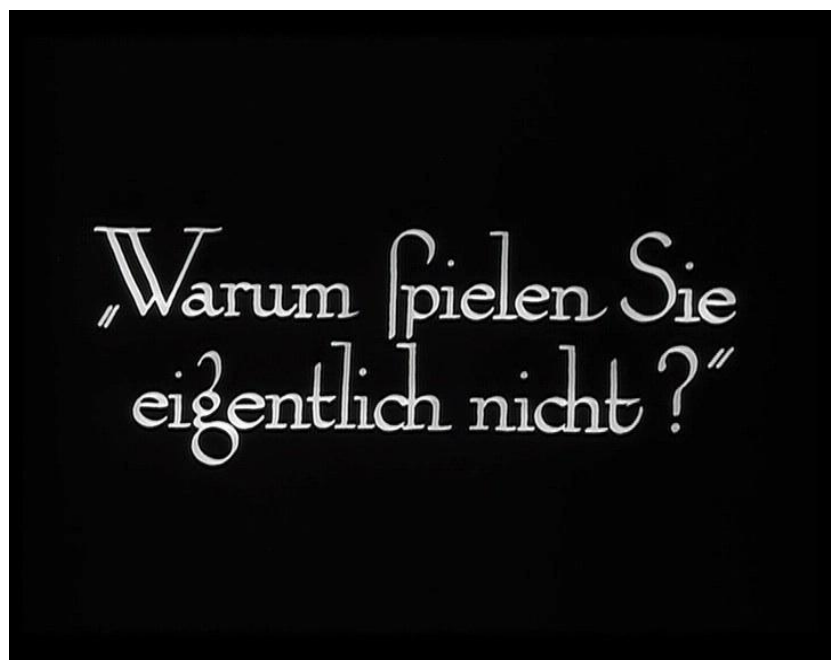

Journal of Crass Cultural Image Studies - Revue d'Études Interculturelles de l'Image

Imaginations, I-I, 2010 Copyright (2. Dpen Journal Systems. ISSN - 1918-8439. 
Edwin Porter used intertitles for the first time in 1903 in the American short "Uncle Tom's Cabin" in order to guide the viewer's comprehension in an episode lasting more than three minutes (Scheunemann 12). At this time these titles consisted technically of filmed stills of text cards that were edited into the actual film so that they filled the entire screen. Only around 1910 did text and image come together on the celluloid and produce the standardized intertitle: white print on a black ground, a white border surrounding the text, the production firm's logo on the top or bottom margin, and the title number in a corner of the image. By this point, then, intertitles functioned not only for purposes of narrative clarity but also for economic identity of the production company and for legal protection against unauthorized cuts. After 1914 dialogue intertitles came to dominate, while explanatory text titles became less and less frequent in order to sustain the viewing illusion of continuity. In fact, according to Birett's (74-82) statistical analysisalbeit based on a very limited corpus of only eighteen international film productions between the years 1908 and 1928 - the ratio of intertitles to image shots tended to diminish consistently into the 1920s, while their function as redundant messages for the action or content of the moving images had by and large gone out of style.

Many contemporaries of the silent cinema considered filming and screening still images of printed titles to be incompatible with its essence. In the original, 1911 version of the essay "Gedanken zu einer Ästhetik des Kinos" (Thoughts on an Aesthetic for the Cinema) Georg Lukács (304) regards the spoken word as a disruptive tautology:

The "cinema" can only represent actions, not their cause and meaning; its figures have only movements, but no soul, and what happens to them is simply an event but not their destiny. (Therefore-and only apparently because of current technological imperfections - the scenes of the "cinema" are silent: whatever is important in the represented events is completely expressed by what actions and gestures, any speaking would be a disruptive tautology. $)^{2}$

Similarly, Paul Wegener (13-15), the actor/director who produced some of the first and most impressive "art films" in the mid-teens, formulated the idea persuasively in a much quoted lecture he gave on 24 April 1916: "In the first instance film is a visual matter. The film poet must begin with the image, must think in images, and choose themes that can be expressed visually." ${ }^{3}$ Because the film as medium builds on the primacy of the image, the medial shift to printed inserts and titles-according to this widespread view-interrupts the flow of images with its extra-diegetic meta-discourse about the images. Moreover, as an

Journal of Crass Cultural Image Studies - Revue d'Études Interculturelles de l'Image

Imaginations, I-I, 2010 Copyright (2. Open Journal Systems. ISSN - 1918-8439. 
iconic mode of communication, the motion picture is both accessible and legible to an international audience because images are not filtered through the grid of words and concepts. Theories of perception reinforced this view that images are more accessible in their "flatness" than the "depth" of language about which texts speak (Schnell 150). The immediacy with which an image delivers information analogically - to the extent that the viewer can comprehend it even with a momentary glance-differentiates it from the logical, analytical, sequential structure of a verbal text, and from the abstract form of writing that must be read.

The analogy or metaphor of film as a universal language because of its dearth of linguisticity and the ostensible self-evidence of its signs is grounded in idealist conceptions of art and the metaphysics of the image. In fact the silent cinema was compared variously to other non- or pre-linguistic systems of representation with the implication of their freedom from the constraints of language. The performative and expressive aspects of the human body in modern dance, the synthetic nature of pantomime, and the collective consciousness behind folklore and fairy tales were all cited and compared to the cinema's silence as a liberating feature. Lack of verbal language was not considered to be a deficiency but rather compensation for the elitism of book culture and an opening into imaginative playfulness. The sharp division between literary culture and mass entertainment predisposed German intellectuals in the 1910s and 1920s to project their own desire for access to the popular audience into the utopian potential of the cinema as a universal language (Hake 130-57).

Especially in the years prior to 1914, when there was a strong move to improve the artistic quality of the German cinema, another widespread view argued that the film's lack of words and its status as a popular medium necessitated stories with simple plots based on emphatic movement and physical actions in order to reduce the spoken commentaries of the film narrator or the printed messages of the intertitles to a minimum. Similar idealistic notions of art and language underlie the idea that pure gesturality is a substitute language or language substitute. If mime and gesture are the most important stylistic components of the film, then-the argument goes - it must be possible to define a standardized repertoire of gestures and expressions. In the context of the modernist crisis of language the silent cinema seemed to provide incontrovertible evidence that gestural language could communicate in ways that verbal language could no longer do in literature and theater. Thus attempts arose to establish a lexicon of hand and body language ("eine Urgrammatik der Gebärden" or a grammar of prototypical gestures) especially for pedagogical purposes in the tradition of handbooks of rhetoric (e.g., Rudenski). This kind of gestology categorizes how an action or function is performed using facial expression, gestures (principally of the hands and arms, but

Journal of Crass Cultural Image Studies - Revue d'Études Interculturelles de l'Image

Imaginations, I-I, 2010 Copyright (2. Open Journal Systems. ISSN - 1918-8439. 
also of other limbs such as the neck and legs), body posture (how someone sits or stands), and movement of the entire body (standing up, sitting down, walking, running). It should be obvious that this approach to the film actors" "language" naively isolates gestures as if they can be separated from the transitory movement of the medium, analytically grasped, and identified with a particular denotation. Moreover, the idea that a language of gestures can be learned and read hermeneutically not only contradicts the concept of an anthropologically given originary language that is legible and universally understood, it also paradoxically erases the post-Enlightenment conception of the individual subject whose inner feelings are the immediate and direct expression of the self, a conviction that feeds the cinematic cult of the actor as star-the very icon of the individuated, expressive personality.

Nonetheless, gestural acting became one of the hallmarks of the expressionist cinema. In this short clip from Paul Wegener's and Carl Boese's Der Golem, wie er in die Welt kam (The Golem: How He Came into the World, 1920) we see Graf Florian (Lothar Müthel) and Miriam (Lyda Salmonova) falling in love: the heaving chests, timid yet desiring eyes, tentatively groping hands, and finally the bodies slowly surging toward one another.

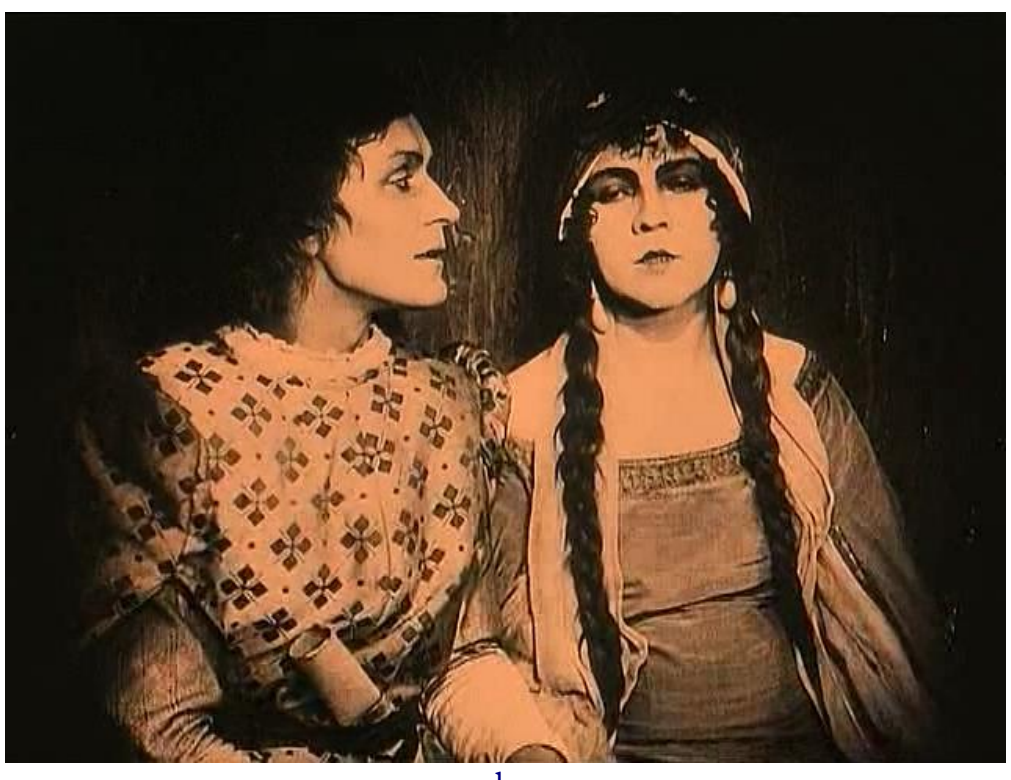

play

Initially the silent cinema inherited this legacy of histrionic acting from the theater, 
but it became clear that the gestural repertoire of the stage did not work in front of the camera. The relationship to space and time in the theater is constituted by the distance between the stage and audience and the central perspective defined by the proscenium stage. In the cinema, however, the camera assumes various distances and focuses the spectator's attention from many different shots and angles, which are in turn the result of fragmented shooting of isolated gestures. It is no surprise, then, that the new film stars of the 1910s like Henny Porten and Asta Nielsen did not come from the theater and did not "play to the audience" but rather learned to act for or to the camera, introducing what the earliest film critics and trade press celebrated as their naturalness and realism (Müller 81-86).

Central for this claim to a universal language in the cinema was the focus on the actor's body. Ignoring the mechanical basis for the production of images, the gesture was understood as a primeval linguistic sign and the face as the mirror of the soul, the site of human identity and transcendence. The focus on physiognomy stressed the anthropomorphic, humanist grounding of cinema's silent language; freed from the constraints of fragmentation and alienation, the intact body promised redemption and human community. Béla Balázs's 1924 theoretical treatise, Der sichtbare Mensch (Visible Man), might be considered the culminating point in a series of film theories proposed in the course of the 1910s and early 1920s that stress exclusively the visual comprehension of expressive movement as the art of the cinema. It is a remarkable document of the sophisticated level this discussion of visual culture had reached but it also illustrates how the idealist grounding of the image maintained the origin of cinematic meaning in the presence of the actor and thus misconstrued the mechanically mediated relationship between reality and representation. The argument reveals a paradox: on the one hand, artistic innovation comes about only through the transformations resulting from the interaction between the arts and the new technical media; on the other, the ultimate goal is the purity of artistic means in each medium. The technical and structural qualities of the popular cinema provide the argument for the specific filmic means of expression that then enable the continuity of high art traditions by employing technologically inspired aesthetic innovations for artistic experimentation.

With this kind of philosophizing about the redemptive quality of visual communication it comes as no surprise that many silent film practitioners, critics, and theoreticians considered intertitles to be a necessary evil, a dramaturgical crutch, or a substitute for inadequate visual narration. On the one hand, they were reacting to the widespread use of titles to camouflage dramaturgical problems. Up into the 1920s it was obviously easier and cheaper to produce such intertitles than to film (additional) non verbal visual material. On the other hand, the very

Journal of Crass Cultural Image Studies - Revue d'Études Interculturelles de l'Image

Imaginations, I-I, 2010 Copyright (2. Open Journal Systems. ISSN - 1918-8439. 
attraction of the new medium lay in the ability of moving images to show a communicating world without resorting to words, that is, without relying on the "exhausted" medium of language. Thus, critic Karl Bleibtreu complained already in 1913 that intertitles were poison for the eyes ("Gift für die Augen"; quoted in Paech 59). Victor E. Pordes (21), a Viennese professor of aesthetics and one of the first to publish a book-length theory of film in 1919, saw a corrosive effect in printed titles, in contrast to the wordless image that offers the spectator the originary feeling ("die ganze Ursprünglichkeit seines Gefühls"). One year later Konrad Lange (85), another scholar, who_as a prominent cinema "reformer" was committed to raising the lowly entertainment to an artistic enterprise, compared intertitles to pieces of printed paper between the images: "It is inconceivable to me that this crutch's lack of artistry has not long been recognized."4

There were, however, counter positions. Precisely because the film is an imagedominated medium, the "alien" print medium draws attention to itself. The alternation between printed titles and moving images was recognized by some as an effective element of the editing rhythm and potentially useful in building narrative suspense, especially in chase sequences and thrillers, where all kinds of retarding elements need to be mobilized. Moreover, the image-text relation functions differently in various film forms (for example, documentaries, narrative films, experimental films, or advertisements), and the relation can be constructed in various ways: competing, harmonizing, intensifying, complementing. D. W. Griffith is reported to have reacted ironically to an interviewer's question in 1926 about the Germans who were by that time making films completely without intertitles (referring undoubtedly to Carl Mayer's screenplays for chamber films); Hitchcock defended printed titles as an efficient way to accelerate the plot and condense the story (quoted in German in Patalas 222). Theoretically, then, image and text (and later sound, too) are equally productive components in the polyvalent materiality of the film.

The expressionist film invented two different responses that were aimed at sublating the metaphysical commitment to visual presence on to the level of ontological immanence. First, in some films written titles were designed as visual ornaments that transformed the printed word into a graphic image. Second, other films displaced written text entirely in favor of the image and the so-called expressionist acting style. The innovations of the expressionist art, theater, and literary avant-garde peaked soon after the end of the First World War from the perspective of personnel as well as aesthetics. Expressionist film style only began to emerge, however, in 1919, and its emergence was to a large extent the result of a marketing strategy on the part of the blossoming postwar movie industry that

Journal of Crass Cultural Image Studies - Revue d'Études Interculturelles de l'Image

Imaginations, I-I, 2010 Copyright (2. Open Journal Systems. ISSN - 1918-8439. 
identified a niche for the "art cinema" to support its national profile in the international movie distribution market. Hence, the relatively small corpus of about 40 German expressionist films out of an annual production of almost 200 features during the early 1920s belongs to what cultural historians consider postor late expressionism among the avant-garde movements. Moreover, these films were specifically produced with an eye toward artistically high quality features and directed at the educated, middle-class public rather than the popular audience. Nonetheless, not a few writers, theater practitioners, and artists saw this development of an expressionist film style as proof that the denigrated "mass culture" was now co-opting even avant-garde energies. In truth the expressionist cinema does introduce something new both from a film historical and aesthetic perspective.

Some examples will clarify this argument, beginning with the 1919 Das Kabinett des Dr. Caligari (The Cabinet of Dr. Caligari) by Robert Wiene, a key work of German expressionism and international film history. Here we find outstanding instances both of text designed graphically and of graphically designed images as an integral aesthetic approach to visual form. In this respect the film marks not only the beginning of a new film style but in a certain sense also its apex, insofar as the graphic style is remarkably consistent like in no other expressionist feature, as three of the film's first intertitles illustrate.

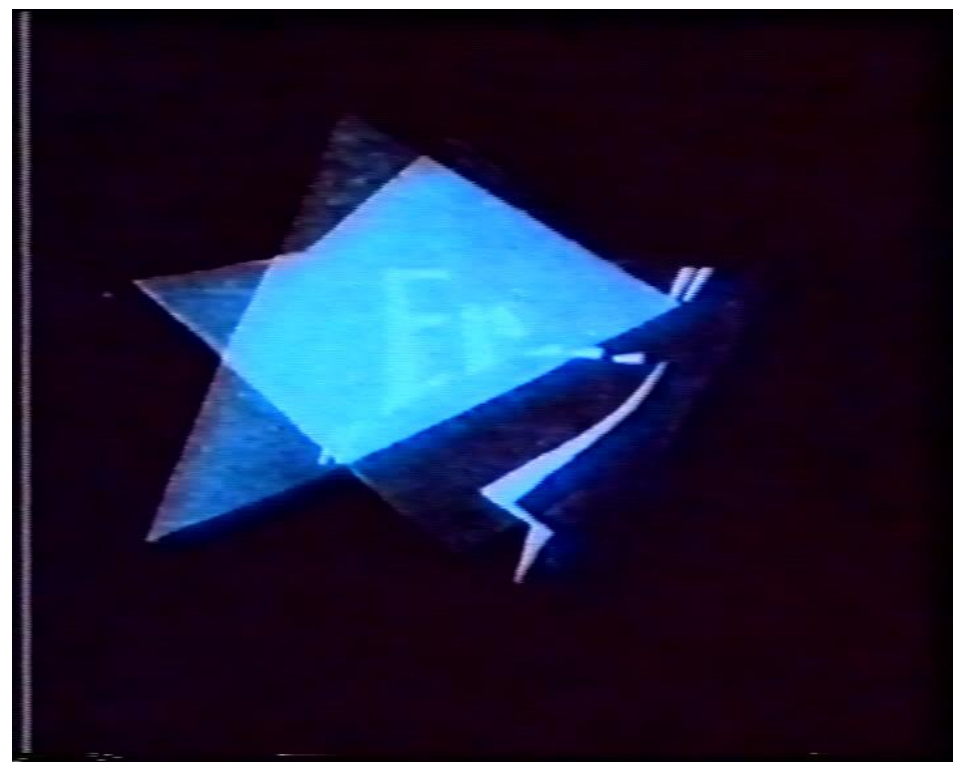

Journal of Crass Cultural Image Studies - Revue d'Études Interculturelles de l'Image Imaginations, I-I, 2010 Copyright (2. Dpen Journal Systems. ISSN - 1918-8439. 

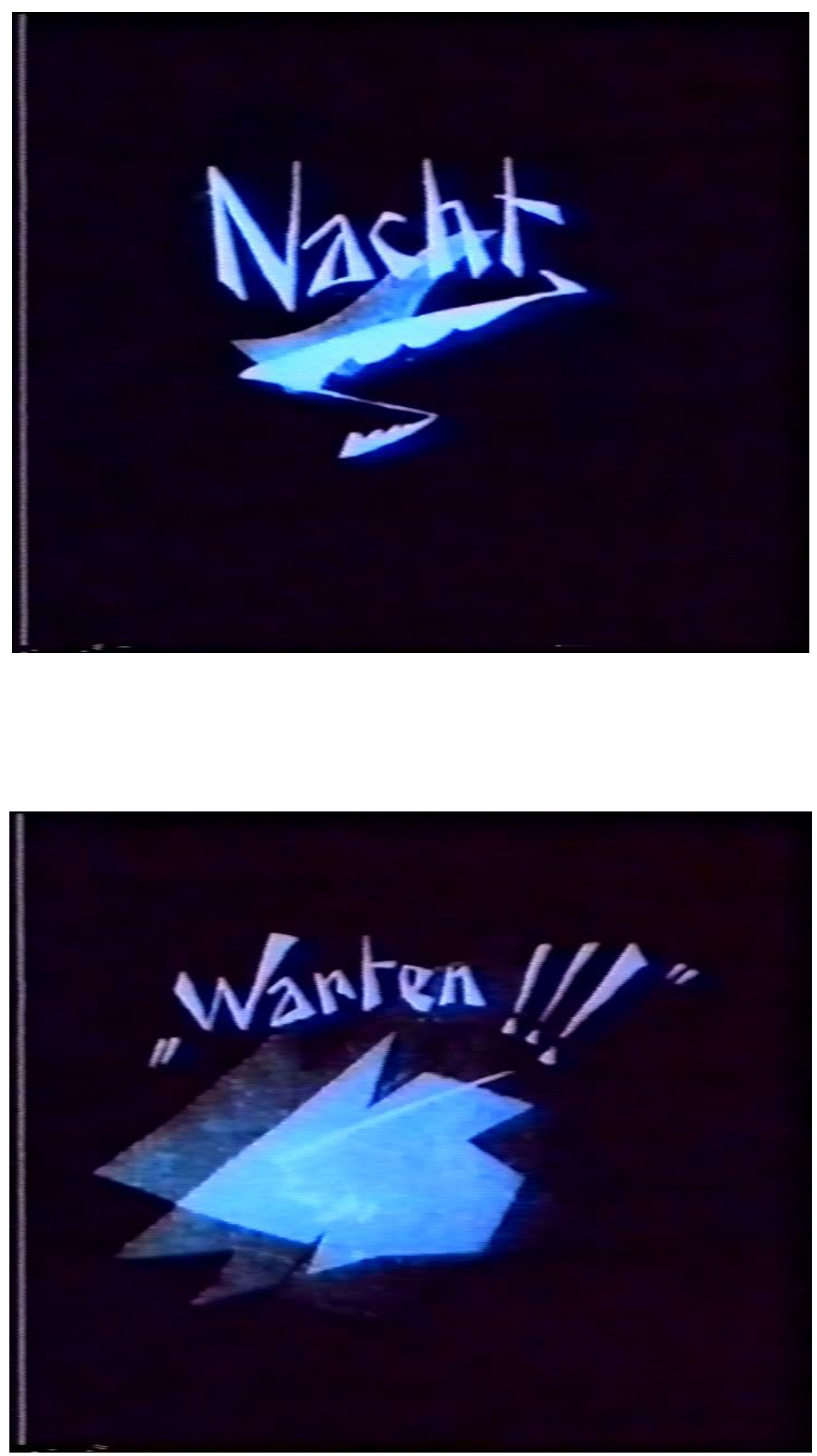

Journal of Crass Cultural Image Studies - Revue d'Études Interculturelles de l'Image Imaginations, I-I, 2010 Copyright (2). Open Journal Systems. ISSN - 1918-8439. 
The first notable detail in these short intertitles is the ornamental design of the printed text that was drafted by the expressionist artist Walter Reimann. The crude, woodcut print-type is not standardized but rather formed like free-hand writing with pointed and broken lines; the individual letters are irregular, with distorted edges; and the sequence of letters is not arranged on a straight, horizontal axis. Dietrich Scheunemann (24-31) has provided careful exposition of the title designs in the Caligari film, pointing out how these graphic qualities in the image of the printed word point to the psychological unease and tension of the film's figures. Behind each of the words is a background as well with broken planes that emphasize the dominant atmosphere of inner turmoil. Finally, the very precision of the intertitles' minimalist, reduced message is a typical device of expressionist stylization to convey heightened emotions. Such intertitles do not serve the story's narrative progress or even mark a specific rhythmic alternation for the editing, rather they intensify the uncanny atmosphere and frightful anticipation at the heart of the narrative. A spectacular example that breaks the frame of the static intertitle is shown in the following clip from the end of Caligari.

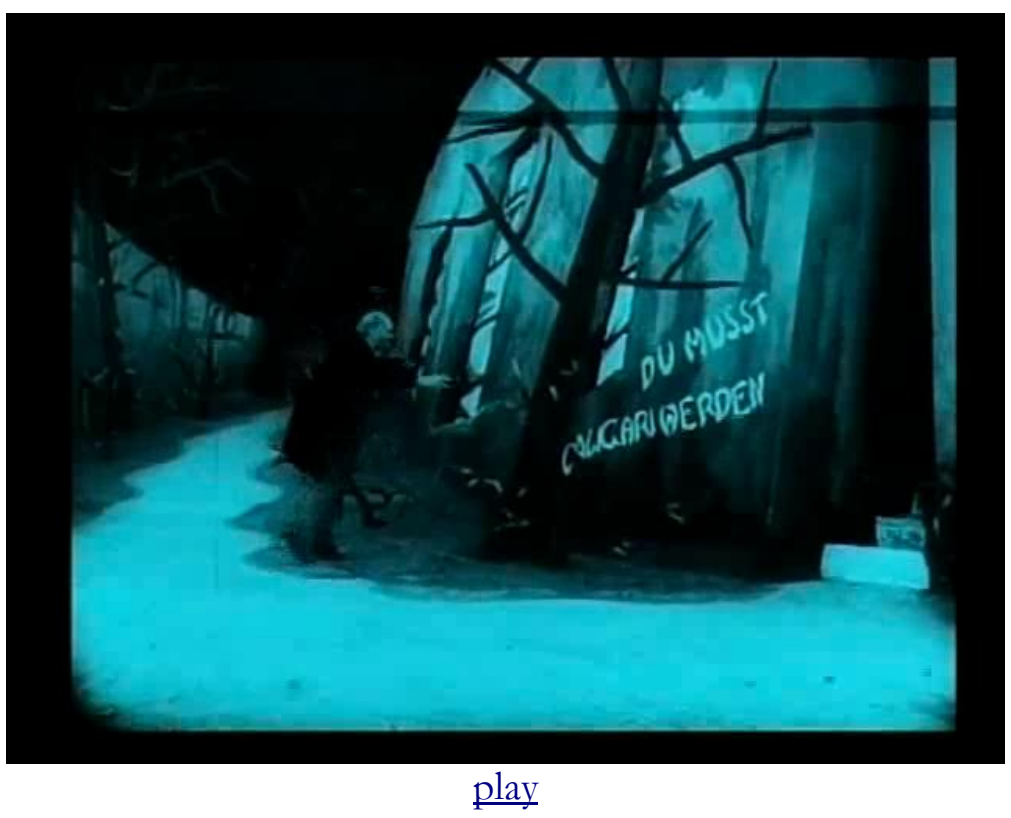

It shows nothing less than the staging of writing, since the ghostly words are now themselves integrated into the image as an overlay of text fading in and out. The animation of the words intensifies the feelings of angst as an autonomous 
component of the image, and the moving text embodies in itself the paranoia that has taken hold of Caligari. The threatening, aggressive writing becomes a projection of the inner forces and obsessions that haunt him, materializing the unconscious realm of hallucinations in a concrete image. In Wiene's Das Kabinett des Dr. Caligari we have an excellent example of expressionist stylization in which all signifiers, even written words, are subordinated to the creation of this out-ofjoint world. Like the actors' bodies, the sets' contours, and the painted decors, the printed word has become a scenic element in its plasticity. Here textuality too is a means of visual expression, demonstrating the fluid transition from text into image.

In a certain sense Wiene's Caligari mobilized already in 1919 the graphic function of writing as iconic and animated typography, a promising start that withered away, for in the course of the 1920s graphism became more and more ornamental in the narrative film while pictorial animation shifted into other areas such as the movement of crowds. Dimitri Buchowetski's Danton (1921), influenced by a stage production of Georg Büchner's play at the Deutsches Theater in Berlin, shows the way bodies can be treated as a graphic cipher in the cinema.

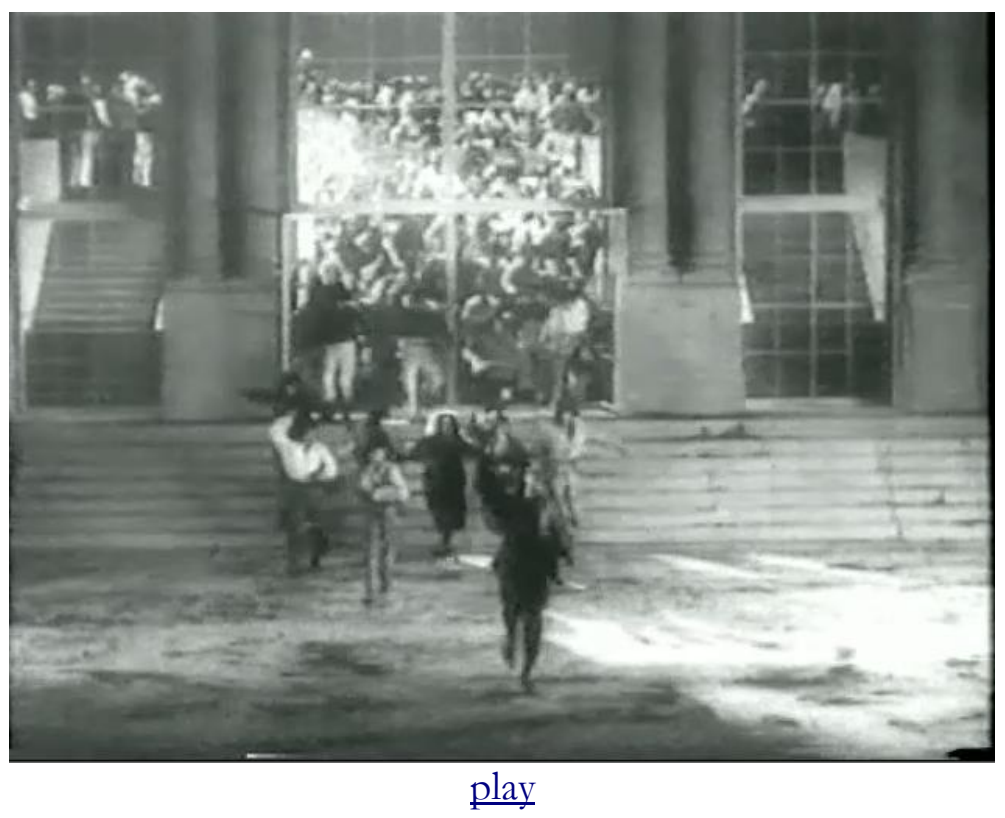

The crowds shot from a low angle and waving their arms rhythmically and then

Journal of Crass Cultural Image Studies - Revue d'Études Interculturelles de l'Image Imaginations, I-I, 2010 Copyright (2. Open Journal Systems. ISSN - I918-8439. 
streaming down the steep steps of the Convent in a frontal shot create a dynamic sense the scenic space. At the same time, however, the camera technique and editing in both Wiene's Caligari and Buchowetski's Danton were quite restrained. The distinctive dramaturgy of light and movement that would become the real innovations of the expressionist cinema led many film makers to seek new techniques and technologies of lighting and camera movement to narrate film stories. For them printed text was of secondary importance, although they too used discrete intertitles or inserts as an expressive film component with its own aesthetic value, as the following examples illustrate.

In the tradition of Caligari-one could almost speak of an intervisual citationFritz Lang uses in two episodes from his 1926 Metropolis typographically designed inserts as "emotional titles," adapting to written text the sonic characteristics of spoken language. The individual letters forming the word "Moloch" signal surprise and fear through the special calligraphy of the printed text.

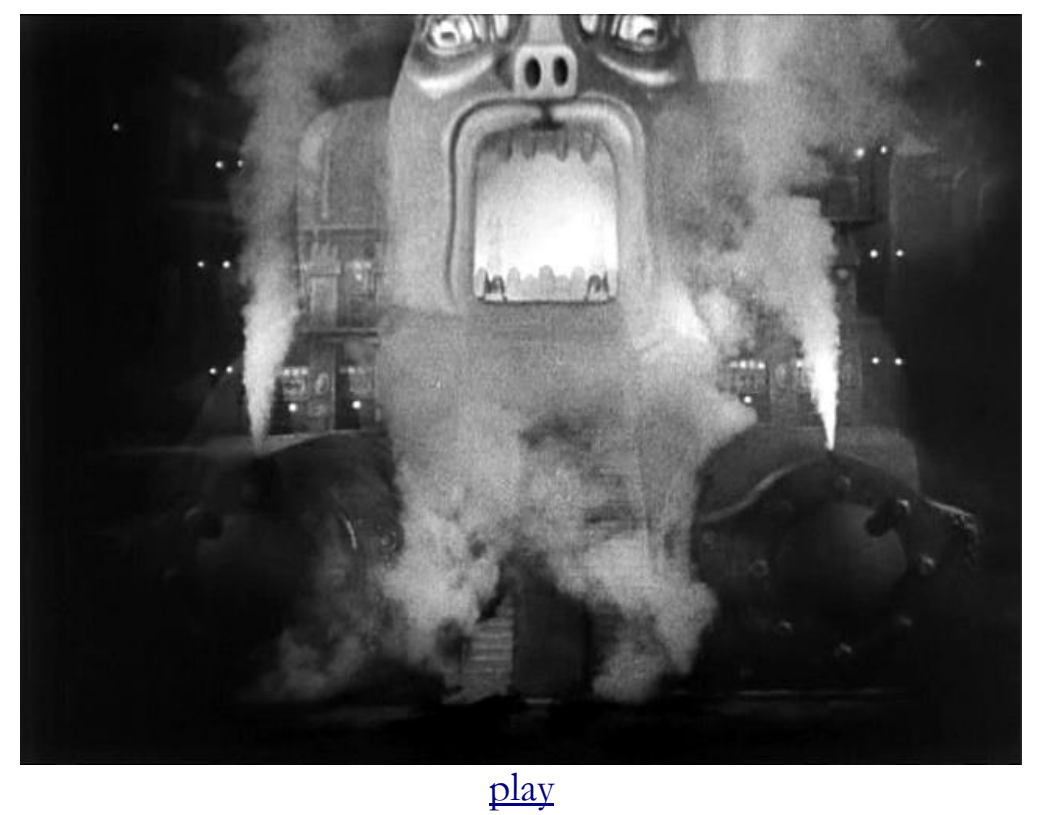

Similarly, the drops of blood or sweat oozing from the word "Babel"- the latter referring to the biblical tale of desire for universal language and its ultimate lack of fulfillment-animate the very idea of signification, in contradistinction to the 
disrupted mechanism of referentiality practiced by modernist texts.

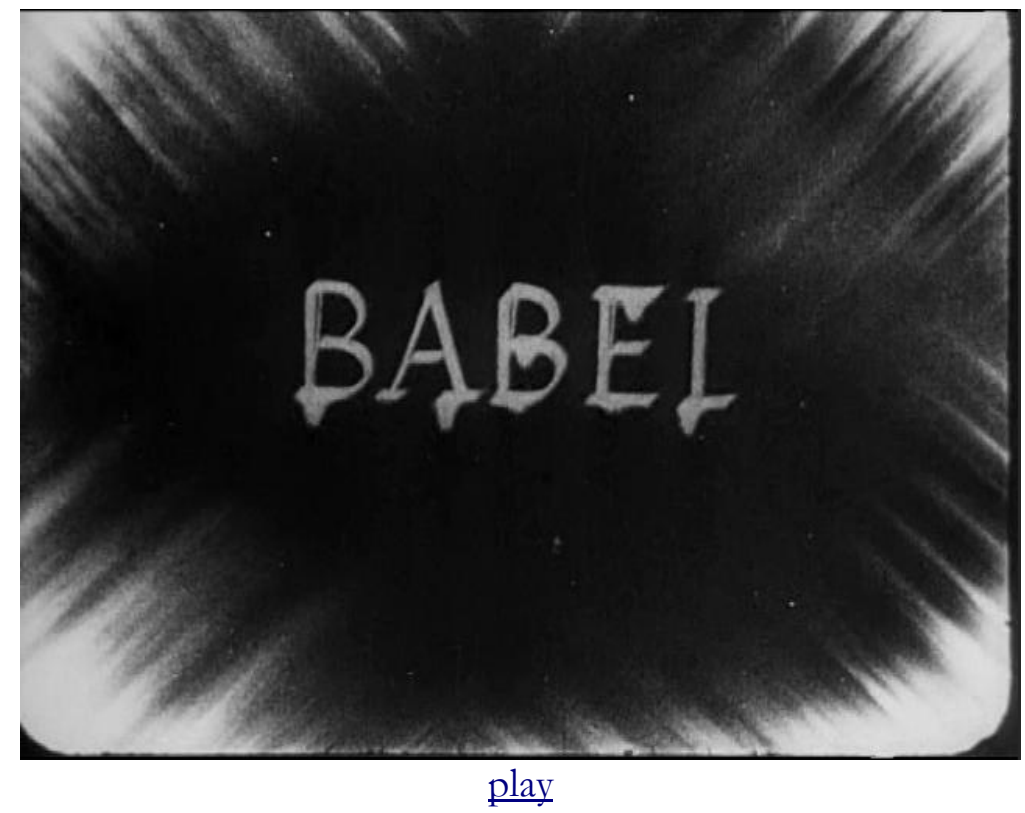

Writing always has both a figural and a verbal aspect in the sense that it is read as well as looked at. The distinction is trivial until the writing is calligraphically or typographically realized, as in these cases.

To return briefly to Der Golem, the plot visualizes the theme of writing itself as the key to life. Inserts show parchment roles with the ruler's decrees that guarantee or destroy the existence of the Jews in their protective ghetto; they show pages from the books that the Rabbi and his assistant study for a clue to the secret of life; and they prominently display the crucial cabbalistic message written on a scrap of paper. 

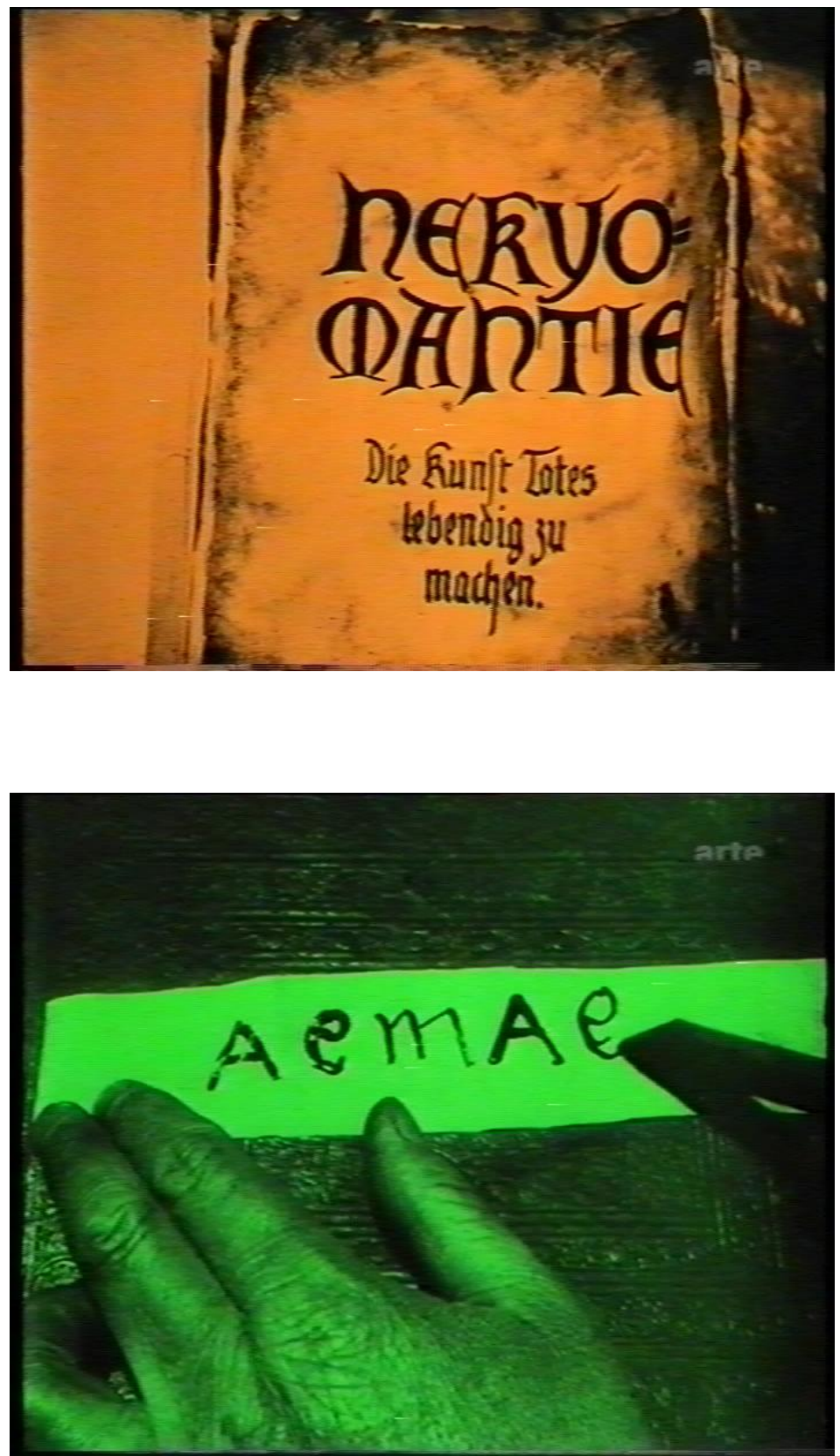

Even more important, however, is the revelation of the word that can awaken the Golem, the man-made clay figure, to life. Here language possesses a transcendent, divine power that-objectified in the word-brings the hidden into the open. 
Conjured by Rabbi Loew in a drama of flames, lightening, and storming shapes, Astaroth, the dead spirit, utters the word "aemaet" that manifests itself as ephemeral writing with the breath, for this is the spirit as word that will infuse the inanimate figure with life.

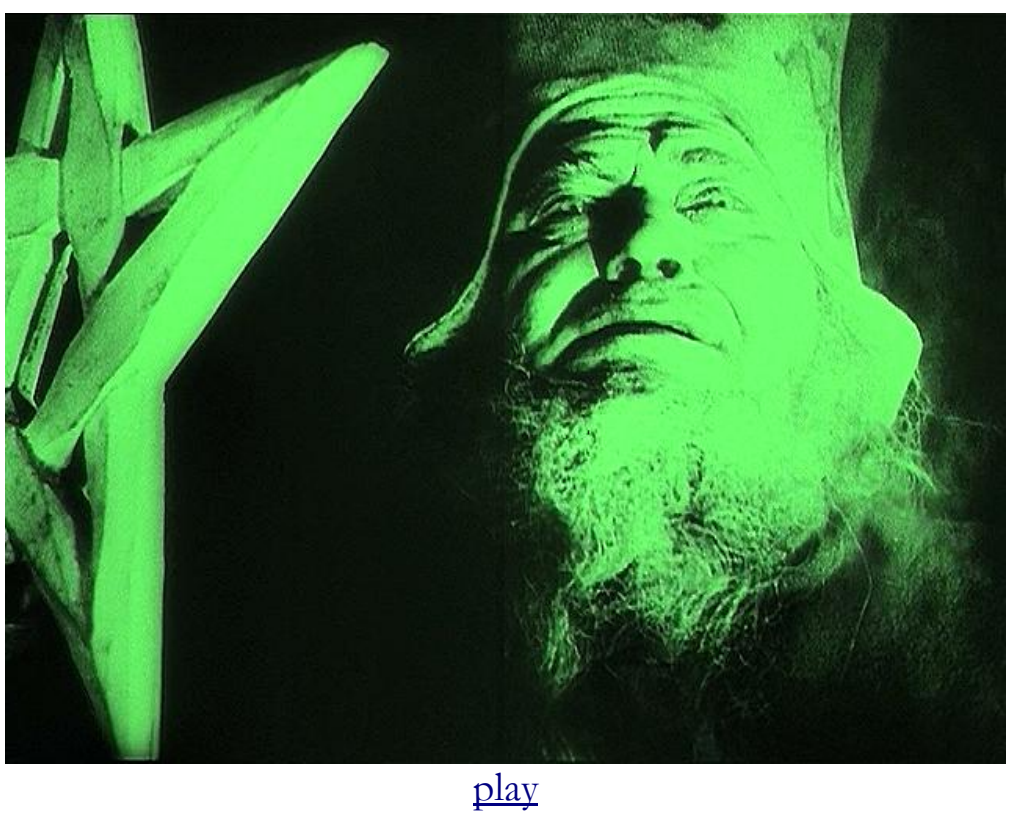

The graphism of the magic word, achieved here through sophisticated trick effects, shows the writing of the text in moving images as its very reading-and ultimately redemption, since this word will create life. In this case the abstraction of print culture is transformed into the transparency and vitality of visuality.

Some filmmakers pursued a different strategy in the early 1920s, seeking to do away with intertitles entirely. The first experimental films by avant-garde artists were non narrative, abstract visual studies with no intertitles at all. Walther Ruttmann's “Opus" series of short animated films, for example, stages encounters between light, volumes, planes, and movement in order to explore the dynamic energy of the relationship between time and space. 


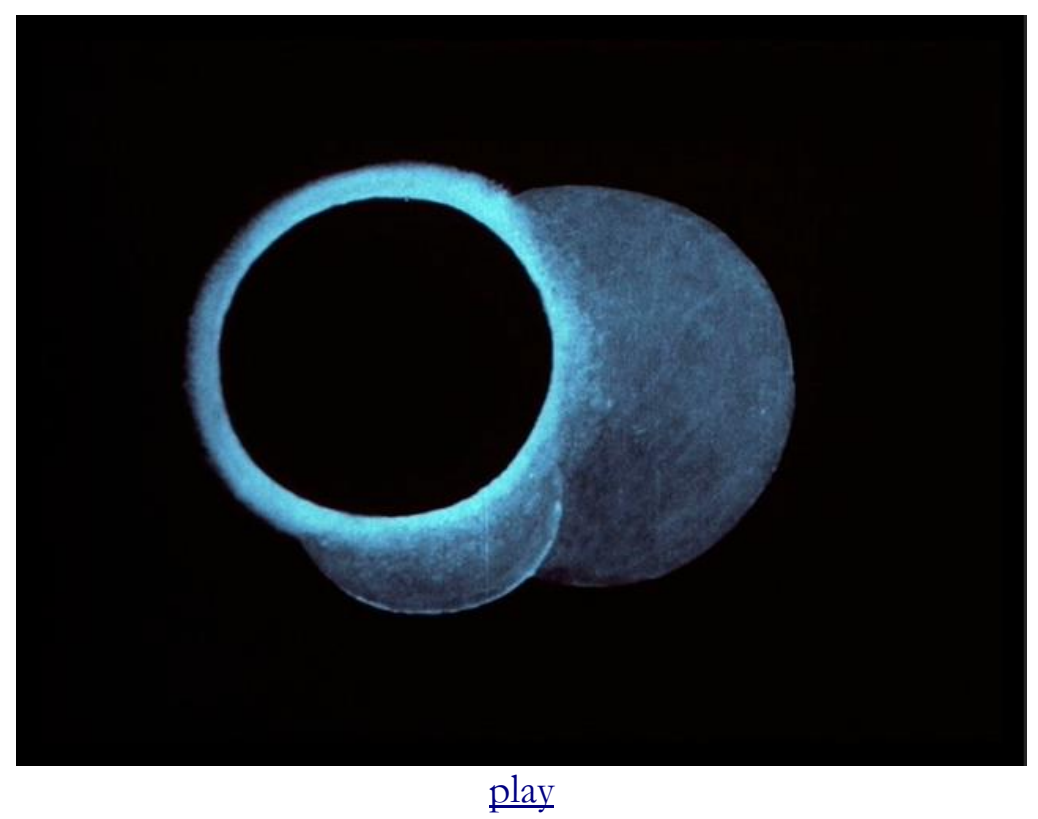

Expressionist chamber films such as Leopold Jessner's Hintertreppe (1921) and Lupu Pick's Sylvester (1924) strove to reduce the use of intertitles to a minimum and instead conveyed the narrative through other expressive means of the cinema such as gesture, body movement, facial expressions, and contrasts of light and shadow. Since these dramas, based on screenplays by Carl Mayer, explicitly thematize speechlessness or focus on characters who are condemned to silence, it is only logical that the inability to communicate underlying the respective story's tragic fate made the printed form of speech superfluous (Paech 53).

Friedrich Wilhelm Murnau's Der letzte Mann (The Last Laugh, 1924) marks a highpoint in this use of the camera for purposes not only of representation but also narration, again based on a screenplay by Carl Mayer. The following examples from different points in the film demonstrate how Mayer avoided intertitles entirely but yet employed printed words diegetically, that is, as part of the visual narration: the illuminated sign of the Atlantic Hotel where the doorman works the front entry, the message on his daughter's wedding cake ("Den Hochzeitsgästen," or To the Wedding Guests), and a cut-in to the exclusive brand name label of a Mumm champagne bottle that denotes class status. 

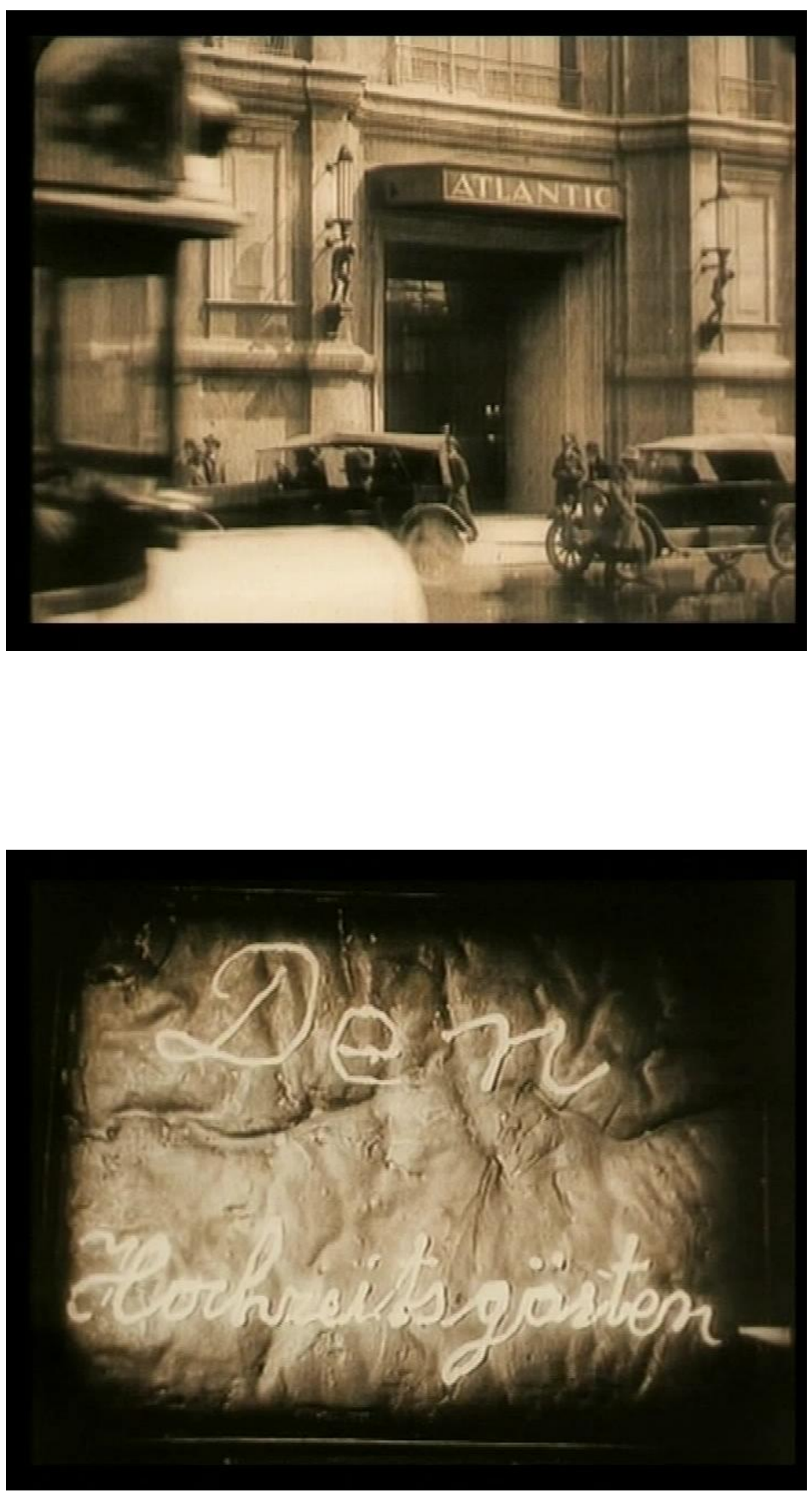

Journal of Crass Cultural Image Studies - Revue d'Études Interculturelles de l'Image Imaginations, I-I, 20I0 Copyright (2. Open Journal Systems. ISSN - 1918-8439. 


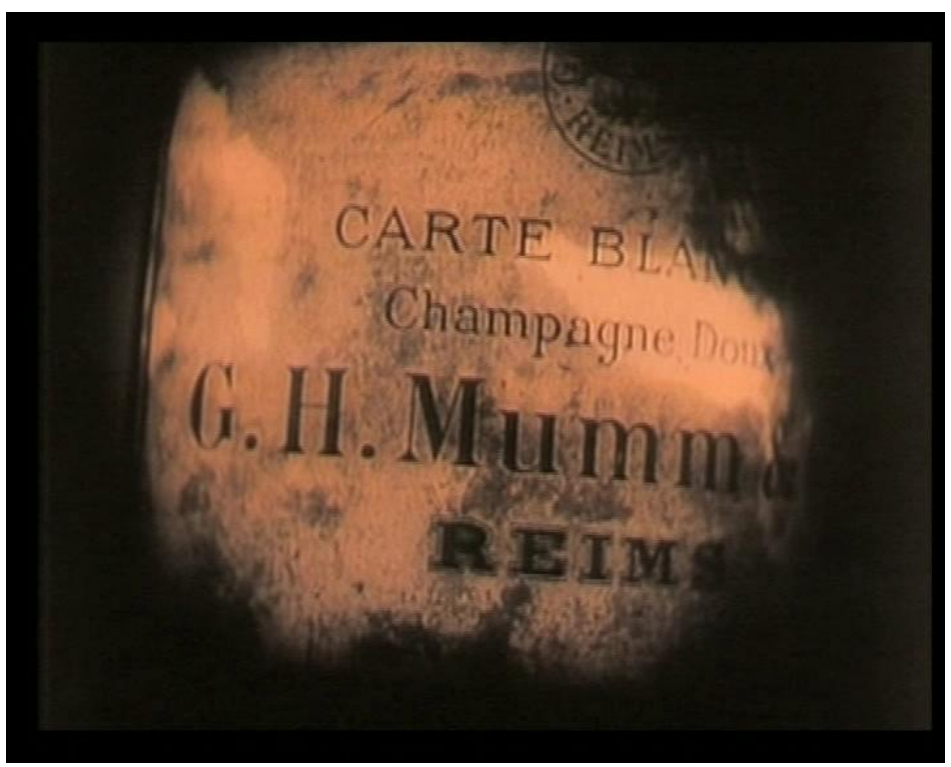

A central sequence shows the protagonist reading his demotion letter. The camera spies on the doorman from outside the manager's office, then passes through the door's transparent glass threshold and assumes the doorman's subjective perspective as he haltingly scans the lines of text and individual printed words. Murnau employs here two perceptual variables that dominate the reading process: duration (focus on letters, words, and sense units) and control (speed, segmentation of meaning, and sequencing or repetition), and he thereby visualizes through the reading of the printed text the protagonist's highly emotional, interior turmoil as he comprehends the shocking news of his demotion to a toilet attendant because of his old age ("Der Grund ist Ihre Altersschwäche," or the reason is your old-age infirmity). 


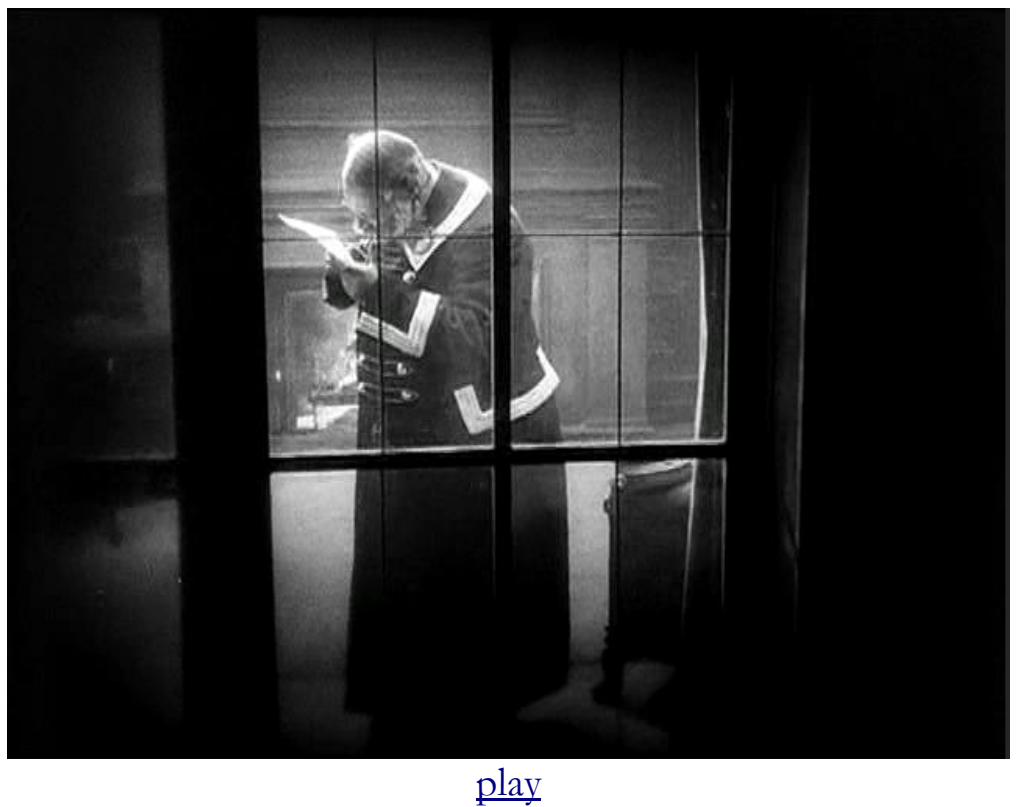

A later insert of a newspaper clipping introduces the surprising, unforeseen turn of events from a tragic fall to a fairy tale-like happy ending. It reports that the millionaire A.G. Monney died in the toilet attendant's arms, and according to the former's will, his entire wealth is to be claimed by the person in whose arms he dies.

\section{Gine jenjationelle (Erbjachajt.}

Wie not) erinnerlid,), veriádied hilirglid) im 2Baidraum des Ifllantic-5iofel der beriibmite

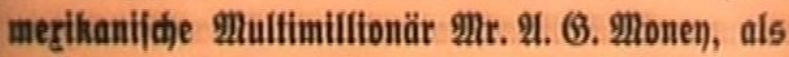
er fid die sände wuid). Jebt ifit nun unier den Papieren diejes Gonderlings ein jenjationelles Tefifament gejunden worben, das denjenigen zum Uniberjalerben jeines unermejilidjen Bermögens cinjelf, in befien Irmen er fterben wïrde. 
The speechless, subaltern doorman is transformed by the printed announcement into a "speaker": with demonstrative gestures, winks of the eye, and (silent) whispers-all those familiar gestures of the expressionist actor Emil Jannings-he becomes now the sovereign manager of the waiters and hotel personnel. Murnau shows how film images produce a kind of speech without words, a text without print, a visual narration.

By the mid 1920s film expressionism had already reached its prime. New technological advances provided expanded applications for intertitles and textual images by means of sophisticated optical printers that enabled a more complex and freer integration of text and image. The moving or "unchained" camera, pioneered by cinematographer Carl Mayer in Murnau's Der letate Mann, also changed perspectival relations as well as the very relation between viewer and screen, creating new visual experiences of dizziness, falling, and climbing, and transforming film acting from the pathos-laden histrionics of the expressionist style to a more flowing style (Prümm 238). Yet the decisive catalyst for revising the cinematic relationship between image and text came from the Russian avantgarde. Building on Vsevolod Meyerhold's pedagogy of abstract gesture production (biomechanics) and Ilya Ehrenberg's notion of the mechanization of all gestures, Sergei Eisenstein was the first film maker who tried to connect, for example, film acting with the technical conditions of cinematic medium. He developed a film semantics based on meaning production as a successive process in which a lexicon of gestures can exist only as an inventory of polyvalent elements (Law and Gordon). In other words gestures are not indeterminate but rather they are constituted culturally and historically, and the fact that a film actor-say, Charlie Chaplin-is internationally comprehensible was proof for Eisenstein that the ambiguous polyvalence of gestures defines the very strength of the silent cinema.

Similarly, Soviet film makers like Eisenstein, Vladimir Pudovkin, and Dziga Vertov understood the function of intertitles in a fundamentally different way than the German expressionists. The Russian school of montage was based on a constructivist principle that attempted to approximate visually the musicality, rhythm, and tempo of sound, unrelated to speech and the representation of verbal language. Montage editing works with the calculated effects of contrast, antithesis, intervals, and collision in order to produce a dynamic tension. In this context printed intertitles assume a variety of functions from historical quote to expository information about characters, mood, or behavior to the representation of intonation (a crescendo of voices) and tempo (suspense, delay) within a sequence

Journal of Crass Cultural Image Studies - Revue d'Études Interculturelles de l'Image

Imaginations, I-I, 2010 Copyright (2. Open Journal Systems. ISSN - 1918-8439. 
of images. ${ }^{5}$ The following two examples illustrate how some of these possibilities were adapted in Walther Ruttmann's 1927 constructivist film Berlin, Sinfonie der Großstadt (Berlin, Symphony of a Great City). In the first sequence the printed signs of "Anhalter Bahnhof" and "Berlin" have an expository: as they move into view, they announce the train's arrival in Berlin from the countryside in the early morning.

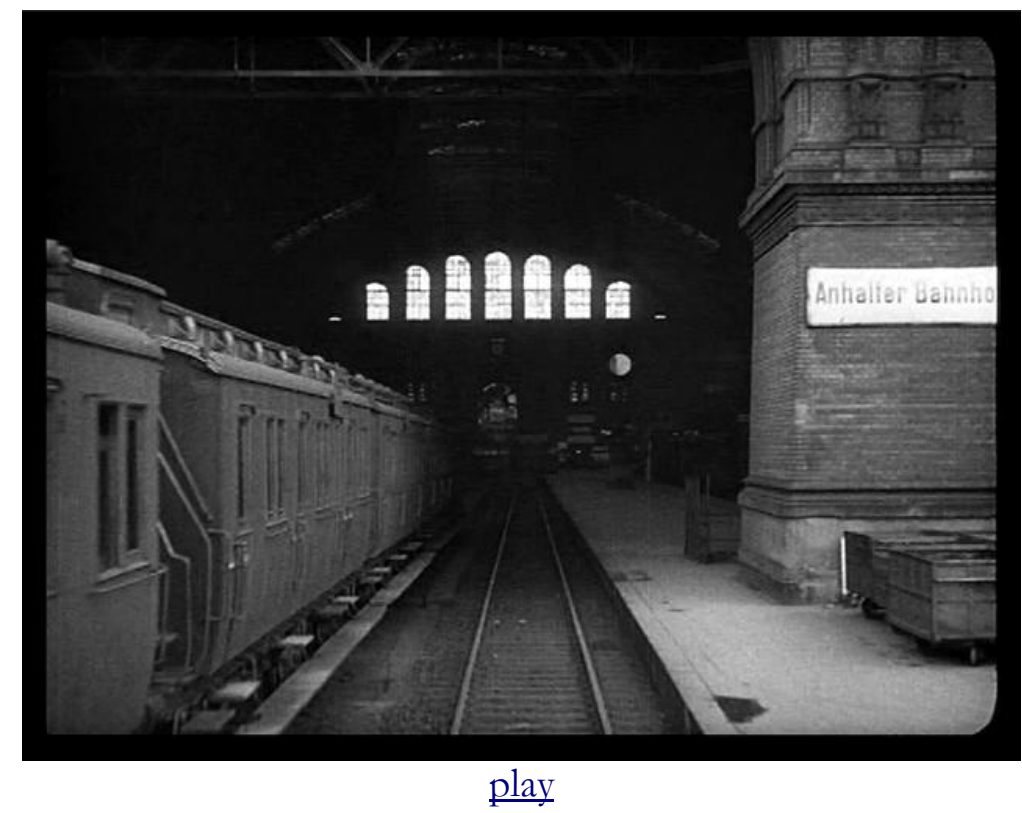

In the second sequence from the afternoon section, the accelerating images of newspaper headlines rolling off the printing presses (Crisis, Murder, Stocks, Weddings, Money) segue into the subjective camera speeding along the tracks. 


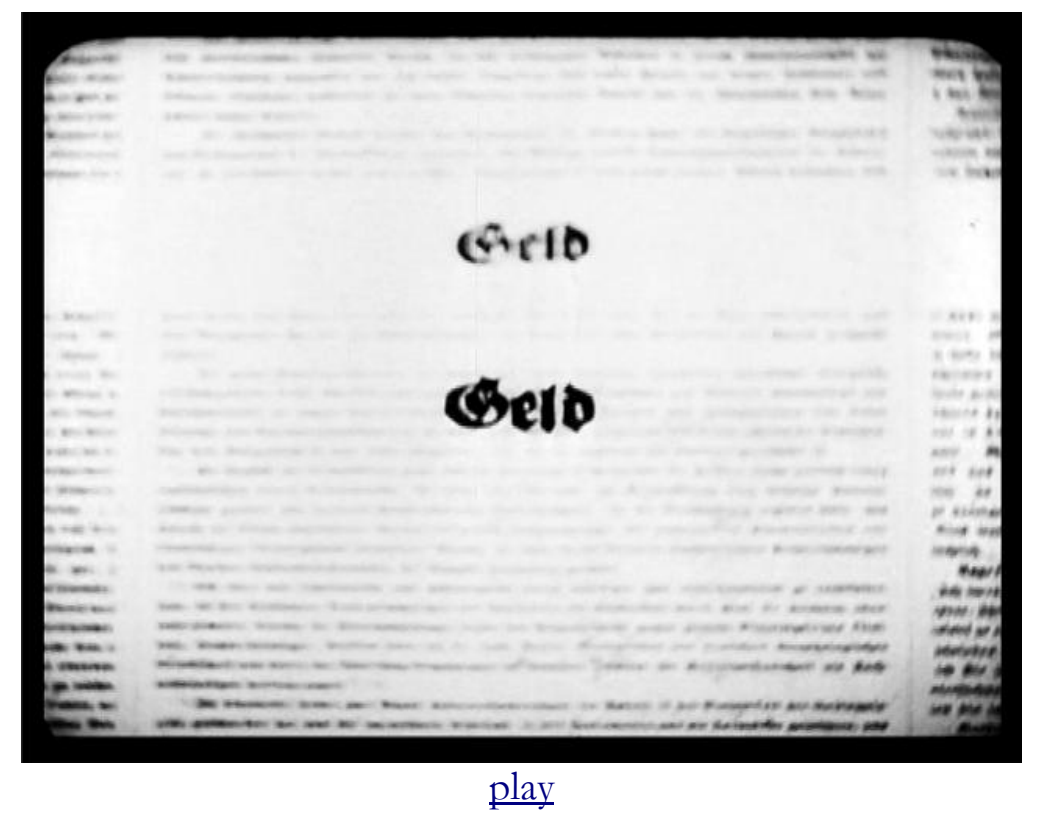

For Ruttmann the integration of printed signs and moving words generates a rhythm through the tension established vis-à-vis the speeding train and the rotation press. Text and image follow a graphically calculated principle reinforced by the original music (composed by Edmund Meisel) that describes "a day in the life of the metropolis."

Finally, for the sake of contrast it is worthwhile to consider two examples of notable image-text relations from the early sound cinema. Fritz Lang's $M$ (1930) no longer needs intertitles but insists on pointing out the insufficiency or displacement of writing in the now reconfigured media partnership of text, image, and sound. In this detective story an entire city has been set on edge because of the anonymous (written) letter of confession circulated by a serial child murderer. Perched behind the still unknown man, the camera focuses on the writing of the postcard, while the sound track carries the absent-minded, nervous whistling of the tune that will ultimately give away the culprit's identity (a brief passage from Edvard Grieg's Peer Gynt Suite, "In the Hall of the Mountain King”). 


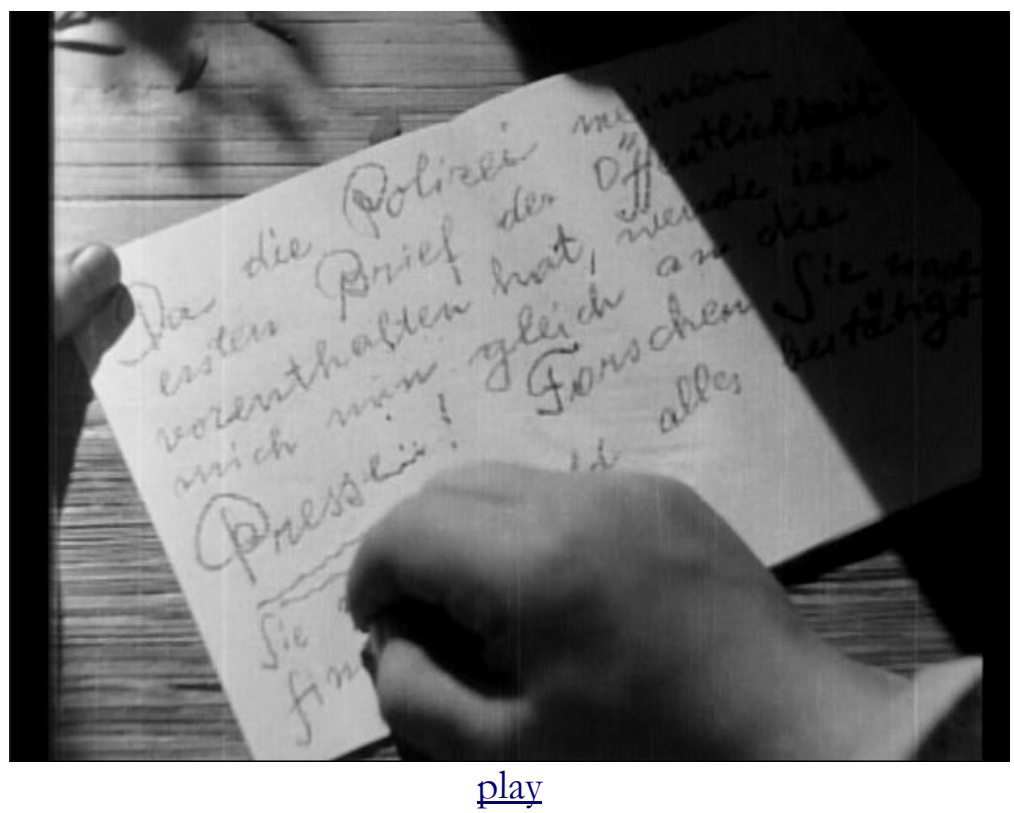

Moreover, the sound bridge of the voice-over reading the "wanted poster" $(10,000$ Mark reward...) connects visually the sound, words, and printed message. In this very early talkie the serial murders can be solved only by means of sound when a blind beggar, that is, someone who can not see, recognizes the whistled tune he connects with the murderer's presence of the murderer. Writing is only one device, but yet a crucial one in tracking the culprit, for the pursuers trace the letter " $\mathrm{M}$ " in white chalk on the black overcoat of the suspected killer in order to make him visible for their pursuit. In contrast, Slatan Dudow and Bertolt Brecht's 1932 Kuble Wampe oder: Wem gebört die Welt? (Kuhle Wampe or Who Owns the World?) still employs intertitles in an early sound film as a self-reflexive structuring device. The disruption of visual and narrative continuities by the calculated placement of interruptive titles articulates an aesthetic response, often with an ironical punch, to the miseries of modern, urban life. The neighbor woman, in this example, comments matter-of-factly on the suicide of a young man in her apartment house: "He still had the best years in front him," punctuated by the sound of the hearse door closing before we see it drive off, and then followed by the insert: "Das schönste Leben eines jungen Menschen” (The best years of a young man). 


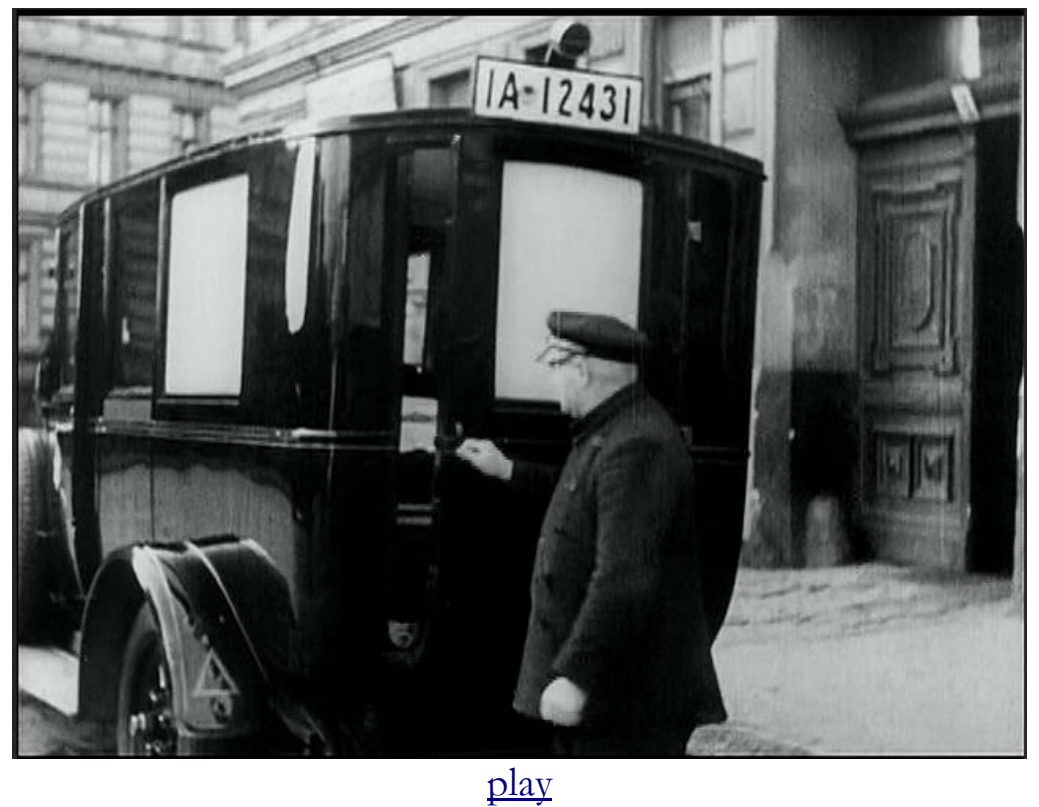

Brecht's radicalization of the autonomy of all aesthetic elements in the Epic Theater and the cinema ("die Trennung der Elemente" or separation of elements) corresponds to his socio-political intention of not only communicating knowledge to the audience but also positioning the audience to produce it. The play with discontinuities between image, dialogue, sound, and text in this example from Kuble Wampe aims at the activation of the audience, pulls her out of a contemplative reception mode that can arise in a highly emotional story, such as this one about the suicide of a young man.

To conclude, I have shown how the status of language in the German silent cinema was positioned within a context of competing practices and discourses during a momentous shift in the mediatization of seeing. The expressionist film specifically is defined by its pictorial understanding, paying close attention to lighting and set design in order to create innovative, sometimes intentionally confusing interior and exterior spaces; it is also oriented primarily toward literary and painterly sources. This formal sophistication did succeed in demonstrating the artistic quality of the new medium to a mass audience, but at the same time its formal coherence, which also included gestural acting and graphically inspired intertitles, purposely disguised the medium's technological innovations that challenged traditional, institutional ideas of art. As a result, the relationship to the mechanical means of representation yielded an experimental cinema, but one that displaced the alienation of modernity into interiorized narratives of angst and 
dislocation and into an aesthetics of the image sustained by a strong antitechnological thrust. "Neues Sehen," the new seeing to which the expressionists were committed, just like the other historical avant-gardes, sought to expand visual perception as a pre-condition of revitalizing modern culture. They saw redemptive value in the cinema's turn from the abstraction of print culture to a new kind of transparency and visibility. In other words the philosophical and metaphysical dimensions of the mediatization of seeing were recognized from early on. But the cinema as a technical medium, the realization of the media-specific construction of expressivity in front of the camera into forms of filmic representation on the screen would have to wait for other innovations and models.

\section{References}

Altman, Rick. Silent Film Sound. New York: Columbia UP, 2004.

Balázs, Béla. Der Sichtbare Mensch. Balázs. Schriften zum Film I. Berlin: Henschel, 1982. In English, Visible Man. Trans. Rodney Livingstone. Ed. Erica Carter. New York: Berghahn, 2010.

Birett, Herbert. "Alte Filme: Filmalter und Filmstil. Statistische Analyse von Stummfilmen.” Ed. Ledig, Der Stummfilm. 74-82.

Goetsch, Paul und Dietrich Scheunemann, eds. Text und Ton im Film. Tübingen: Gunter Narr, 1997.

Hake, Sabine. The Cinema's $3^{\text {rd }}$ Machine: Writing on Film in Germany 1907-1933. Lincoln, NE: U of Nebraska P, 1993.

Hedigr, Vinzenz. "Reiz, Qualität und Ausdruck: Zur Funktion von Schrift und Typographie in Kinotrailern." Schrift und Bild im Film. Ed. Hans-Edwin Friedrich and Uli Jung. Bielefeld: Aisthesis, 2002. 139-62.

Lange, Konrad. Das Kino in Gegenwart und Zukunft. Stuttgart: Enke, 1920.

Law, Alan and Mel Gordon. Meyerhold, Eisenstein and Biomechanics: Actor Training in Revolutionary Russia. Jefferson, NC: McFarland, 1996.

Ledig, Elfriede, ed. Der Stummfilm: Konstruktion und Rekonstruktion. Munich: Verlegergemeinschaft Schaudig/Bauer/Ledig, 1988.

Lukács, Georg. "Gedanken zu einer Ästhetik des Kinos (1911)." Prolog vor dem Film: Nachdenken über ein neues Medium 1909-1914. Ed. Jörg Schweinitz. Leipzig: Reclam, 1992. 300-05. In English, "Thoughts on an Aesthetic for the Cinema." Trans. Lance W. Garmer. German Essays on Film. Ed. Richard McCormick and Alison Guenther-Pal. New York: Continuum, 2004. 11-16.

Müller, Corinne. "Zur Veränderung des Schauspielens im stummen Film: Am Beispiel insbesondere Henny Portens.” Der Körper im Bild: Schauspielen Darstellen - Erscheinen. Ed. Heinz B. Heller, Karl Prümm, Birgit Peulings. Marburg: Schueren, 1999. 71-92.

Journal of Crass Cultural Image Studies - Revue d'Études Interculturelles de l'Image Imaginations, I-I, 2010 Copyright (2. Open Journal Systems. ISSN - 1918-8439. 
Orosz, Susanne. "Weiße Schrift auf schwarzem Grund: Die Funktion von Zwischentiteln im Stummfilm, dargestellt am Beispiel aus Der Student von Prag (1913).” Ed. Ledig, Der Stummfilm. 135-51.

Paech, Joachim. "Zwischen Reden und Schweigen - die Schrift." Goetsch and Scheunemann, eds. Text und Ton im Film. 47-60.

Patalas, Enno. "David Ward Griffith: Vom Buch zum Film." Frieda Grafe and Enno Patalas. Im Off: Filmartikel. Munich: Hanser, 1974. 221-25 (rpt. from Süddeutsche Zeitung, 1972).

Pordes, Victor E. Das Lichtspiel: Wesen - Dramaturgie - Regie. Vienna: R. Lechner Universitätsbuchhandlung, 1919.

Prümm, Karl. "Das schwebende Auge: Zur Genese der bewegten Kamera." Die Medien und ibre Technik: Theorien - Modelle - Geschichte. Ed. Harro Segeberg. Marburg: Schüren, 2004. 235-56.

Rudenski, Dyk. Gestologie: Abhandlung über die Physiologie und Psychologie des Ausdrucks. Berlin: Verlag der Hoboken-Presse, 1927.

Scheunemann, Dietrich. "Intolerance - Caligari - Potemkin? Zur ästhetischen Funktion der Zwischentitel im frühen Film." Goetsch and Scheunemann, eds. Text und Ton im Film. 11-40.

Ralf Schnell. Medienästhetik: Zu Geschichte und Theorie audiovisueller Wahrnehmungsformen. Stuttgart: Metzler, 2000.

Stratmann, André. "Der Zwischentitel im Stummfilm," 6 July 2010, http://www.beepworld.de/members78/stummfilm-fan/zwischentitel.htm.

Van Wert, William F. "Intertitles." Sight and Sound 49.2 (Spring 1980): 98-105. Wegener, Paul. "Von den künstlerischen Möglichkeiten des Wandelbildes." Deutscher Wille [Der Kunstwart] 30.1 (January 1917): 13-15.

Image Notes

Still images 1A and 1B:

Inserts, two sides of Edgar Hull's calling card, Fritz Lang, Dr. Mabuse, der Spieler (1922)

[DVD grab, C Friedrich Wilhelm Murnau-Stiftung, 2004]

Sill image 2:

Dialogue title from Fritz Lang, Dr. Mabuse, der Spieler (1922)

[DVD grab, C Friedrich Wilhelm Murnau-Stiftung, 2004]

Clip 1:

Flirtation between Graf Florian (Lothar Müthel) and Miriam (Lydia Salmonova) from Paul Wegener and Carl Boese, Der Golem, wie er in die Welt kam (1920) 
[DVD clip, C Friedrich Wilhelm Murnau-Stiftung, 2004, new music by Aljoscha Zimmermann]

Still images 3A, 3B, 3C

Intertitles with expressionist graphic design from Robert Wiene, Das Kabinett des Dr. Caligari (1919): “Er" (he), "Nacht” (Night), "Warten!!!” (Wait)

[DVD grabs, C Film Preservation Associates, 1996]

Clip 2:

Graphic writing from Robert Wiene, Das Kabinett des Dr. Caligari (1919): "Du musst Caligari werden" (You must become Caligari)

[DVD clip, C Film Preservation Associates, 1996, new music (C) Timothy Brock, 1996]

Clip 3:

Crowds streaming forth from Dimitri Buchowetski, Danton (1921)

[VHS clip, (C) Bundesarchiv Berlin]

Clip 4:

Graphic writing of "Moloch" from Fritz Lang, Metropolis (1926)

[DVD clip, (C) Films sans frontiers, 1999, new music by Galeschka Moravioff]

Clip 5:

Graphic writing of "Babel" from Fritz Lang, Metropolis (1926)

[DVD clip, (C) Films sans frontiers, 1999, new music by Galeschka Moravioff]

Still images 4A, 4B

Examples of writing from Paul Wegener and Carl Boese, Der Golem, wie er in die Welt kam (1920): Rabbi Löw and his assistant seek answers in a book titled "Nekromantie - Die Kunst Totes lebendig zu machen" (Nekromancy - The Art of Bringing Life to the Dead); Rabbi Löw writes the secret word on a scrap of paper, to be fastened to the Golem's chest [DVD grabs, C Friedrich Wilhelm Murnau-Stiftung, 2004]

Clip 6:

The divine power of the word from Paul Wegener and Carl Boese, Der Golem, wie er in die Welt kam (1920): "aemaet"

[DVD clip, C Friedrich Wilhelm Murnau-Stiftung, 2004, new music by Aljoscha Zimmermann] 
Clip 7:

Excerpt from short animation film by Walter Ruttmann, Lichtspiel Opus II (1921)

[DVD clip, (C) Edition Filmmuseum, 2008, piano score by Joachim Baerenz]

Still images 5A, 5B, 5C

Examples of print from Friedrich Wilhelm Murnau, Der leţte Mann (1924)

[DVD grabs, C Friedrich Wilhelm Murnau-Stiftung, 2003]

Clip 8:

The doorman reads his letter of demotion in Friedrich Wilhelm Murnau, Der letate Mann (1924)

[DVD clip, C Friedrich Wilhelm Murnau-Stiftung, 2003, original score of

Giuseppe Becce adapted by Detlev Glanert]

Still image 6

Diegetic print shows the newspaper article announcing the surprising plot turn from Friedrich Wilhelm Murnau, Der letzte Mann (1924)

[DVD grab, C Friedrich Wilhelm Murnau-Stiftung, 2003]

Clip 9:

Signboards announce the train's arrival in Berlin, from Walther Ruttmann, Berlin, Sinfonie der Großstadt (1927)

[DVD clip, C Edition Filmmuseum, 2008, original film score by Edmund Meisel]

Clip 10:

The headlines roll of a page of the newspaper, from Walther Ruttmann, Berlin, Sinfonie der Großstadt (1927)

[DVD clip, (C) Edition Filmmuseum, 2008, original film score by Edmund Meisel]

Clip 11:

Writing and whistling from Fritz Lang, $M$ (1931)

[DVD clip, (C) Atlantic-Film S.A. and The Classic Collection, 1998]

Clip 12:

Interruptive intertitle from Slatan Dudow and Bertolt Brecht, Kuble Wampe oder: Wem gehört die Welt? (1932)

[DVD clip, (C) absolute medien, 2008]

Journal of Crass Cultural Image Studies - Revue d'Études Interculturelles de l'Image

Imaginations, I-I, 2010 Copyright (2. Open Journal Systems. ISSN - 1918-8439. 


\section{Endnotes}

1 Friedrich Korner mentions a "school for narrators" ("Erklärer-Schule") in his 1929 dissertation for the University of Vienna, "Der deutsche Film: Tatbestand und Kritik einer neuen Kunstform" (75), quoted in Orosz 135. While the contextualizations and developments in Germany did not necessarily correspond to those in the United States, there are indeed many similarities in technological innovations and trends; for an excellent historical introduction to the complexity of issues in regards to sound in the American silent cinema, see Altman, especially part IV on "Nickolodeon Sound" for an extensive discussion of the film narrator.

2 “Das 'Kino' stellt bloß Handlungen dar, nicht aber deren Grund und Sinn, seine Gestalten haben bloß Bewegungen, aber keine Seelen, und was ihnen geschieht, ist bloß Ereignis, aber kein Schicksal. (Deshalb_ - und bloß scheinbar wegen der heutigen Unvollkommenheit der Techniksind die Szenen des 'Kino' stumm: was an den dargestellten Ereignissen von Belang ist, wird durch Geschehnisse und Gebärden restlos ausgedrückt, jedes Sprechen wäre eine störende Tautologie.)"

3 "In erster Linie ist der Film eine visuelle Angelegenheit. Der Filmdichter muß vom Bild ausgehen, in Bildern denken, und Stoffe wählen, die bildhaft auszudrücken sind."

4 "Es ist mir unbegreiflich, daß man das Unkünstlerische dieses Hilfmittels nicht längst erkannt hat."

5 Van Wert's discussion of intertitles in Pudovkin's Mother and Eisenstein's Battleship Potemkin provides numerous examples for this differentiation of intertitles (101-103). His comments on the intertitles in Wiene's Caligari are less pertinent because he did not have access to the restored film print and because he uses the issue of the film's intertitles to engage in a speculative argument about the script's authorship, which in the meantime has been definitively settled, contrary to Van Wert's assumptions. For additional examples of creative and unusual intertitles, see André Stratmann, "Der Zwischentitel im Stummfilm," 6 July 2010, http://www.beepworld.de/members $78 /$ stummfilm-fan/zwischentitel.htm. 


\title{
imaginatinne
}

\section{The Vanished Child:}

\section{An inquiry into figures and their modes of appearance}

\author{
Bertrand Gervais [Trans. with gullLaume bauer]
}

WHAT IS A FIGURE? When does it appear? How can we describe the moment of its appearance? By what process does an indistinct noise become a sound? How does a simple thing become a sign, filled with meaning?

A figure often appears in a moment of enticement. At first, there is nothing. Then, suddenly, something pops up and changes everything. It is a revelation, an unprecedented moment in which a presence appears to us, in which a truth imposes itself subtly and dictates its own law. Witold Gombrowicz described this precise moment in his journal. He identifies it in a resolutely sarcastic manner:

$[\mathrm{F}] \mathrm{rom}$ the immensity of phenomena taking place around me. I draw one thing. I notice, for example, the ashtray on my table (the rest of the objects on the table slip into non-being).

If I can justify why I noticed the ashtray in particular ("I want to drop my cigarette ash"), everything is all right.

If I noticed the ashtray accidentally, without any intention, and I never return to this observation, everything is still as it should be.

If, however, having noticed this phenomenon without significance, you return to it for a second time ... woe! Why did you notice it again if it is without significance? Ah, so it means something to you after all, if you returned. ... Oh yes, by dint of the fact that you concentrated unjustifiably on this phenomenon one second longer, this thing already begins to stand 
out, becomes remarkable. ... No, no (you deny), this is an ordinary ashtray! -Ordinary? Why are you denying it if it is ordinary?

This is how a phenomenon becomes an obsession. (161)

We recognize easily Grombrowicz's caustic humor, but the situation he describes delineates the initial moments in the actualizing process of a figure. It appears in this gaze that lingers and, all of a sudden, invests itself in the creation of an object, a semiotic object, whose power comes from this very gaze, which captures and composes it. One second too many, says Gombrowicz, that is all that is needed for an ashtray to be transformed into a sign, this haunting symbol, which is a figure. Further, the obsession, which can emerge from this intuition points to the way in which a figure, if it appears at first sight as a truth for the subject, remains always principally opaque, illegible. The figure is a truth, but one that must be interpreted and whose effects just barely begin to make themselves felt. It attracts and, at the same time, resists appropriation by the subject; it manifests itself as an enigma that is both troubling, in its compelling demand for resolution, and reassuring, in the way that it is already set in place.

The figure is an enigma; it sets the imagination in motion. This object of thought is given a meaning, a function, and even a destiny. Once apprehended, the figure becomes the focal point of an imaginary construction, a construction of the Imaginary. ${ }^{2}$ It does not remain static, but calls for interpretations through which the subject simultaneously takes hold of the figure and loses itself in its contemplation.

Imagination at work

In Don DeLillo's novella, The Body Artist, we find a simple, yet incredibly effective example of the process of figuration. Lauren, the heroine, approaches a town in her car. She catches sight of a man seated on a veranda. He is blond and his face is large:

She felt in that small point in time, a flyspeck quarter second or so, that she saw him complete. His life flew open to her passing glance. A lazy and manipulative man, in real estate, in fairview condos by a mosquito lake. She knew him. She saw into him. He was there, divorced and drink-haunted, emotionally distant from his kids, his sons, two sons, in school blazers, in the barest blink. (70)

Here is a figure in all its spontaneity: an imaginary construction, a thought that unfolds itself out of almost nothing, from a glance given to a silhouette spotted 
between the branches. Lauren fabricates an entire life on the basis of a fleeting look. Despite its frailty, its ephemeral nature, this figure imposes itself on her thoughts, but on ours as well because we easily succeed in imagining this bitter and disillusioned man. However, this figure is based on nothing. It is only a fantasy, a daydream into which a woman ventures during a few instants, while sitting behind the wheel of her car. There is no man on the veranda. As the text subsequently makes clear, when passing in front of the house, Lauren understands that "she was not looking at a seated man but at a paint can placed on a board that was balanced between two chairs. The white and yellow can was his face, the board was his arms and the mind and heart of the man were in the air somewhere [...]" (70). The figure is an imaginary object, a product of the imagination that, even though it is more or less motivated, springs up to crystallize otherwise diverging thoughts.

Lauren's projection, this musement initiated by a fleeting vision, points to the way in which a figure appears, to the subject who approaches and seizes it, as a complex sign having a precise configuration, composed of a set of traits, as well as a singular way of being (setting in motion, for example, its own narrative and iconic logic), involved in both acts of imagination and representation, made for one's self and for others.

Playing an essential role in this essay, the term musement must be clarified. A simple definition describes it as the drifting of thoughts, a kind of mental wandering, a pure game of associations, which begins when we drift into a continuous movement of thought. It is a rush, which runs through us until we free ourselves from it for one reason or another. It is a form of internal discourse, whose function is not that of an occasional drifting, but, truly, that of the motor of our thoughts.

The concept was initially defined by Charles S. Peirce in his article "A Neglected Argument for the Reality of God" (262-63). ${ }^{3}$ Peirce began by describing musement as a kind of daydream, with no loss of consciousness, no complete absence of the self. It is a form of play, of pure play, as he puts it, a play with no rules except the very necessary ones of liberty, of associations, and of the establishment of new ties.

There is a certain agreeable occupation of mind which, from its having no distinctive name, I infer is not as commonly practiced as it deserves to be; for indulged in moderately $[. .$.$] it is refreshing enough more than to repay$ the expenditure. Because it involves no purpose save that of casting aside all serious purpose, I have sometimes been half-inclined to call it reverie, with some qualification; but for a frame of mind so antipodal to vacancy and

Jaurnal of Crass Cultural Image Studies - Revue d'Études Interculturelles de I'Image

Imaginations, I-I, 2010 Copyright @2. Open Journal Systems. ISSN - 1918-8439. 
dreaminess such a designation would be too excruciating a misfit. In fact, it is Pure Play. Now, Play, we all know, is a lively exercise of one's powers. Pure Play has no rules, except this very law of liberty. It bloweth where it listeth. It has no purpose, unless recreation. (262-63)

Musement is imagination at work with all that this faculty possesses by way of the unforeseen. Think of Lauren imagining a man from a simple branch, constructing a narrative out of thin air.

Thomas Sebeok followed Peirce's definition quite closely, putting the emphasis on imagination, taking up Jacob Bronowski's position (Sebeok 3). Michel Balat, the French semiotician, has gone on to present musement as the continuous movement of thinking, a stream that flows through us. We can silence this musement, we can bury it away under the strata of our rationality, keep it at a distance, just like we can try to take hold of it, to make it meaningful during periods of introspection or with the help of various processes. But, we cannot stop it. It is at the root of our cognitive and mental activity. Balat compares its process to free association, practiced in psychoanalysis, which is not musement per se but rather a way to imitate its play. This comparison, however, accentuates not so much the great freedom of this form of association, but its uncontrollable, unintentional nature. There is something impetuous in musement, and what we recuperate is only the smallest share of it, a fixed, stopped musement, like water in a glass taken from a river. As Balat writes, it takes:

[T] he form of that kind of thought to which we only have access when an impromptu, discordant event reveals it to us. "Well, I was thinking...," a sentence we could read as "I was in the middle of a thought" (or of a thinking process). This first kind of musement is not directly accessible to us since, while we were musing, we had no consciousness of this. Musement presents itself to us as pure hypothesis, pure possibility, a walk in the original Universe, the indefinitely present moment irreparably destroyed by actuality or actualisation which provides a past tense. In its highest activity, musement constructs, builds up this kind of idea which may or may not pass the barrier of expression without completely fading away but to which the evidence of its presence reality testifies. ${ }^{4}$

Musement is that which goes on in the background while our attention wanders. It gives access to the shadowy area of thought, which can only be seized by sudden movements, by plunges into the pure play of possibility. Because it is of the order of the unspeakable, of that which breaks away, musement does not give itself headlong to us in all the transparency of a frank and direct glance, but rather it

Jaurnal of Crass Cultural Image Studies - Revue d'Études Interculturelles de I'Image

Imaginations, I-I, 2010 Copyright @2. Open Journal Systems. ISSN - 1918-8439. 
offers itself up to be constructed or reconstructed by way of complex inferences. Continuing the comparison with psychoanalysis, Balat adds that:

Just as latent thoughts are inferred (by an inference Peirce calls "abductive") from the manifest content of a dream, so musement-insofar as it is not part of the consciousness's domain-must be inferred from the ideas which, because they impose themselves in actuality, censure access to it while opening it up to us. From this moment on, the content of musement will be dependant on that which denies it, at least where access to consciousness is concerned. ${ }^{5}$

Musement can only be grasped through approximations: that which we manage to catch is given up in a necessarily fragmented and raw manner, for it is the motor behind our thoughts, the very process by which they coalesce and stay dynamic. We gain access to some of its results only by chance, an impromptu accident, a brusque movement.

What triggers it is also at stake. If we come out of it abruptly, it seems that we just simply slip into it, unknowingly or inadvertently. One way, as Lauren's example shows, is to be suddenly engrossed by a figure, even one as flimsy as an imagined man on a veranda. Fascinated by a figure, our mind wanders easily and we immerse ourselves in a world of thoughts and associations, of desires and longings, building a narrative as we go along, inventing, as Lauren does, a complete destiny. The story she invents is fragile, it blows away as rapidly as it is conceived; but, in its brief lifespan, a figure coalesces and imposes itself to her consciousness as a complex sign, charged with meaning.

Figure and musement are intrinsically linked. To lose our self in the contemplation of a figure is an apt representation of musement. The appearance of a figure can trigger it, and it can also fuel it. In its weakest amplitude, this musement might resemble a simple distraction, a roaming similar to that which takes hold of Lauren in her contact with the paint can. In its strongest amplitude, it leads to dispossession. In Thomas Mann's Death in Venice, for instance, Gustav von Ashenbach becomes mortally obsessed by the figure of the ephebe embodied by the young Tadzio. In Vladimir Nabokov's Lolita, Humbert Humbert follows a similar path in his obsession for the figure of the nymphet Lolita. ${ }^{6}$ Both characters are destroyed by their fascination for figures who all at once enchant them and lead them to their own demise.

The Vanished Child

Jaurnal of Crass Cultural Image Studies - Revue d'Études Interculturelles de I'Image

Imaginations, I-I, 2010 Copyright @2. Open Journal Systems. ISSN - 1918-8439. 
The examples taken from Grombrowicz and DeLillo allow for the identification of two moments in the actualization of a figure, those of its perception and its imagination. Indeed, there can only be a figure if the subject identifies an object in the world, believing it to be filled with meaning. The figure only manifests itself in this revelation of meaning to come. In the same way, it only reveals itself if the subject endows this sign with traits and a narration with which he or she can identify and is able to generate for him or herself. The figure is the outcome of a semiotic production, a production of the Imaginary.

To identify the third moment in the actualization of a figure, I will to give a third example that is the figure of the Vanished Child, discovered while reading Sophie Calle's Disparitions (or, in English, Disappearances). This example will enable me to show that a figure, in order to emerge, requires not only to be perceived and imagined, but, moreover, to be manipulated, the third moment. To imagine a figure is, indeed, to manipulate a form.

What does it mean to manipulate a form? It implies a vast array of processes, among which are: to identify and name it; to play with its image, to develop it; to seek its origin; to use it in various situations, real or imaginary; to muse over it; to muse, therefore, to lose oneself in its contemplation; then, to regain some form of control, trying to tell its story and to explain the fascination it induces; and ultimately, to represent it. The figure is a dynamic sign, which has multiple functions: it serves as a focal point, drawing attention, but it is also used as an interface and a relay, a way of understanding as well as an interpretive principle. It will become clear as I describe the singular situation at the core of Sophie Calle's Disparitions.

In Hebdomeros, an extended prose piece published in 1964, the painter Giorgio de Chirico suggests the following exercise: "When you have found a sign, turn it backwards and forwards on all sides; look at it full face and in profile, threequarter face and foreshortened; make it disappear and notice what shape is assumed in its place by the memory of its appearance" (51-2). The figure is a specific form, which substitutes itself for the vanished object, but whose shape remains ever present in memory. Moreover, in Roman times, the words "figure" and "form" were synonyms so that referring to one was practically the same as referring to the other. ${ }^{7}$

The figure is a form, but one that is based on an initial absence. In fact, like all signs, it takes the place of an object, designated as its referent, of which it reveals its absence while simultaneously giving the illusion of its presence. Yet, this

Jaurnal of Crass Cultural Image Studies - Revue d'Études Interculturelles de I'Image

Imaginations, I-I, 2010 Copyright @2. Open Journal Systems. ISSN - I9I8-8439. 
presence is entirely symbolic and, as a result, paradoxical. It is a presence-absence. The absent is not there, yet never ceases being there, by way of its figure, and it gives rise to speech acts and thoughts. As Roland Barthes writes when describing the act of speaking or of imagining another: "Endlessly I sustain the discourse of the beloved's absence," adding, "the other is absent as referent, present as allocutory" (15).

Absence is at the very heart of semiotic processes. Signs and figures exist only because objects in the world are set at a distance. Every transformation of an object into a sign, from a speech act to a simple musing, is the manipulation of this enduring absence, a game involving figures, which expresses nothing other than the fragility of their own construction. For Barthes, absence, as soon as it implies duration, necessitates manipulation. He writes that it is essential to "transform the distortion of time into oscillation, produce rhythm, make an entrance onto the stage of language. [...] Absence becomes an active practice, a business (which keeps me from doing anything else); there is a creation of a fiction which has many roles (doubts, reproaches, desires, melancholies)" (16). As a dynamic sign, the figure is the result of a manipulation, which succeeds in making the absent present, thus sustaining this precarious presence of another, who is never completely there.

The figure is an object of thought, an idea actualized in a specific context, and, as it is with all such objects, its reality is evanescent and fragile. Yet, it is on this basis that our thinking unfolds, that our acts of reading become something other than the simple progression through texts, but rather explorations into imaginary worlds.

This relationship with absence is illustrated in an extraordinary way through one of Sophie Calle's texts. In Disparitions, the artist introduces a peculiar situation. At the Isabella Stewart Gardner Museum in Boston, a collection of paintings has been stolen, including those by Rembrandt, Manet, Vermeer, Degas, and others. In her will, Mrs. Gardner had insisted that nothing would be touched after her death. "Following the robbery," Sophie Calle writes, "the spaces left by the paintings and the objects were left empty" (11). "Taking advantage of this unusual installation, the artist asked the staff working at the museum, including curators, attendants, and other employees, to describe the stolen objects to her. The paintings, thus, became the pretext to a figural process in which the staff was actively involved. This situation enabled the appearance, if not the apparition as if it was a phantom, of the intriguing figure of the Vanished Child. ${ }^{\prime}$

Jaurnal of Crass Cultural Image Studies - Revue d'Études Interculturelles de I'Image

Imaginations, I-I, 2010 Copyright @2. Open Journal Systems. ISSN - 1918-8439. 


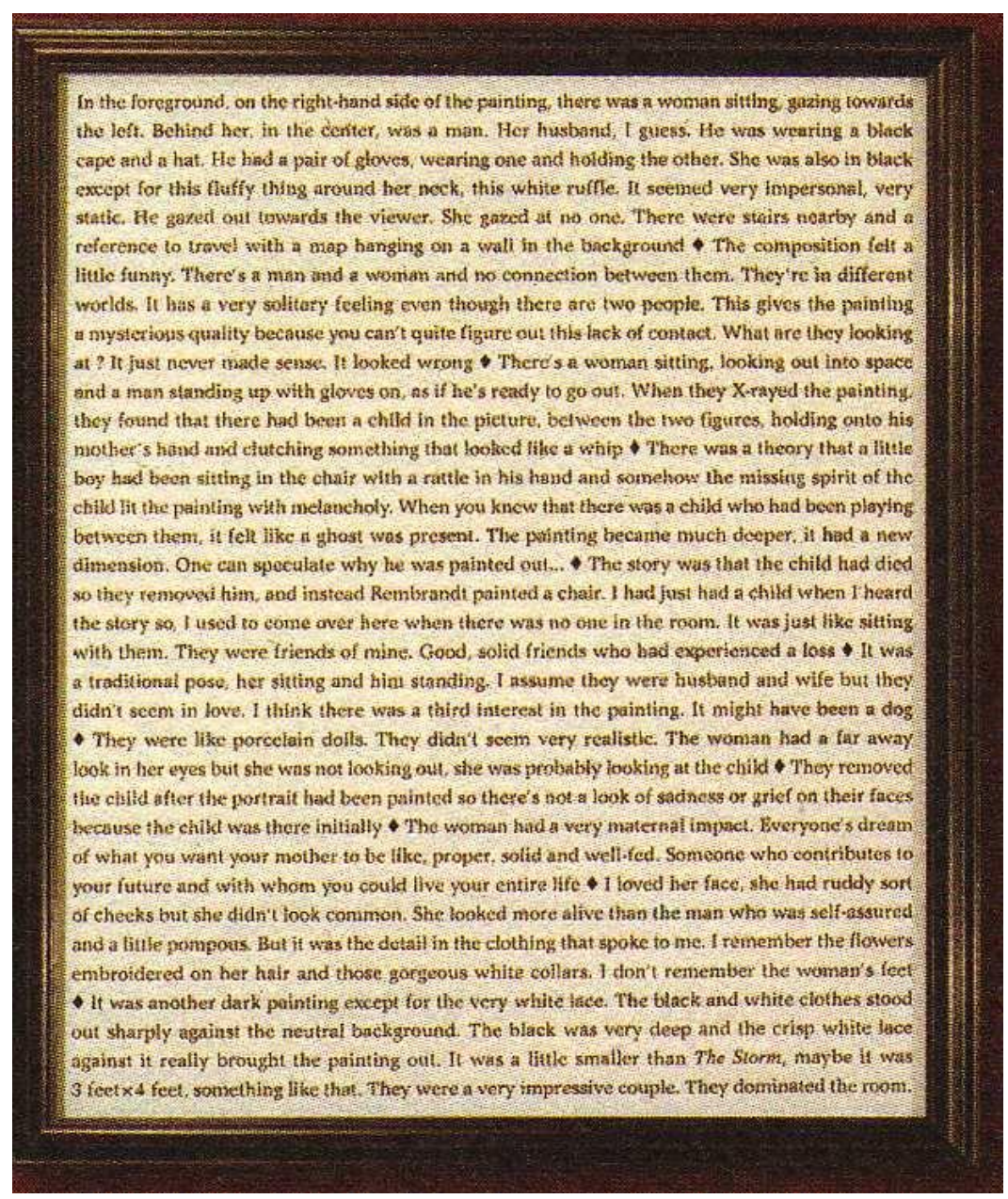

It is important to mention that Sophie Calle's art consists in bringing into the limelight the presence of figures. Daily mundane objects, including address books, beds, telephones, photographs taken during vacations or birthdays, automatic teller machines, posted letters, and dresses, all serve as a pretext in her artwork for the production of narratives, where figures play a key note. In only a few words, her prose, which often serves as caption for her photos and installations, succeeds in capturing the essence of a situation and exploiting its symbolic and affective dimensions. She knows how to bring to light the unexpected in the familiar, exposing the detail in a situation, which transfigures it into something truly theatrical. She makes a novel out of nothing. And out of this singular convergence of elements, through small narratives and unexpected stories, she constructs texts where images play an important role. 
Herve Guibert, the French writer, once said that Sophie Calle was a kind of mischief-maker. In French, the expression used, "faire des histoires," means not so much to tell stories but to complicate things. A "faiseuse d'histoire," in this sense, plays both on Calle's capacity to make a situation confusing and to tell a good story, turning the next to nothing into an event. Much like the literary minimalists (Raymond Carver, Donald Barthelme), Sophie Calle does not write extensive narratives, but stays close to the core of her stories. She takes hold of a given material, be it biography or anecdote, and transforms it into a short fiction, never more than a few pages long. These narratives are like entries in a blog. However, this undertaking is carried out by the creation of figures. This is the case for one of her texts included in Disparitions that brings to light the figure of a vanished or deleted child. Like a figure in the carpet, this child haunts a stolen work of Rembrandt, a portrait painted in 1633, entitled "Portrait of a Couple."

The strategy used in Disparitions has an essentially intermedial quality. The Rembrandt chapter is composed of a photograph, depicting a space that has been left vacant as a result of the robbery of the painting (a wall covered over by drapes in front of which three chairs have been placed). There is a reproduction of a frame in which the twelve accounts have been transcribed with a label identifying the painting and indicating the date of the robbery (March 18 $\left.{ }^{\text {th }}, 1990\right)$. In addition, a French translation of the twelve collected accounts has been included, and each one of these texts has been placed end-to-end, separated by a very discreet lozenge.

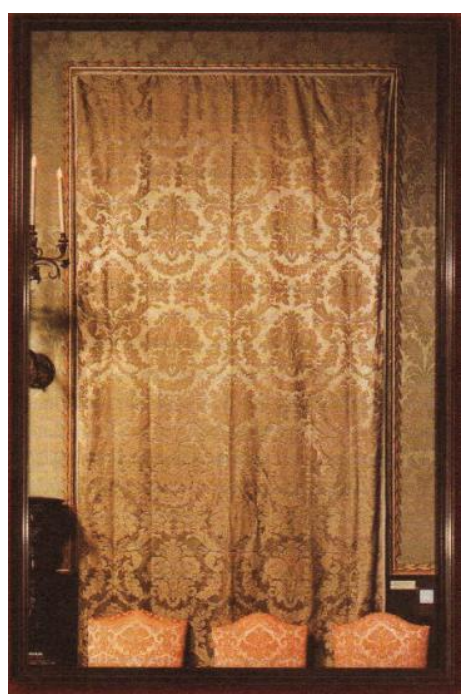

The first two accounts concerning the portrait converge in their expression of the uncanny. For the first witness, the man and the woman painted by Rembrandt appear distant. The man is said to be looking towards the viewer, whereas the 
woman seems to be looking at no one. Everything seems impersonal and static. As the second witness puts it, they are in different worlds: "One feels," s/he said, "a tremendous impression of solitude, in spite of there being two people. This impression gives the painting a mysterious quality because you cannot really understand this lack of contact. What are they looking at?" (24).

The absence of the painting gives rise to words, in the form of a witness account that little by little reconstructs a form, a figure, that of a portrait subtly gone amiss in which separation and a subdued sorrow avail over the feeling of love. The portrait bares the hollowed out traces of a tragedy that divides the couple. We have no difficulty piecing together the scene, even if our only access to it is through brief accounts; and we might be familiar enough with Rembrandt to imagine the stern black clothing of the two spouses, the somber character of their portrait, and the chill evoked by the absence of any relationship between them.

We learn quickly that the painting has been modified. Something has been hidden beneath the surface of the stolen painting. Indeed, the third witness explains the following: "When they examined the painting under $\mathrm{x}$ ray, they found a child between the two characters, holding the mother's hand and tightly holding what resembled to be a whip" (24). Thus, the strangeness of the painting derives from a modification that had been brought to it, a figure that had been removed. This figure was that of a child, covered up perhaps following his death.

This presence of a blotted out child is echoed in the next accounts: "When you knew that there was a child," the fourth witness said, "playing between them, we had the impression that a phantom was present. The painting became more profound. It took on another dimension" (24). As for the eighth witness, s/he asserted that they "had taken away the little boy after the painting had already been completed, in such a way that their faces appear neither sad nor troubled, since the child was originally there" (24).

The accounts are not in agreement with each other concerning the attitude of the couple. Certain of the witnesses see them as two people torn apart from each other, a couple who has already undergone separation in spite of the painting that brings them together. Yet, other witnesses describe them as attentive parents: the woman appears "very maternal," "lively," "respectable, strong, and well-nourished. Someone who cares about your future and with whom you would be able to spend an entire life" (25). The witnesses' opinions differ in accordance. On the one hand, with their knowledge of the disappearance of the child, and on the other hand, with their basic patterns of identification, as their insecurities and doubts are projected onto the depicted characters.

Jaurnal of Crass Cultural Image Studies - Revue d'Études Interculturelles de I'Image

Imaginations, I-I, 2010 Copyright @2. Open Journal Systems. ISSN - 1918-8439. 
Our reconstruction of the painting is a patchwork of partial accounts. We must imagine a vanished child in a painting that has itself disappeared, and we can only do it taking into account the manner in which the witnesses represent the painting for themselves, for their testimonies are based on their own knowledge of the painting's history, their own subjective and esthetic perceptions, and their unique process of identification.

Moreover, there is not only one painting, but two. The first one is the painting of the family with the child. The second one represents a strangely distant couple. The discrepancy between the two paintings results evidently from the disappearance of the child, which goes to show that an absence easily becomes a sign. As a matter of fact, there is a third painting, the one that appears through the witnesses accounts, that of the Vanished Child. This painting is one in which the distance between the couple hides a tragedy that the palimpsest reveals by means of erasure. For the painting itself, the disappearance of the child becomes a source of imbalance in its volumes, a subtle perversion, from which it suffers the aftereffects. Adding to the presence of this third painting, we can even identify a fourth one: the stolen painting whose whereabouts and destiny are unknown. Did the thieves know about the Vanished Child? Was the painting damaged or destroyed?

As readers, we can re-imagine the painting, projecting on to the canvas of our mind a family's tragic destiny, and we can even envision the painting's peculiar fate. The tragedy of the painting is embodied in the fact that nothing remains of it in the museum other than the vacant space left in the wake of its disappearance. The painting and the child have ended up sharing a mutual state of absence. Their destinies have become entangled as the result of a surprising contamination. Of all the paintings that were to be robbed, one bore the marks of a disappearance under its varnished surface.

The child is imbedded in a multilayered disappearance: disappearance of the life of his parents, disappearance of a portrait, and disappearance of the painting itself. However, despite all the layers of absence, an embedding that goes deeper and deeper, the child imposes itself as a figure. Surprisingly, the disappearance of the painting ends up bringing to the surface the disappearance of the child. The robbery gives rise to an act of reminiscence, which dwells upon the tragedy at the very heart of the disfigured scene.

As it were, Sophie Calle's intervention undoes that of Rembrandt. By textualizing the witnesses' accounts, she ends up bringing to the surface what the painter had succeeded in covering up. What the image had kept hidden, the words reveal, in its

Jaurnal of Crass Cultural Image Studies - Revue d'Études Interculturelles de I'Image

Imaginations, I-I, 2010 Copyright @2. Open Journal Systems. ISSN - I9I8-8439. 
very complexity, for, undoubtedly, the figure of the Vanished Child is a semiotic entity of a surprising intricacy. The figure organizes itself around a vacant center, a child that can no longer be seen by anyone, a child who the parents themselves no longer wanted to see. It is also characterized by its singular way of being as well as its own narrative and iconic logic.

This manner of being is ghostliness. The child is a revenant who does not want to be forgotten. Therefore, the painting is haunted by a phantom that now, because the painting itself has disappeared, is the only one left present. The figure of the Vanished Child is, therefore, not just the result of an appearance, but of an apparition, with its overtones of the uncanny and the supernatural. This ghostly or spectral dimension heightens the symbolic aspect present in the process by which an object is transformed into a figure, giving it a spiritual dimension. The figure becomes more than a sign, but becomes a presence, a real presence, which accentuates its experiential nature.

The fourth witness said that, "the spirit of the disappeared child illuminated the painting with a melancholy tone" (24). And, now, this spirit endures alone as the sign of a tragedy at the very heart of this representation. We do not see the Vanished Child, but he sees us. Hidden under a coat of paint, a veil concealing him, he observes us. He attracts our attention with his singular presence. Sophie Calle's text leads us to manipulate the child's absence and opens up a scene that requires all our attention. And, in the end, this scene is so powerful that we are left seeing nothing else than the revenant. The portrait becomes overshadowed by this image of the Vanished Child whose power comes precisely from its invisibility. We easily fill in the gap left by its absence. The vacant wall of the museum becomes a blank text, which we hasten to fill from the very instant our eyes are set on it.

Here is a tragedy left to be imagined, a tragedy whose repercussions we can feel, despite our remoteness from the initial scene. This tragedy is at the core of an act of narration, which gives all its force to the figure of the Vanished Child. However, this force does not stem from the tragedy of the parents or the tragic fate of the child, but from the destiny of the painting, its unusual story. The figure is dense with a series of enigmas, each giving rise to a potential story, and opening the door to an active musement. Why did the parents ask for the figure of their child to be blotted out from the painting? What tragedy brews under this draconian decision? In what manner did Rembrandt carry this out? What kind of fate has his painting encountered throughout the centuries? Who was this Isabella Stewart Gardner, whose collection is at the origins of the museum? Did she have any knowledge of the existence of this Vanished Child? How was the robbery committed? Where is the actual location of the painting today? How was the 
decision taken to leave vacant the walls on which the paintings were originally hung? Why was Mrs. Gardner's will taken so literally? Why did the curators decide to follow her request to leave everything as it was after the robbery? How did Sophie Calle learn about this particular situation, choosing, finally, to inscribe it at the heart of Disparitions? Musing on these questions, one cannot help wonder how labyrinthine destiny can be!

The figure of the Vanished Child comprises all these questions, all these stories left to be told. This revenant does not only haunt a painting. It marks its destiny. It is as if Sophie Calle's artistic project had already been anticipated, serving as the only way to erase the child's absence from the surface of the painting. It was necessary for the painting to disappear in order for the vanished figure, through the witness accounts, to reappear and impose itself as its essential figure. This paradoxical movement resembles that which is described by Benjamin as an experience of déjà vu:

The phenomenon of déjà $v u$ has often been described. Is the term really apt? Shouldn't we rather speak of events which affect us like an echo-one awakened by a sound that seems to have issued from somewhere in the darkness of past life? [...] It is a word, a rustling or knocking, that is endowed with the power to call us unexpectedly into the cool sepulcher of the past, from whose vault the present seems to resound only as an echo. (Berlin 129)

This is a word, a rustling, writes Benjamin, but it is also a figure, which out of the blue appears suddenly to compel our attention. The figure at the heart of this déjà $\mathrm{vu}$ is subjected to double distance, being both near and far away; it is near, yet continually shying away, but also far, while reappearing with the force of something that has been repressed.

What does the figure of the Vanished Child have to say? Evidently, it speaks of us, since it is nothing other than what we have invested in it, without ever even thinking about it. The production of this figure exposes our own fears and desires. As a form, it supports these emotions, enabling their expression. We must all have in our proximity a vanished child that never ceases haunting us, giving rise to memories and narratives. This child says nothing, yet he never stops challenging us, taking a pervasive hold on our imagination through his very absence. 
Imaginations / Gervais 85

\section{Rethreading a figure}

What type of interpretations has Rembrandt's painting been submitted to? What is the impact of Sophie Calle's text on our understanding of the painting? The different accounts offered by the witnesses can only give us a subjective portrait of the painting's content. And we can ask ourselves: where exactly was the child before being blotted out?

The clash between the painting, as it can still be found in catalogues, and its representation in Calle's text brings to light certain unexpected problems, which confirm the interpretive aspect inherent to any description. If the witnesses' descriptions of the parents positioning in the painting generally respect its composition - the man described as standing in place, the woman as sitting, the two appearing distant, as if they were worlds apart-they prove to be much more tenuous where the child's place in the painting is concerned. The third witness indicates that the child held "the hand of the mother and strongly clutched what resembled to be a whip" (24). If it is impossible to comment on the whip (other than the fact that this detail of the description is in disagreement with the fourth witness account in which the object in the boy's hand is described as being a rattle), the actual location of the chair in the painting tells us that this child could not be holding the hand of his mother. The space separating the couple is insufficient for the child to be able to squeeze between them, and the mother's hand lies propped upon the armrest of her chair.

Furthermore, according to the fourth account, the child was seated on a chair. Yet, the only chair in the portrait is positioned at a distance away from the mother. The child, therefore, could not at the same time be seated and be playing between his parents. According to the fifth witness, in fact, the chair had been painted in his place. Reading the accounts, it becomes impossible to decide where the child was. Was he standing, or seated in a chair? Was this chair present in the painting from the beginning, or painted in later to cover up the child's erasure? In examining the painting, it is tempting to conclude that the chair has been added after the fact. Rembrandt must have replaced one volume (the child) by another (the chair) in order to avoid totally offsetting the portrait's composition.

Indeed, despite the precisions given by the third and fourth accounts, which do not, in any way, contradict those given by the other witnesses, the child was not "between his parents," that is, in the space separating them. Actually, the three of them constituted a triangle, and the child was situated at its upper apex. In the painting, each one of the figures occupies a distinct space. Though slightly shifted to the left, the father is farther back and to the center. ${ }^{10}$ The mother occupies the

Jaurnal of Crass Cultural Image Studies - Revue d'Études Interculturelles de I'Image

Imaginations, I-I, 2 ZII Copyright @2. Open Journal Systems. ISSN - I9I8-8439. 
right corner, situated halfway between the two figures. She serves as a necessary intermediary between them. The child is in the foreground, in the left corner. If the man seems open to the world-his gaze affirming this interpretation, while the globe to his right confirms it-, as for the mother, she directs all her attention to the child. In addition, her maternal gaze and her motherly face make this portrait, otherwise quite austere, a friendly family scene.

However, the disappearance of the child turns this perspective on its head, making the painting appear enigmatic. What did the woman look at? The witnesses cannot give a precise answer: "She did not look at anyone," she "looks into the void," " $[t]$ he woman had a remote gaze, but she did not look outside of the painting. She was probably looking at the child" (24-5). The focus of her gaze is open to all kinds of variations. Because the child has been blotted out, the mother no longer looks at anything. She contemplates the void, and her gaze loses itself in the space that has literally been deconstructed. She is midway between anticipation and oblivion. Her progeny has become an absence that her gaze indentifies by its awkwardness. Something attracted her attention, which will never be brought back. She seems to lose herself in the contemplation of a figure that she alone is still able to discern. Yet, this object is no longer present in her world. It has become a pure object of thought upon which she muses. The enigmatic dimension of her gaze is explicable through the musement in which the disappearance of the child has caused her to become immersed.

Where was the child before being blotted out? The portrait shows that he did not occupy the space between the parents, but rather, a privileged position at an apex. His disappearance opened the family triangle on a void. In his place, there remains only an empty chair. Did the child look upon his mother or, as it is with his father, did the world open at his feet? Was he dressed in black, like his parents, or did he wear the same color as the chair cushions of which the red could be a veiled reference to his erasure? The chair, in any case, marks the absence of the child, for it is literally turned toward the mother and empty, an emptiness that opens the mind to the mysteries of absence. Further, if the mother does not look at the chair, the chair, on the other hand, looks at her. It confronts her. It is a sign that only truly holds meaning for her, a sign that is motivated by this filial relation that has been erased.

The unoccupied chair from Rembrandt's portrait is a discreet appeal to the imagination and to the act of refiguring. It is left to us to transform this void into a sign of absence, to sit a child there and to imagine a figure, which could return the mother's admiring gaze.

Journal of Crass Cultural Image Studies - Revue d'Études Interculturelles de l'Image Imaginations, I-I, 2010 Copyright @2. Open Journal Systems. ISSN - 1918-8439. 
Imaginations / Gervais 87

\section{The Auratic Child}

A figure is the result of an act of appropriation. It requires being perceived, imagined, and manipulated. Further, it requires being designated. Every figure has a name, without which the process of figuration remains uncertain. Thus, the figure of the Vanished Child is neither in the painting of Rembrandt nor in Sophie Calle's text, even though it draws its origins from both these works. It appears through an act of reading. Above all, not only is this figure a sign, an object of thought, it also serves as an interface, a dynamic interpreter, giving rise to interpretation. Further, it talks to us about distance and desire.

As soon as the Vanished Child reveals himself, his apprehension is the confirmation of a double distance. He only appears present in the moment in which his absence reveals itself. Present and absent all at once, present because absent, the Vanished Child inscribes himself in a paradoxical space as an entity having an astonishing temporal density, which culminates over time and distance. He becomes the embodiment of a past that looks upon us in the present. This figure exposes a version of the past of which we know nothing, yet, much like an enigma, becomes the source of an endless musement. In the words of Paul Ricoeur this distention of the mind (a distention of "our" mind) is divided up between a disappearance, its enigma, and resolution (34). It gives to the figure a surprising force, which is that of the Imaginary. As long as it holds within itself an element of mystery, it is a pure potentiality. Its indetermination opens the way to the forms of appropriation. This logic has no limit, and above all, it surpasses the spectator's gaze. "Under our eyes, outside of our gaze," Georges Didi-Huberman writes, "something here talks to us about a haunting presence, as if it came back from far away, something which both concerns and escapes us" (102). ${ }^{11}$ The words of Huberman perfectly describe the figure of the Vanished Child. Behind the veil of its own erasure, this figure escapes our complete appropriation, while simultaneously, penetrating us with his gaze. ${ }^{12}$

As a figure, the Vanished Child corresponds to what Didi-Huberman calls, using Walter Benjamin's terminology, an "auratic object." Such an object is "close and distant at the same time, but distant in its very proximity" (102). From the subject who gazes upon it, the figure requires, "a kind of incessant sweep or back and forth movement, a heuristic process in which distances - contradictory distancesare experienced dialectically" (102). The Vanished Child respects this double distance perfectly. He remains both close and distant at the same time. His appearance in Sophie Calle's Disparitions and the illusion of his presence render him almost palpable. Yet, on the other hand, this same presence remains evanescent because any direct trace of him has been eliminated (the painting

Jaurnal of Crass Cultural Image Studies - Revue d'Études Interculturelles de I'Image

Imaginations, I-I, 2010 Copyright @2. Open Journal Systems. ISSN - 1918-8439. 
having been stolen). His figure is only a phantasm, whose reality cannot be confirmed.

In the writings of Benjamin, the notions of trace and aura are intimately linked. They are two different aspects of a same phenomenon. Benjamin thus affirms the following: "The trace is appearance of a nearness, however far removed the thing that left it behind may be. The aura is appearance of a distance, however close the thing that calls it forth. In the trace, we gain possession of the thing; in the aura, it takes possession of us" (Arcades 447). This tension between appearance and disappearance, between possession and dispossession, is at the heart of every figure and the process of enticement to which the subject is exposed, giving rise to musement. Through its traces, its singular manner of existing in the world, the figure gives itself to the spectator, yet in doing so, it exposes the subject to a process of seduction and subjugation, which is the expression of its aura. This aura is actually the very inscription of a figure's desirability. The figure attracts and draws attention unto its self, while continually avoiding being fully grasped. The Vanished Child is exemplary of this way in which a figure appears, stimulating a desire to be seen, but disappearing at the very moment its longing becomes insistent. After all, there is nothing left to be seen. To say that this figure returns our gaze is to forget that the only gaze in question is our own. The figure acts as an intermediary, since it is nothing more than a sign, a semiotic entity constructed from our reading of a text. Yet it acts as a form of transmission and a way of circulating meaning. Its force resides in its capacity for mystery and the fact that the traces at its origin have little to do with its experience and meaning.

The aura is the recognition of uniqueness. It comes to light in the convergence of time, space, and perception, whose interactions produce an astonishing experience. To this end, Benjamin explained the aura to be a singular web of time and space, in which the close and distant, the present and absent, the almost palpable and the constantly evanescent interlink suddenly in the constitution of a complex sign. Benjamin gives an example in order to illustrate the figure's nature, which is both evanescent and immediately appealing, evidence of its inherent double distance. In this example, a man muses following "with the eye-while resting on a summer afternoon - a mountain range on the horizon or a branch that casts its shadow on the beholder is to breathe the aura of those mountains, of that branch" (Benjamin, "Work" 105). He loses himself, while becoming, in a certain way, immersed in their aura. ${ }^{13}$

It is neither the mountain nor the Vanished Child himself who possesses the aura. Moreover, the aura manifests itself under a combination of precise circumstances. The branch is not endowed with this aura. Similarly, the Vanished Child in

Jaurnal of Crass Cultural Image Studies - Revue d'Études Interculturelles de I'Image

Imaginations, I-I, 2010 Copyright @2. Open Journal Systems. ISSN - 1918-8439. 
Rembrandt's painting only becomes a figure within a singular set of conditions. It took my reading of Calle's text to make it appear.

In fact, anything can become a figure. Anything can acquire an aura. This aura does not, in itself, belong to the object. It is the result of a projection made by a subject, who attributes a value, dynamism, or even, a soul to any given object or being. It is the result of a musement, whose pure play manages to bridge all the gaps, to force associations and to actualize the creation of singular imaginary beings. Further, this transfiguration is the outcome of a process of appropriation, which does not leave the object intact, but converts it into a signifying form, an object in which the subject has emotionally and symbolically invested. If there truly was a boy who was eliminated from the painting, the figure of the Vanished Child only appears as a result of a singular reading of Sophie Calle's text. The figure draws its origins from a tragedy. Just as Benjamin's branch has no aura in itself, this figure imposes itself only after it has been integrated into the framework of a subject's life and experiences. It is by the act of reading that the absent son has become the figure of the Vanished Child.

\section{A Figural semiosis}

The figure is an auratic object. It is a complex sign, which distinguishes itself by its singularity, its value, its semiotic density, its evanescent quality, and its own logic of narration and creation of (mental or actual) images. All of these characteristics define what is meant by aura. Moreover, for Benjamin: "If we designate as aura the associations which, at home in the mémoire involontaire, tend to cluster around the object of a perception" (Baudelaire 145). The figure, as an auratic object, corresponds to this type of complex sign, which calls for the production of even more intricate images and narrations. The Vanished Child comes with his own set of images. Certain of these are tragic, while others are anecdotal. This figure is not a static and inert entity. To the contrary, it is a dynamic form, which gives rise to interpretations as well as symbolic and emotional developments, with just as large of a variety as the readers who apprehend them. However, from the very instant it is perceived, a figure imposes itself on the subject as a reality on which we can muse on our own. In this way, it also engages voluntary and involuntary memory, feelings, and affects, all of which become interlaced, giving it meaning.

It speaks of us, through Sophie Calle's text, because it is only what, without thinking, we have projected on to it. When such a figure appears, a situation opens up, through which our fears and desires are played out. It is a form that supports these feelings, while also enabling their expression. Such a figure fascinates by the intensity with which it operates. And it is intimidating because it relies essentially

Jaurnal of Crass Cultural Image Studies - Revue d'Études Interculturelles de I'Image

Imaginations, I-I, 2010 Copyright @2. Open Journal Systems. ISSN - 1918-8439. 
Imaginations / Gervais 90

on an absence. It cannot say anything by itself, but its image never stops haunting and taunting us, taking a pervasive hold on our thoughts through its very absence.

\section{References}

Auerbach, Eric. Scenes from the Drama of European Literature. Theory and history of literature, v. 9. Minneapolis: U of Minnesota P, 1984.

Barthes, Roland. A Lover's Discourse: Fragments. New York: Hill and Wang, 1978.

Benjamin, Walter. Berlin Childhood Around 1900. Cambridge: Harvard U P, 2006.

---. Charles Baudelaire: A Lyric Poet in the Era of High Capitalism. London: Verso, 1989.

---, Howard Eiland, and Michael William Jennings. "The Work of Art in the Age of Its Technological Reproducibility: Second Version." Walter Benjamin: Selected Writings. Volume 3, 1935-1938. Cambridge: Harvard U P, 2002.

---, and Rolf Tiedemann. The Arcades Project. Cambridge: Belknap Press of Harvard U P, 1999.

Calle, Sophie. Disparitions. Arles: Actes sud, 2000.

De Chirico, Giorgio. Hebdomeros: A Novel. London: Peter Owen, 1964.

DeLillo, Don. The Body Artist. New York: Scribner, 2001.

Didi-Huberman, Georges. Ce que nous voyons, ce qui nous regarde. Paris: Minuit, 1992.

Gombrowicz, Witold. Diary 3. (1961 - 1966. Evanston: Northwestern UP, 1993.

Guibert, Hervé. "Panégeryque [sic] d'une faiseuse d'histoire." Sophie Calle, à suivre. Paris: Musée d'art moderne de la Ville de Paris, 1991.

Hoopes, J., ed. “A Neglected Argument for the Reality of God.” Peirce on Signs. Chapel Hill: U of North Carolina P, 1991.

Ricoeur, Paul. Temps et récit. Paris: Seuil, 1983.

Sebeok, Thomas. The Play of Musement. Bloomington: Indiana U P, 1983.

Image Notes

Image one: Sophie Calle, Disparition, tableaux volés, Arles, Acte Sud, 2000, p. 21.

Image two: Sophie Calle, Disparition, tableaux volés, Arles, Actes Sud, 2000, p. 20.

Endnotes

1 Guillaume Bauer and Bertrand Gervais translated this article. A French version appeared in Intermédialités ( $\mathrm{nr} 7$, spring 2006). The notion of figure presented here was extensively described in 
Bertrand Gervais' essay Figures, lectures. Logiques de l'imaginaire. Tome I, Montréal, Le Quartanier, 2007, 243.

2 The French term, l'imaginaire, does not easily translate into English. Jean-Paul Sartre presented it as an act of consciousness; Jacques Lacan defined it as an order, imbedded in a triadic relationship with the Real and the Symbolic order. It is used here as an interface between the subject and the world whose actions are revealed by specific figures.

${ }^{3}$ A web version of "A Neglected Argument for the Reality of God" is available at http://en.wikisource.org/wiki/A_Neglected_Argument_for_the_Reality_of_God). The concept is a central part of my study on the labyrinth and the forms of forgetfulness in La ligne brisée: labyrinthe, oubli et violence. Logiques de l'imaginaire. Tome II, Montréal, Le Quartanier, coll. " Erres essais » 2008, 207.

${ }^{4}$ http://www.balat.fr/Le-Musement-de-Peirce-a-Lacan.html. My translation.

${ }^{5}$ http://www.balat.fr/Le-Musement-de-Peirce-a-Lacan.html. My translation.

6 Thomas Mann, Death in Venice, Bantam, 1988 (1922); Vladimir Nabokov, Lolita, Paris, Olympia Press, 1955.

7 In "Figura", Eric Auerbach reminds us that: "Originally figura, from the same stem as fingere, figulus, fictor, and effigies, meant 'plastic form" (11).

${ }^{8}$ Quotations from Sophie Calle, Disparitions are my translations.

${ }^{9}$ Sophie Calle reproduces the same textual strategy in Souvenirs de Berlin-Est (Arles, Actes sud, 1999) and Fantômes (Arles, Actes sud, 2000). Moreover, the editor brings these three books together in a boxed set with a particularly revealing title: "L'absence."

10 The painting is divided into two parts, which are almost equal in dimension. Its right side is predominately black and is occupied almost exclusively by the mother who is seated. The father and son are situated on the left side, which is less somber in color. If the father seems indifferent to the child, the two share the same space. Their physical contiguity brings them closer and assures a relationship between them.

${ }^{11}$ Quotations from Georges Didi-Huberman are my translations.

12 The Vanished Child is much like the reverend Hooper, from the Nathaniel Hawthorne short story, “The Minister's Black Veil” (The Hawthorne Treasury, New York, The Modern Library, 1999, 110-20). The minister hides his face behind a veil, which, even at the point of death, he never takes off. The mystery surrounding the reasons why he has chosen to hide his face behind this accessory is never revealed. There is no point in the story in which the pastor explains this choice, or, even, for what sin, it serves as penitence. However, this veil transforms a man who was a simple pastor into a figure holding great power. He becomes a celebrity, his sermons become widely known, and his influence grows. What the veil hides and reveals all at once, an enigma of an exaggerated sin never to be identified, gives rise to the greatest of fascinations. Like that of the Vanished Child, his aura originates from the fundamental indetermination his veil entails. 
13 Casten Strathausen effectively discerned the singular nature of this situation described by Benjamin, which is above all else an experience. Strathausen emphasizes the way in which the aura is an ephemeral specter, which is captured in the web of time and space. As he writes, "It does not refer to an independent, material thing, but describes a particular form of human experience. " (Carsten Strathausen, "Benjamin's Aura and the Broken Heart of Modernity," in Benjamin's Blind Spot, Lise Patt, ed., New York: Institute of Cultural Inquiry, 2001, 5). 
Imaginations / Scrivano 93

\section{imaginatinne}

\section{On the Undecidability of Images (in communication)}

Fabrizio Scrivano [TRans. LSE HoGan]

W.J.T. MiTCHELL SUSTAINED THAT one can remain paralyzed in front of an image when this image simultaneously stirs up various alternative readings. It has to do with a "sparkling effect" of the meaning, making the image seem like a desiring machine, causing the spectator to feel interrogated by the image and thus to find within it a desire for autonomous communication. With this hypothesis, Mitchell wanted to justify the origin and the permanence of the magic attributed to the image in old and new cultures, where these images could be treated as animal objects or volitional beings, as venerated idols or as fear-inspiring amulets. An enormous power is attributed to these images, possibly even greater than what can be controlled by observers and the actual producers of the images. Certainly, there exist a rhetoric and a logic of fear, which exceed the ancient rhetoric and logic of wonderment.

As Rudolf Arnheim has often lamented, against an intrusive and unrestrained usage of images, there is actually little training about images, so that the knowledge or awareness of the effects produced by images in human beings and their world perception is, at best, an autodidactic experience. In fact, only an educated class has any idea of how images work. Hence there is a general impression that images hold a certain power and that they are instruments of a power that remains hidden.

Nevertheless, it is hard to deny that, simultaneously, the opposite feeling is equally

Journal of Crass Cultural Image Studies - Revue d'Études Interculturelles de l'Image Imaginations, I-I, 2010 Copyright (2. Dpen Journal Systems. ISSN - 1918-8439. 
widespread among the many, that is, that images are the best and most direct way to transmit the evidence of things and situations. In other words, that images are a technology of diffusion of the real aspect of reality (whatever this expression means). In evaluating the faithfulness of images, we have always made use of a principle of the likeness between the image and the direct visual experience, which, evidently, no longer holds any validity, at least since the invention of photography and the practice of montage, which enabled the production of perfectly convincing, yet false, images.

There is no contradiction in this natural ambivalence of the image, which makes it simultaneously a repository of secret power and a mirror of the real. There is no contradiction since it is well known that reality is magical!

The truth is that images are at the same time material reality and symbolic reality: they are perceived as things, perhaps as things indicating things, while also being perceived as signs, as instruments of meaning. Images are not only used to show or to bring something into evidence; they are also often used, if not predominantly, as a language, as observation tools. The distinction between these two usages is not always evident-acknowledging that it is actually valid: in fact, the channel through which images are experienced, sight (including the entire apparatus of sight, from the eyes to the mind) has such an important implication for the body that, often, the characteristics of abstraction of the visual function cannot be perceived nor completely valued.

This state of affairs makes it more difficult to understand images in the scope of communication, because the image always has an ambivalent content: it shows things and articulates meaning. For its purposes, communication sometimes trades on-not always knowingly - this double denotation or reference of the image. This complicates the whole problem, because it immediately concerns the distinct spheres of the organization and the use of knowledge; that is, it deeply concerns epistemological convictions (from hypotheses on reality to the consolidation of certainties) as well as behaviour (from the emotive to the ethical) incited by the image.

In this problematic outlook, I would now like to address a handful of questions related to communication. Communication is an act or a status, which, seemingly, our behaviour cannot ignore: whether it is active or passive, whether it is interpretative or deliberative, whether it is interested or distracted, it is so pervasive as to result in a permanent yet corrosive condition of experience and knowledge. ${ }^{1}$ The questions concern how, and what, we communicate through and with the image; whether it might contain, retain, or produce something that is pertinent to 
the field of communication; whether the communicative function of the image in some way alludes or refers to this something. I will not directly formulate these questions because, at this point, I do not think I can provide adequate responses to those vast problematic areas in which they are introduced. Instead, I propose concrete cases, without any ambition of these functioning as models; I hope these will serve to establish some useful interactions with the object.

The Communicative Image and the Demonstrative Image

We all realize perfectly the fact that a large part of our dispositions towards represented objects has a phantasmagorical origin. That is, both our mental attention and the represented object are amenable to the mediation of the image: in cases where it is evident and others where it is not, we expect the image to be predominantly a medium of information. This is true even in cases where it is otherwise evident that the image has, as its object, itself or its elaborative process, or its resulting effects. Even with a serious divergence regarding the linguistic usage of visual forms (if the field of information and the field of art diverge at all), the certainty of the visual forms' occurrence does not always correspond to an equal assurance of their enjoyment; rather, their occurrence is accompanied by a sensation of being devoid of conscious means of defence towards them. I would also like to address this insecurity, hoping that it will provide a means, as sometimes happens, of not hiding behind the shield of some weak certainty.

Therefore, I would begin by showing the possibility of collision between the area of the production of images that seek to inform, and that of images that question their own visibility; we could name these the functional and the artistic areas. Let's try to imagine, for a second, what would be the capacity to effectively orient oneself with a public washroom sign, which, instead of the typical man/woman sign, used Marcel Duchamp's 1917 image of a Urinal.

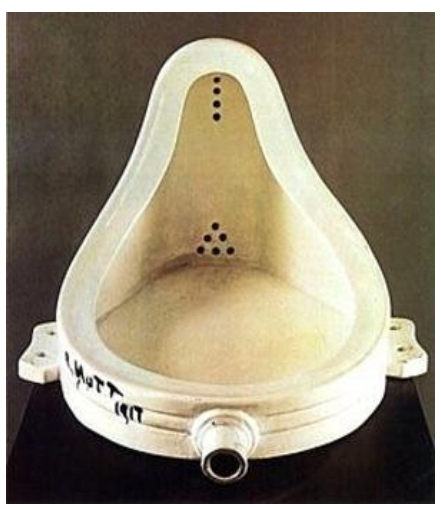

Journal of Crass Cultural Image Studies - Revue d'Études Interculturelles de l'Image Imaginations, I-I, 20I0 Copyright (2). Open Journal Systems. ISSN - 1918-8439. 
Might a woman mistakenly enter into a place marked with a male object of use, or would she interpret the urinal as an icon that indicates the species by the gender? To start, we might ask: what is it that makes us understand that the sign actually indicates the presence of a washroom and that it is not just another of so many vulgar reproductions hanging on a wall?

These are possibly ill-placed questions, but an eventual answer converges toward a single point: understanding to what measure a certain competence concerning the origin (the source) of the sign might influence or somehow relate to the communicative function. Or better still, understanding whether this competence is necessary to the understanding of the sign. This is an important question both in the informative circuit, especially concerning authenticity, and in the artistic circuit, especially concerning originality, statement, or temporal arrangement.

Still on the subject of washrooms, I would like to show below, a few alternatives to the figural indication of the space that are not problematic. The first is conventional, yet not deprived of a decidedly plastic (though not aesthetic) meaning that guarantees its recognisability:

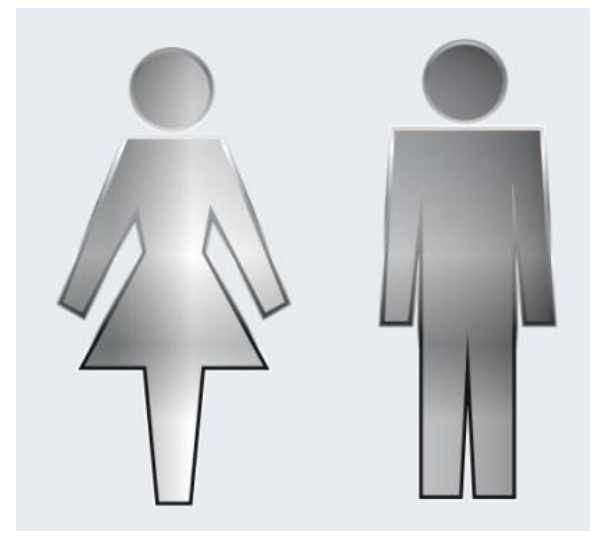

The stylization of the figures allows us to grasp the meaning without too much deductive reasoning. There is no need to figure out the transitions between sign and meaning, and the image-place association is quite automatic.

On the other hand, the designation in this next label is strongly metonymic instead of plastic: 
Imaginations / Scrivano 97

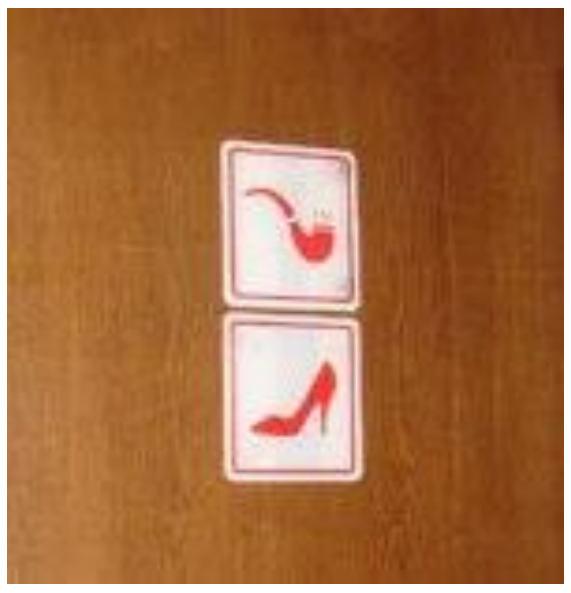

It relies on logic of identification that allocates the image to a genre and the rhetorical process of designation is certainly more evident to those who perform it. In other words, in this image, I have to perform a conceptual connection between what is indicated in a synthetic and unambiguous manner and the persons who are designated in the space behind the door.

When appended on a door, both labels simply indicate that behind the door there are toilets, for men as for women: I do not know whether there will be any further separation of spaces or whether the same space is meant for the use of both genders. Moreover, in the second case, we could perforce imagine that the washroom is reserved for pipe-smoking women, but how can we decide whether the "high-heeled shoes" symbol precedes and includes the "pipe smoker" symbol? In effect, I could think that it is a washroom designated for transvestites, that is, men (who smoke pipes and we know that women do not smoke pipes!) who dress as women (in high heels): a hardly plausible interpretation, yet not impossible. If, alongside this door, there were other doors with similar labels but combined differently, for example, a pipe with men's shoes and high-heeled shoes with lipstick, then this hypothesis would be more tenable. But then, why would we patronize a place that presents such complicated gender signs?

One more image, plastically effective and direct, yet a bit confusing, could be this one: 


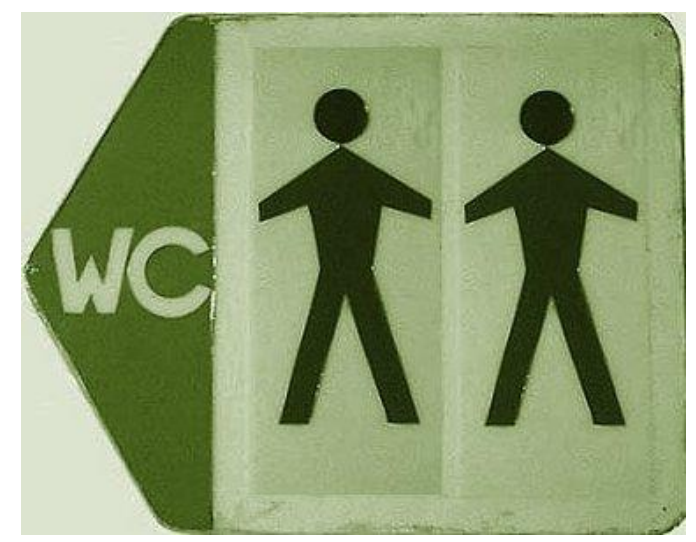

It is simple enough, yet we cannot help but wonder what is signified by the duplication of the stylized male figure: two toilets? Men accompanied by men? Wait in line? I'll repeat it in case you didn't get it the first time?

We normally ignore these small perplexities of communication, but their existence demonstrates an important point: the image contains a hidden residue. The image is a screen where the practice of indicating occurs by activating a relationship between sign and meaning, but it is also something that stands in front of, and stands for, an object. At the same time, an image is a thing and semantics about things (similarly to words).

That the perception of the image has an unexplained and inexplicable residue in the actual moment of it is sensed and in the moment of it is elaborated on, appears to be a proven fact. What is less clear is why this happens. We could put forward at least two hypotheses:

a) the first is that this kind of "mute," unexpressed, meaningless residue is something that the perceiver needs, practically as a means to find comfort in the existence of some element of material reality in the image. It is as if a sort of island devoid of any meaning were produced in the act of perception itself that would allow us to separate what is necessary to articulate linguistically from that which, instead, should not be articulated but instead given to ensure a grounded judgement;

b) the second hypothesis is that this residue forms an intimate part of the nature of the image, that is, it is something that cannot be omitted so that the image may be truly what it is.

In the first case, it would be a question of a sort of cognitive mode, which could also be considered as an epistemological preconception that can understand or 
manifest the act of consciousness only as the explanation of an independent reality, which must always and only be interpreted. Rather, in the second case, there is something different from the meaning, something that goes in a different direction from the indexical and generical sign function, a quid requiring a completely different reading or open to a totally different experience. In both cases there is space for a sort of double value or a double scope of the image.

All the mystique about the image, that is all the discourses that have attributed certain virtues to the image have only highlighted this duality, by highlighting the perception of this residue that we are talking about: magic, with the attribution of effective grounds for the image; veneration, with the anagogical drive towards the represented object; and also iconoclasm, with the prohibition of capturing the soul within the form, all appear as ways of signifying that, at the moment when the image establishes a duration (a temporal extension characterized by such a high level of fixity as to recognize the permanence of an object), it also reveals (in the actualized context of the image) the presence of a redundant, uncontrolled reality, at least not belonging to the same order as the visual form.

Outside of a clearly metaphysical dimension, the perception of a residue can also be interpreted as the product of the difference between spoken and visual languages: if in the former, the primary function is naming and in the latter, it is pre-eminently display, then we should suppose that verbal language signifies, while the image demonstrates: but while it is very clear that the signifying of something occurs within the limits of a system (be it a language or a code), for which this something is a discrete object of the system, it is certainly less evident that the object shown by the image is something, which is discrete in a system of images. It is as if the abstract graphic elements of writing and the equally abstract phonetic elements of speech were perfectly grasped (perceived) by users as essences that cannot be reduced to the objects for which they appear to stand, while visual forms (lines, colours, etc.) would be in greater continuity with the represented world, as if they were made of the same material. It is clear that this differentiation, although it is described a bit coarsely at this point, is a fairly widespread misapprehension.

What this misapprehension especially conceals, or at least, what it does not allow us to clarify, is the fact that verbal language and the image have a common origin in the act, which does not explain anything about their nature, form, and structure. But at least it helps us to understand that language and image acquire meaning even at the moment in which they are understood, accepted, and enjoyed as an act, as a behaviour, as an action; which simply means the meaning is not only in the signification, but also in the behaviour of signs in a context where strongly heterogeneous elements interact: persons, instruments, environment. This is a

Journal of Crass Cultural Image Studies - Revue d'Études Interculturelles de l'Image Imaginations, I-I, 2010 Copyright (2). Open Journal Systems. ISSN - 1918-8439. 
sensorial dimension, the scope of which is properly measured in the quality of the exchange, that is, in communication and in the ultimate analysis, dealing with an exchange of meaningful and symbolic values, in a rhetorical sphere.

But let's go back to the case that was initially proposed and namely, to the question of whether, and in what way, the signalling of the presence of a toilet behind a door or around a bend, through the reproduction of Duchamp's Urinal, could correctly transmit the information "the washroom is here." In the case of the plaque displaying the artistic object, we could say that the content of the image is not exhausted by what we understand perception to be. To those who possess an adequate historical-artistic competence, the "Duchamp shape" would probably be understood before the washroom marker; while those who lack this competence, that is, those who do not recognize Duchamp, would primarily perceive a strange and unusual sign as opposed to typical ones that might even appear too explicit for indicating the presence of a toilet.

The difference between the two apprehensions of the image is that the artistically competent viewer grasps the metaphorical aspect of the sign, while the incompetent one does not grasp the metaphor, though he might understand the message "the washroom is here." The latter may miss another level of meaning that may not be in the structure of the image, but rather in its use. I have not haphazardly chosen the Duchamp example: it is well known that the aim of this idle art (which is practically an oxymoron) was to displace the perception and the expectation of the viewer by proposing for the viewer's contemplation an object of much more prosaic use than the strictly artistic one. I cannot reflect here on the various positions that criticism has assumed concerning the operation of this artist, whether it is a gesture or a composition, ${ }^{2}$ but I can only emphasize the intention of eliciting the beginnings of a dialogue by the mere presentation of the object, as petulant and irreverent as this dialogue might be, due to circulating precepts about the status of the figurative arts; a dialogue undoubtedly based on the act of rendering the object unrecognizable, estranged, irrelevant in certain familiar conditions of visibility and exposability. The recycled use of this image as an indicator cannot but appear charged with irony yet, I repeat, the interesting fact is that, in such a case, the message to be communicated maintains its primary effect even though large parts or layers of meaning may not be completely understood. In what sense, then, can we speak here of residue? Can we consider as such that which the incompetent viewer is missing, that is, that complex level of representation that makes the message ironic as well as amusing? And if so, then in what way does this residue continue to be present, to form part of the image, even in the case where it is not understood, and therefore not actually communicated.

Journal of Crass Cultural Image Studies - Revue d'Études Interculturelles de l'Image Imaginations, I-I, 2010 Copyright (O). Open Journal Systems. ISSN - 1918-8439. 
Imaginations / Scrivano IDI

The Secret of the Image

In the theoretical writings of Cesare Brandi, we can find a few observations about this duality on which I am focusing, between the image as presence and as meaning. ${ }^{3}$ They may only be a few sentences, but they are incisive and strategic in the economy of the Brandian presentation, and hence they are graced with certain brilliance. For example, on the first page of Segno e immagine (Sign and Image), we can read this observation, "between the sign and the image, there is no heterogeneity as there is between phenomenon and category; sign and image are, at the source, the same thing that consciousness directs in two different directions" (13). The image is mirror-like and due to this characteristic, it achieves a figurative mode; on the other hand, the sign involves the cognitive content, it indicates a semantic value: image and sign are thus two diverging modalities of representation (which Brandi understood as an act of consciousness), inasmuch as the first attributes to its object the empirical characteristic of being present and "available" (underlined in the text, perhaps a concession to vorbanden?), while the second dissociates the form from the design, that is, it does not value the presence of the sign as vehicle, it does not consider the current experience significant for the explanation of the meaning.

Brandi claims that these two directions of consciousness (I could also call these fields of representation) must remain separate because only in this way does civilization register a concrete progress (which, we suppose, consists of an enhancement of self-consciousness, of experiences, and of the languages used in depiction or expression). This position closely resembles that laborious task of separation performed by Konrad Fiedler between figurative arts and the other spiritual spheres that require skill, attention, and thought. By attributing to the artistic activity a highly peculiar capacity for the development of consciousness, and by persistently separating it from any other process of representation, Fiedler actually seems to be attributing to art a real and proper cognitive value, by identifying a particular field for a figural, or more fittingly, a visual knowledge. ${ }^{4}$ This is something that Brandi does not appear to consider appropriate, and not only for reasons of terminology. But aside from the division of the domains of the representational activity, and despite this substantial difference and the diversity of outcomes, the two authors set off analogically, taking into account the proper relationship between tools and their modality, from a deep reflection on verbal language and ultimately on the problem of the articulation of meaning in a specific language.

This removed any abstraction from its horizon of meaning, at least in Sign and

Journal of Crass Cultural Image Studies - Revue d'Études Interculturelles de l'Image Imaginations, I-I, 2010 Copyright (2). Open Journal Systems. ISSN - 1918-8439. 
Image, or rather, until the dominant critical requirement became to track the means by which the image presented itself totally as a figure, abstraction here meaning the way in which the figure is, or becomes, a sign, that which attributes meaning. Towards the end of the essay, in the pages dedicated to Abstractism, Brandi writes in reference to Burri that by positioning himself on the side of the sign rather than that of the image in communication, in the direct trade between the work and the spectator, he postulates much of his justification historically as much as aesthetically (83-4). It is the word "communication," briefly defined as a "commercial trade" between the consumer and the object (thereby suggesting a meaning that seeks to underscore commodifying trends and alluding to fetishistic drives), that appears to shine a light: the exchange occurring between the viewer and the work of art, to be interpreted perhaps as the fact that something is taken from the artwork, is the result of the function of the sign. Since the sign does not present its vehicular form but merely the suggestion of its referent, the viewer experience is not accomplished in the presence of the object, but rather in the demarcation of its absence. For this reason, the image-sign is merely communication, it is not a stand-alone item but a means.

Brandi's clear rejection of a semiotics that echoes a need for "communication to the bitter end" now more than ever appears to be a quasi-heroic attempt at maintaining, in the area of sensory experience, something that the ancients would have called secret. A dimension of the artwork that risks being completely lost in our dense culture of communicative exchanges, if it is not already completely lost. And this is, I believe, one of the most significant and original features of the Brandian reflection.

Indeed, what else could be something that appears linguistically articulated yet is devoid of a significant function; something that marks a presence yet leaves us disconcerted, if not a secret? And it is this question that directs Brandi's theoretical work toward his General Theory of Criticism that will seek to establish in the referent the relationship between artwork and reality: the concept of presentness (astanza) used in this essay seeks to determine a site of experience (consciousness) that is clearly distinct both from that possible sphere of a merely empirical presence (flagrancy), and from its conjectural and meaningful forms (semiosis). And since presentness manifests itself only with art, and in art, there is no doubt that Brandi is indeed searching for a dimension of meaningfulness for the artistic experience (102). But for Brandi, the meaning of the artistic experience is not to be confused with the signified, in whatever form it may be produced: in fact, the meaning of art relates more to matters of perception than to those of semiosis. The second part of General Theory of Criticism leaves no doubt as to the fact that access to presentness is possible through the senses, or at least, through the

Jaurnal of Crass Cultural Image Studies - Revue d'Études Interculturelles de I'Image Imaginations, I-I, 20I0 Copyright (2). Open Journal Systems. ISSN - 1918-8439. 
various types of "givenness": presentness is not realized outside of perception; presentness is not a hallucination, but rather, it is a disconnected and autonomous perception in respect to the representative function.

Thus, the idea of maintaining an intimacy, a sort of exclusive proximity with the thing just to establish a secret connection with the object that is being perceptively experienced, is a rather particular feature of Brandi, but it is not completely isolated even though it has, and has had, different faces, and has elicited, and continues to elicit, so many different attitudes. First, there was and there is (also outside of modernity, as we now assume this to be) a widespread notion that modernity, with its science, its technology, with its consistently applied knowledge, and with its obsessive praxis, ended up depriving human beings of the hidden dimension of the experience, to the point of rendering it uncertain or even impossible..$^{5}$ I would evoke the disconsolate mood of a sculptor such as Arturo Martini who, while perhaps mourning its disappearance, attempted on various occasions to recapture in art (and in life) the secret that is concealed in things. ${ }^{6}$ Attributing the blame to the growing intrusiveness of means of communication for seizing the full meaning of art, Martini, in La scultura lingua morta (Sculpture as dead language), while reporting the cause of a widespread abandonment of the art, urged a proximity with the mystery of the object, something other than the explanatory evidence of the form, which too often appeared to him as volume without plastic sense. Elsewhere, he also said that for the ancients, space was also composed of a fourth dimension: mystery. ${ }^{7}$ Or I could even evoke Italo Calvino's observations about the Trojan Column: a work enveloped in so much mystery, but the greatest, according to the author, is that it is not absolutely understandable or imaginable to whom is destined such precision of illustrated narration. ${ }^{8}$ It is impossible to see from below, it is too far to be seen by any surrounding building, nothing seems to allow a continuous reading of the story that is sculpted into it. Whom or what does it serve, then, Calvino wonders.

If these kinds of doubts, expressing a certain anxiety more than a real and proper question awaiting a response, have something in common, it appears to be in the sense of an inexplicability produced by the proximity between the image and the thing. In a 1973 essay dedicated to René Magritte, Ceci n'est pas une pipe, Michel Foucault reestablished the distance between the statement and painting as it unfolded; painting (not only Magritte's, but all the others that dissociate the representative figure from the form, deliberately relinquishing the mimetic relationship of the image), with the intention of scrupulously, cruelly separating the graphic element from the plastic element, with the aim of breaking the ancient conviction that likeness is sufficient for explaining the image. According to Foucault, this belief derived from the fact that, without much discussion, without 
much care for the many unstable elements that are continually reproduced in the two divergent and complementary systems of writing and drawing, the dimension of difference (with respect to the thing) had been assigned to the first, while the dimension of likeness was assigned to the second. But I will not linger over that essay which sees in Magritte's operation an open challenge to the rigidity of these two systems, to show how little is needed (entrusting the writing with a contradictory meaning from the image that it presumably captions) to produce a distressing short circuit.

Rather, I would like to evoke an episode of epistemological crisis that persisted throughout the twentieth century, the experience of which is evidenced in Brandi's opposition of sign-image. In short, to conclude (temporarily, of course) on this aspect, I propose this observation: we have no actual verbal linguistic code that would permit us to express the significance of the discrete in the sphere of visual perception. When we speak with someone, our attention to the words and their reception is constantly displaced between a positive (recognition of an identity) and negative (recognition of a difference) assimilation: "he said money, not honey," "he said exhausted, not just tired," also reflexively "I said disturbing, not upsetting," are sentences that we quickly elaborate to trace the word back to the system (in the semantic domain, obviously): that is, the specificity of the circumstance. All this had been denied in the plastic arts, and it is not too bold to say that what has so often been identified as "dissolution" in the arts is none other than the attempt to free the image, the visual experience, from the objects.

\section{The Blindness of Writing}

If, during the last century, figurative art has sought in plastic art a proper articulation of sense and meaning to the point of constructing one or various languages to coordinate the relationship between figurative image and imagination; to the point of involving a gestural, bodily, or kinetic reference in the visual grammar; to the point of becoming completely unrecognizable, no longer analogous to the world and even less to itself; if all this has occurred in the world of visual arts, however, a similar process has also been performed in the literary field. Perhaps more sporadically, perhaps less-clearly manifested, but certainly with the same breaking force and the same capacity of estrangement. It may seem that the two areas, the literary and the figurative, show weak points of convergence, but for both, the issue at stake is representation, that is, how sign and image relate to each other. Therefore, what I will talk about could also be taken as a reverse example, a sort of photonegative.

Among the various cases that can be recalled, I will mention one here that

Journal of Crass Cultural Image Studies - Revue d'Études Interculturelles de l'Image Imaginations, I-I, 20IO Capyright (2. Open Journal Systems. ISSN - 1918-8439. 
characterizes itself as being a theoretical perspective critically confluent with literature; indeed, it is quite similar to the work of Brandi and moreover, it is chronologically parallel to it. In L'entretien infini (1969), Maurice Blanchot, among the many questions asked in this complex and articulated text-essentially dedicated to delineating the discontinuities and ruptures that characterize the literary experience, a structural, rather than formal, discontinuity capable of involving the production, as much as the enjoyment, and the artwork itself-, I would even say that underlying the discourse of the essay, he presented a radical critique of the programmatic and substantive course of development in the modern novel: that of thinking about narration as a kind of dialogue with visibility, with the visual experience, and essentially with the image. According to Blanchot, this was a way to ensure a horizon of meaning, perhaps of coherence, of verisimilitude, of similarity with the represented world, in the story. The knowledge to be developed in a long-lasting environment (Blanchot contrasted this with the night, darkness, blindness) is only capable, in his view, of inhibiting any experience that could place man on the limit of the mystery. I can only remember his reasoning on the concept of attention: there is a personal one that is assessed according to the relationship established with the object, focusing on it and referring all meaning to it (it is another way of talking about knowing through principles of objectivity and truth) and hence, destined to be an instrument, a means of juxtaposition, an apparatus of transparency; there is also an impersonal attention, open to the occurrence of the unknown, to the mystery that is perpetuated by never crossing the threshold of the knowable (another way of talking about the experience of non-thought) and destined to become a habitable space, although without reference and without centre, and therefore unstable and uncertain, a completely opaque matter.

First of all, it is the principle of similarity that is at stake, the one on which is based the possibility of recognition, the possibility of establishing a true relationship among the elements involved in the representation. When Blanchot, quoting Mallarmé in the subtitle, refers to writing as a foolish game, he engages its most powerful implication: the lack of meaning is not a defect of the discourse but its objective; not for the sake of paradox or contradiction, but rather for the fact that writing acquires its greatest meaning when it does not direct the sign toward a search for signification, toward the cognitive resolution of language, but rather, toward the affirmation of a permanence, of an existence that does not require being explained so much as being experienced.

There is another consequence worth noting: narrating, including through images, is no longer the production of discourse as narrative; at the moment where narration waives the task of serving as a suture between the experience and the

Journal of Crass Cultural Image Studies - Revue d'Études Interculturelles de l'Image Imaginations, I-I, 20IO Capyright (2. Open Journal Systems. ISSN - 1918-8439. 
world, the artwork loses its value as a document, as a documentary collection of experience because the only possible experience is only, and already, all in the text. More than retracing the dimension of absence to which the book and the artwork refer (Blanchot is looking particularly to combating the exteriority that produces limitations and the enclosure of the book within the limits of the intelligibility of the story), it would be better to juxtapose another essay to this reading, namely, Le plaisir du texte, written in 1973 by Roland Barthes. This essay also seeks the meaning of the literary experience in the cracks, in the coarseness, in the difficulty produced by the reading, all discontinuances that abolish the distance between the act and its comprehension, between reading time and historical time. What is significance? It is sensually-produced meaning, affirms Barthes: pleasure and enjoyment appear to abolish the distance from the narrated objects or rather, that distance that is produced at the moment in which the word makes itself visible, and the reading is transformed into an image. And together, they do away with that need for consistency that appears to characterize writing: this is a very abstract place to mark the experience, a place where any plastic tie between sign and referent are abolished, a place made possible by the fact that all the meaning is established as it extends and explores the space that it takes up; yet, the need to see in it something that would emerge only and constantly in the marking of its absence is never exhausted. In other words, Barthes seems to deny the transparency of the means and to resolve the tension of the meaning within an obfuscating experience.

\section{Conclusion: Fallacious Modelization?}

Perhaps we have strayed a bit too much or too quickly from our starting statement, and so we must return without hesitation to the problem of what and how we communicate through the image.

On closer inspection, the various positions considered above appear to converge in a negative response to the simple fact that "through the image," we go somewhere: if the visual-related experience has no primary function as a communicative vehicle, if it is not the form of something outside of itself, the image cannot be thought of as a conveyance-independently dominating the spatial or temporal expanse. If it is a place, then it must in some measure consist of filled and empty spaces (it is this ascertainment about the text that directed Blanchot and Barthes). Just like a body whose integrity in parts and harmony, if it exists, is only rarely perceptible as a whole: we more easily feel parts of the body, now a finger, now a foot, sometimes something inside. In other words, the whole image is never to be taken at the level of phenomenon: it may be a product of sensorial responses tracing back to the phenomenon; precisely because it is

Journal of Crass Cultural Image Studies - Revue d'Études Interculturelles de l'Image Imaginations, I-I, 20IO Capyright (2. Open Journal Systems. ISSN - 1918-8439. 
possible to move within those responses, it is equally possible to design a unique dimension for them, but only their discontinuity allows us to imagine a continuity. If this totality of fullness and emptiness is the structure of the image, what is the point of asking ourselves what it communicates? Maybe something can be conveyed through it? Or perhaps only the filled spaces can be responsible for this transfer? Can this eventually occur without confusing the transferred object with the transferring object? Would the recipient discern a possible overlap?

I am deliberately skirting questions that border on the absurd; they are as such because they exacerbate a state of confusion in respect to the object, so that no one could say what it is made of, or whether it is comparable to matter. And this is exactly what has been at stake from the beginning: on what do we base the reality principle? The attempt to understand what happens when the image in a Duchamp piece is used to indicate something that the artwork negates as its own content, could be addressed again at this point. Certainly, the fact that an image may have different levels of reality is inconsistent with the idea that every thing, to be real, must also be unique and monodimensional.

Vilém Flusser repeatedly proposed the idea that our behaviour toward the matter has undergone a profound alteration in the last century. ${ }^{9}$ The author argues that the notion that man be related to the subject through a process of abstraction capable of producing either forms or outlines, or anything else, is rapidly dissipating; perhaps spurred by the means of production, perhaps by the instruments of communication, it is increasingly the case that the product of abstraction itself is perceived as matter. The fact is that we are witnessing a curious phenomenon of inversion whereby producing an abstraction no longer means proceeding from the concrete to the intangible, but rather, from the intangible to the thing. Thus, the activity of representation seems to have become a filling activity of the tangible rather than that of forming the intangible. The aim of the symbolic action is more that of giving shape to forms than that of shaping bodies.

But if this observation were feasible, then we could say that the formation of meaning is no longer to be found in the composition of an abstract system capable of performing an explanatory action within its own boundaries, but rather in the composition of the matter entrusted with the whole experience. This position appears very interesting to me: because it allows a glimpse into what is involved in the production of images aimed at conveying a message, even one as simple as "there is a washroom here." In a way, it involves the production of reality.

I would like to illustrate this condition with an episode of what we might call a

Jaurnal of Crass Cultural Image Studies - Revue d'Études Interculturelles de I'Image Imaginations, I-I, 2010 Copyright (2. Dpen Journal Systems. ISSN - 1918-8439. 
news report about information. A few years ago, a video was circulated, and some frames from it were published in several newspapers, documenting a serious tragedy that occurred in the occupied Palestinian territories. In the video, we could see a man and a young boy seeking shelter from an intense burst of bullets; then the boy appears to lose consciousness. The video report explained that when a shootout broke out in the streets between soldiers and the militia, the man and the child were caught in the crossfire: a bullet fired by an Israeli solder had struck the Palestinian boy, killing him. The sequence was particularly distressing because it showed the fear, the struggle, the despair, and the helplessness. In the days following the distribution of the report, certain sources began to deny its veracity, claiming that the video was staged and that it was a fraud. The non-veracity concerned its content: the boy was not really dead, but had happily survived although wounded. This anti-thesis apparently tried to soften the emotional impact of the content of the video and led to the formulation of the following argument by the viewer: since the video is said to show the killing of a boy during a fire fight in which he had been involuntarily involved, but we know that he did not die, then the whole video is also a fraud. This is an obvious fallacy; and while the user may understand that his conclusion on the falsity of the video is unjustified, any produced emotion is irretrievably destroyed. In short, we are discussing the veracity of showing. This is not a pipe, just like This is not a murder. But the important fact, which can provoke embarrassment, is not so much the questioning of the veracity of the scene as the fact that the controversy over the meaning (what it shows) also puts into question the veracity of the video itself; that is, judging whether it is acceptable that a child be involved in a shootout ties in with the reality of the effect that this individual case has produced. Hence, we might think that the exemplary use of the image is still somewhat ambiguous, despite the assured foundation effect of the real. But this also shows that the image is assigned a presence that goes beyond the description.

Finally, I hope that this article has shown that doubleness that can be a source of ambiguity, and that is certainly a cause of undecidability, and hence, that of sensing images as narration as much as something capable of producing a presence. But I fear the consequences of denying that the image can assume the responsibility of being a constitutive form of absence, that is, a reference to an abstract and intangible process, because it would mean removing from the figurative any intelligence, including any intelligence that detects the secret, and surrendering to the idiocy of a world flooded with images. And that is something that, as shown by the images below, we cannot afford.

Journal of Crass Cultural Image Studies - Revue d'Études Interculturelles de l'Image Imaginations, I-I, 2010 Copyright (O). Open Journal Systems. ISSN - 1918-8439. 


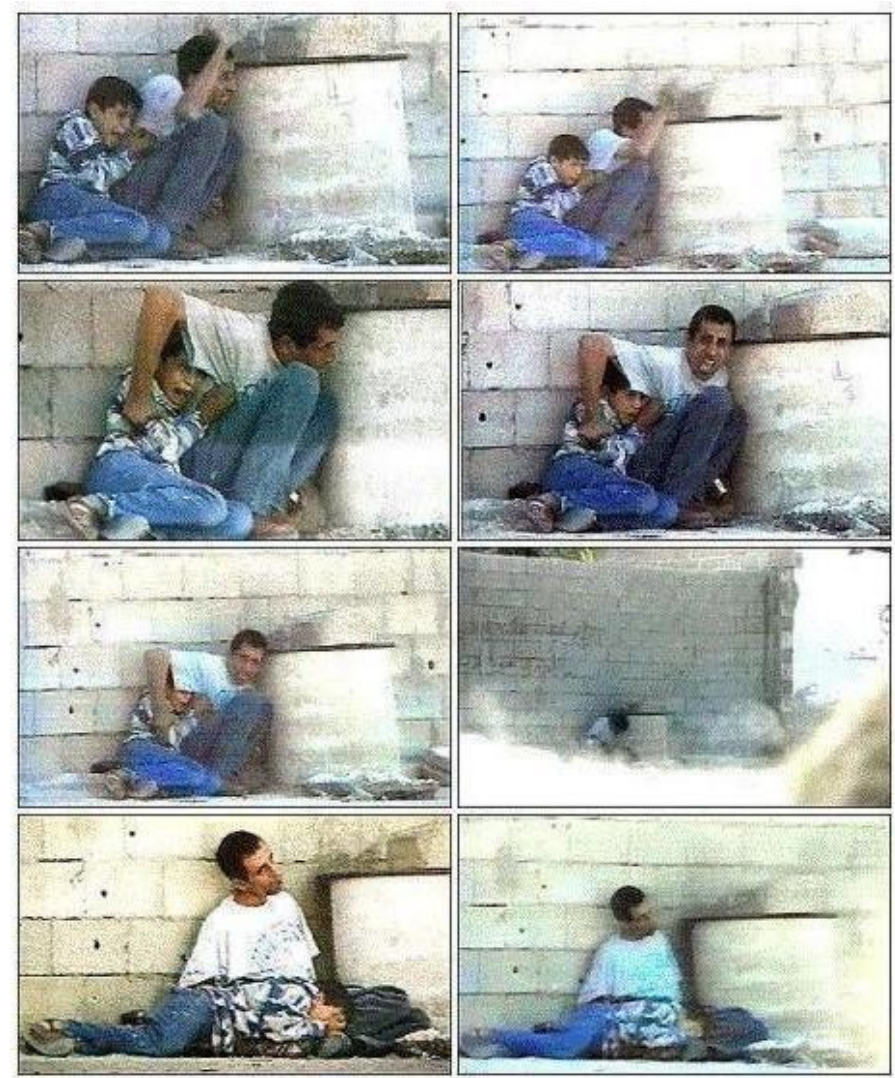

References

Agamben, Giorgio. Infanzia e storia, Distru₹ione dell'esperienza e origine della storia.

Torino: Einaudi, 1978.

Arnheim, Rudolf. Thoughts on art education. Los Angeles: Getty Centre for Education in The Arts, 1989.

Barthes, Roland. Le plaisir du texte. Paris: Editions du Seuil, 1973.

Blanchot, Maurice. L'entretien infini. Francia: Gallimard, 1969.

Brandi, Rudolf. Segno e immagine. 1960. Palermo: Aesthetica, 2001.

---. Teoria generale della critica. 1964. Roma: Ed. Riuniti, 1998.

Calvino, Italo. "La colonna traiana raccontata." Collezione di sabbia. Milano:

Garzanti, 1984. 95-101.

Fiedler, Konrad. Schriften zur Kunst. München: Fink, 1991.

Flusser, Vilém. La cultura dei media. Milano: Bruno Mondadori, 2004.

---. Medienkultur. Frankfurt/Main: Fischer, 2007. 
Foucault, Michel. "Ceci n'est pas une pipe" October (1976): 6-21.

Martini, Arturo. Colloqui sulla scultura 1944-45. Ed. Gino Scarpa and Nico Stringa. Treviso: Canova, 1997.

---. La scultura lingua morta. Verona: Officina Bodini, 1948.

---. Le lettere 1909-1947. Ed. Natale Mazzolà. Firenze: Vallecchi, 1967.

Mitchell, W.J.T. “What do Pictures 'Really' Want?” October 77 (1996): 71-82.

Perniola, Mario. Contro la comunicazione. Torino: Einaudi, 2004.

---. Miracoli e traumi della comunicazione. Torino: Einaudi, 2009.

Image Notes

Image One: “Duchamp's Urinal.” Blog. artnewsblog.com/2004/12/duchamps-

urinal.htm. artnewsblog.com, 1 Dec. 2004. Web. 8 Dec. 2010.

Image Two: Buho. Blog. buhosong.blogspot.com. Buho's Songs, 21 Feb., 2007. Web. 8 Dec. 2010.

Image Three: linguatec.it/images/fun/wc.jpg. Web. 8 Dec. 2010.

Image Four: Scarlettinas. Blog. scarlettinas.splinder.com/archive/2008-09. Trespass, 15 Sept. 2008. Web. 8 Dec. 2010.

Image Five: "Remembering Muhammad al-Durra." Blog. fisan.wordpress.com/2007/03. Try to find the light. 18 Mar. 2007. Web. 8 Dec. 2010.

Endnotes

${ }^{1}$ See Perniola.

2 See Octavio Paz's essay Aparencia desnuda: la obra de Marcel Duchamp (1973) and Jean-François Lyotard's article in Les transformateurs Duchamp (1977).

3 Cesare Brandi (1906-1988) was an art historian and theorist who founded in 1939 the Istituto Centrale del Restauro, the first and most important learning and research centre for the conservation of artistic heritage. The first twenty years of the institute were synthesized in a 1963 essay of great relevance, Theory of Restoration (tran. from La teoria del restauro, by C. Rockwell and D. Bell, Firenze, Nardini, 2005), which was translated into several languages. Brandi posited restoration as a necessary operation for the aesthetic recognition of the work of art, since the operation on the physical substance allowed an interpretation and an outline of its generational transition. However, the essays to which I refer here have not been translated.

4 See particularly Fiedler's essay Über den Ursprung der küntlerischen tätigkeit.

Journal of Crass Cultural Image Studies - Revue d'Études Interculturelles de l'Image Imaginations, I-I, 2010 Copyright (2). Open Journal Systems. ISSN - 1918-8439. 
${ }^{5}$ On the end of experience, see also Agamben.

${ }^{6}$ For example, in a 1926 letter to Francesco Messina: "Mystery, that is what is missing in our whole life- - there is no longer any danger to things, there are no longer robbers in the streets, and even women no longer have any mystery of modesty," 193.

${ }^{7}$ See Colloqui sulla scultura 1944-45.

8 See La colonna traiana raccontata (1980).

9 The writings of Flusser on the new media that have emerged over two decades. See also the essays Das Unding I and Das Unding II (1993) in: Filosofia del design, Milano: Bruno Mondadori, 2003.

Jaurnal of Crass Cultural Image Studies - Revue d'Études Interculturelles de l'Image Imaginations, I-I, 2010 Capyright (2. Open Journal Systems. ISSN - 1918-8439. 


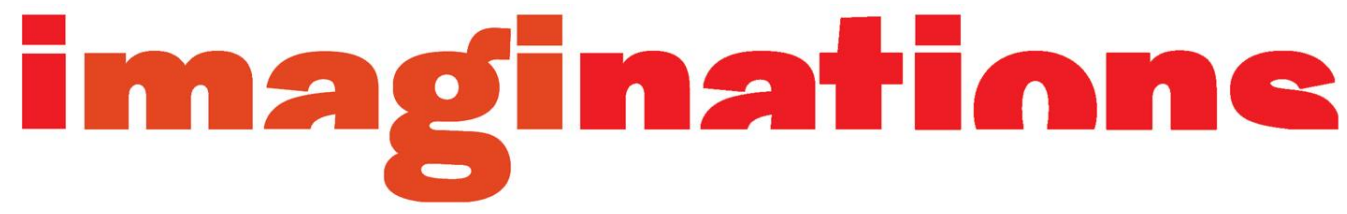

\section{Images of a Sound \\ Portraits and Pictures of Jazz}

Davide Sparti [TRANs. LSE HogaN]

Introduction

As A MUSIC FORM of fluctuating status, jazz is earmarked by a fundamental contamination of contributions from various cultures - from the Afro-American vernacular expressed in blues or gospel music, to popular American song; from modern classical music to African diasporic elements and non-western sources such as Indian music. Perhaps because of its multiple sources, jazz had to wait a long time before attracting the interest of scholars who were not simply aficionados. Therefore, it is only recently that we have come to understand jazz as not merely a musical genre, and even less as a closed genre characterized by a precise origin, by a clear developmental trajectory, by a specific set of protagonists and by a catalogue of accumulated works. Rather, it corresponds to a field, a field where sounds, practices, discourses, and images are interwoven. The field of jazz, rather than merely jazz. In order to illustrate the extent to which jazz must be viewed as a cultural field, I will proceed with an analysis from the exhibit titled "Jazz Eye", dedicated to jazz album covers, which took place last year at the Santa Maria della Scala Museum in Siena. This will allow me to discuss some of the relationships between music and visual art, and also to culturally re-contextualize jazz. It has always been claimed that jazz reflects the social and urban changes of its times, but little attention has been paid to the reverse affirmation, that is, that twentiethcentury culture mirrors jazz, reacting and responding to its presence, re-elaborating its sounds in visual (as well as textual and choreographic) forms.

Jaurnal of Crass Cultural Image Studies - Revue d'Études Interculturelles de l'Image

Imaginations, I-I, 2010 Copyright (2). Dpen Journal Systems. ISSN - 1918-8439. 
Jazz and visual arts

First of all, regarding the interconnections between sound and images, it is important to avoid giving the impression that visual arts and jazz have been devoid of exchanges. On the contrary, there exist various relationships, although these have often been concealed, or presented in a tendentious manner. At a first, more superficial level, consider this quick review.

Apart from the usage of artworks which have lent themselves to the world of jazz album covers (from Rousseau to Matisse, from Hopper to De Chirico), various artists have been directly involved in the production of covers, for example, Romare Bearden, Michelangelo Pistoletto, or Andy Warhol. Numerous jazz musicians have payed homage to paintings, such as Coleman Hawkins' composition titled "Picasso." Correlatively, there are various jazz musicians who are engaged in the graphic and pictorial field, such as Ornette Coleman (always interested in contemporary art. Coleman started collecting artworks- in particular, Larry Rivers and Robert Rauschenberg - in 1960, after arriving in New York), or Sun $\mathrm{Ra}$, whose onirical and cosmic graphics characterize the covers of the autonomously-run recording label Saturn Records. The trumpeter Bill Dixon and the drummer Daniel Humair also paint. Larry Rivers constitutes a model case with respect to the contact between the two realms. Author of the (collapsing) scene painting of The Slave, the drama of the Afro-American activist and poet Leroi Jones (later Amiri Baraka), Rivers, who himself played sax, often represented saxophonists engaged in improvising (as in his work The Saxophonist). As, and with, de Kooning or Kline, he regularly frequented jazz clubs such as the Café Bohemia or the Five Spot (following the urban restructuration of Tompkins Square Park in the early 1960s, the Five Spot - situated on the corner of St Marks and Third Avenue -, was demolished to re-open again a few blocks north of Cooper Square). Alternatively, Rivers frequented the Lower East Side (which became known as the "East Village" in the early 1960s) where the musicians knew the poets who knew the painters who knew the dancers who knew the musicians... Performing with jazz musicians and painters and ballet troupes and (male and female) poets was a common occurrence. Marion Brown and Archie Shepp (with his Judeo-Spanish wife Garth and their four children) also lived on East $5^{\text {th }}$ Street in the East Village. The Nuyorican Poets Café, Slugs, and the Fillmore East were located here too. Here worked Romare Bearden, whose collage - like an improvised jazz solo - draws together and combines everyday objects and fragments of advertising material in an unusual and startling manner.

Staying within the horizon of visual arts but changing medium, we can also consider Shadows, John Cassavetes' first film (1958). Besides a sound track produced with great sensibility by Charles Mingus, the film reveals an improvised

Journal of Crass Cultural Image Studies - Revue d'Études Interculturelles de l'Image

Imaginations, I-I, 2010 Copyright (2). Dpen Journal Systems. ISSN - 1918-8439. 
use of the movie camera. Moreover, Cassavetes resorted to a particular device: he directed the film by only partly explaining to each actor the role of the other actors, in order to bring out an element of surprise during the course of filming.

As evidenced by the Sienese exhibition, from the onset of the 1950, it is the recording companies, especially the independent labels, who create the most innovative solutions in the graphic and photographic field, and in the use of characters, transforming the LP in an aesthetic object (Frank Wolff, for example, co-director with Alfred Lion of Blue Note Records, was a professional photographer). Although it was not able to keep up with musical development, Impulse introduced fiery colors to reflect the emergence of the new music. Consider today's ECM, whose covers favour black, white and gray overtones, expressing a need for space and freedom of movement that is amply reflected in the subtle, almost zen ambience of the music. The album cover not only characterizes the artist or the single LP (the image is introduced before the sound, and it is often the image that has the capacity to attract in the auditory world), but the well-defined identity of the recording company. With the arrival of the CD, the cover space is more restricted, but the cardboard covers colored with the peculiar tactile quality of the German company Winter and Winter, or the photographic images of the digi-pak from the Swiss company Hatology still reveals the capacity to express singularity. Moreover, Jazz-photography is not only evidence of the musical event - that is, it is not limited to merely commenting on the music. The art of the immediate snapshot and that of improvisation are confronted with the same performative spontaneity. As Barthes (1982) explained, the essence of photography does not stem from the frame (the cropping) but rather, from a sharp detail that flows outside of the framing and dazzles us. Yet, even jazz, as music of revelations and surprises, is characterized by the impact of unexpected moments sound bites that strike us, tearing us away from the passive enjoyment of the piece. This is exactly what Roland Barthes calls punctum, that uncommon manifestation/occurrence that invades our perception and shatters the frame of our expectations.

\section{Music, protest and freedam}

Secondly, the crossover of image and sound is articulated on the referential level of the content. Album covers - to remain on the subject - represent a mirror of the times and of their political changes.

Despite de-segregationist provisions, blacks in the1960s could shave white men in barber shops, but they could not share a drink in the same club; they could look after the white man's children, but were not allowed to use the front door of the house. Even the drinking fountains in the parks were marked "White" (because of

Jaurnal of Crass Cultural Image Studies - Revue d'Études Interculturelles de l'Image

Imaginations, I-I, 2010 Copyright (2). Dpen Journal Systems. ISSN - 1918-8439. 
discrimination in mortgage loans, it would not be until 1967, in Levitttown, Pennsylvania, that an Afro-American family would be able for the first time to buy their own home). As a means of protest against such a situation, in 1960, four black men organize a sit-in in Greensborough, North Carolina. Before the end of the semester, six thousand students in the South emulate them (more than two hundred would end up in jail), and in 1961, they would number seventy thousand, including among them many white activists. The record We insist. Freedom Now by the drummer Max Roach actually depicts a sit-in event. Album covers begin to reflect the political significance that jazz musicians attribute to their own artistic mission.

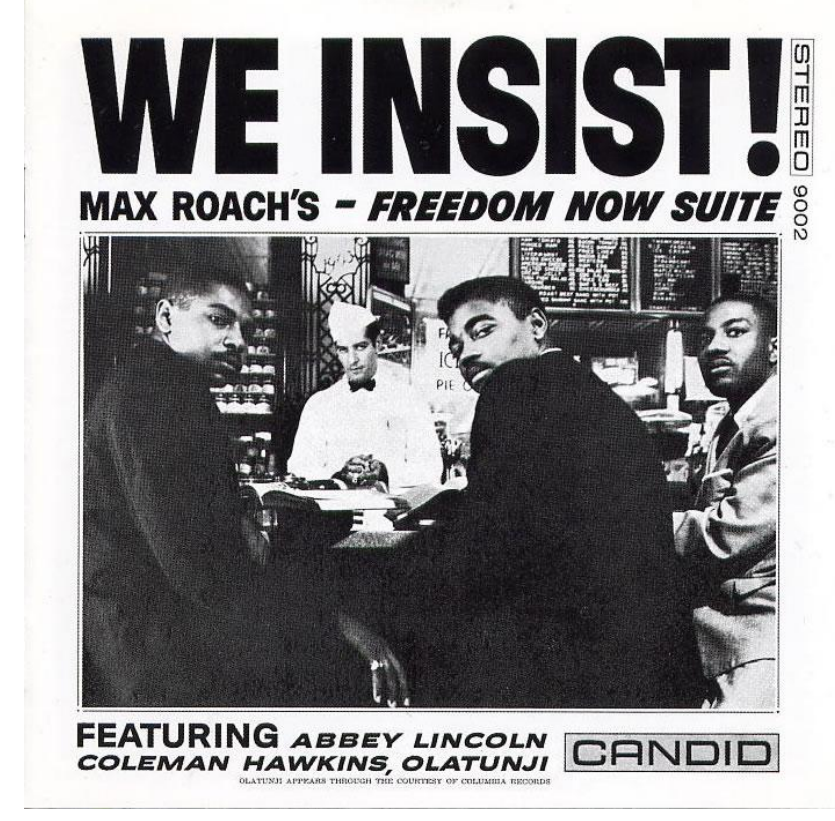

Segregation and discrimination determined travel arrangements, the clubs in which they could play (as well as their relationship with the audience - there were even laws that prohibited "fraternizing with white customers"), wages, and the opportunity to access the world of cinema and television. If it was common practice for whites to play with blacks in Afro-American clubs, it was unheard-of for blacks to play with whites in prestigious white clubs. As Lionel Hampton relates, he and Teddy Wilson, on tour with the group led by Benny Goodman, were systematically treated like servants, valets, or water-boys destined to assist the star. Like servants, they were made to enter the hotels through the service doors, 
and whenever, by contract, they had the right to sleep in the building, they were lodged in the basement, next to the boiler.

When, in the 1960s, Sonny Rollins conducted the quartet with Jim Hall on the guitar (that is, the Sonny Rollins Quartet, not the Jim Hall-Rollins Band), the club owners and sound technicians invariably and immediately addressed themselves to Hall regarding any questions about the performance, ignoring Rollins (Nisenson 156). When, in a New York East End cabaret, Peggy Lee announced that she wanted to do an imitation of the great Billie Holiday, rejoicing broke out, while at that same time, Billie Holiday was on the street, unemployed and generally considered a drug-addict. Charlie Parker's mother remained a poor housewife while the record company cashed in millions thanks to her son's records. This disregard for Afro-Americans, moreover, infuses even the discursive approach to jazz. Who wrote the first book about jazz? A Belgian (Robert Goffin). Who compiled the first discography? A Frenchman, Delaunay. Who named the first streets or parks after jazz musicians? France (Bechet and Armstrong) and England (Max Roach Park in Brixton).

Going back to album cover images, even though cultural membership often tends to be concealed within abstract figures (Miles Davis' first album for Columbia, titled "Miles Ahead!" was initially released with the photograph of a white woman in a sailboat), from the end of the 1950s representations of black women (young models, rather than musicians) became less uncommon. However, as Gitler noted (Gentile et al. 47), a cover with a fully-dressed man and woman was withdrawn and substituted by a different image. The original image of Counting Five in Sweden depicted (black) trumpeter Joe Newman with his (white) wife Rigmor (the mixed, or interracial, union was considered an obstacle to the sale of the album...).

Jaurnal of Crass Cultural Image Studies - Revue d'Études Interculturelles de I'Image

Imaginations, I-I, 2010 Copyright (2). Dpen Journal Systems. ISSN - 1918-8439. 


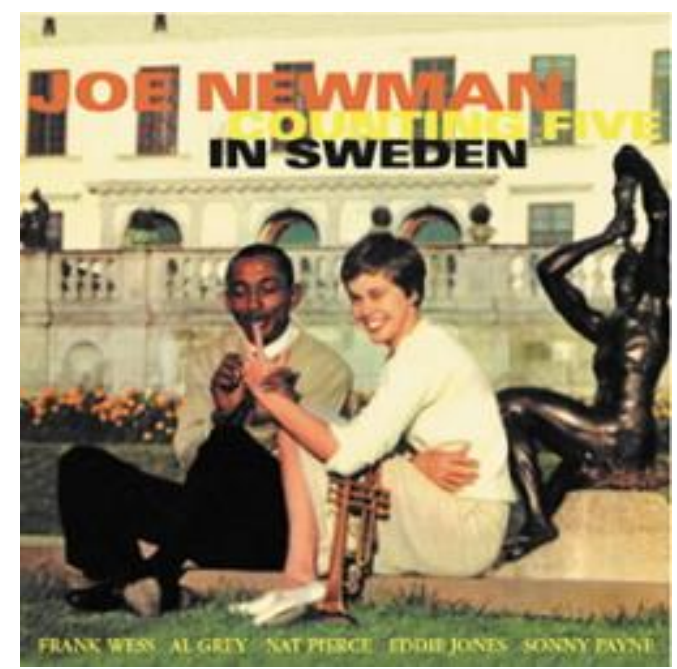

Let's not forget that in 1960, in New Orleans, the Afro-American drummer Ed Blackwell and his (white) wife Frances were imprisoned for miscegenation. And again, when the black trumpeter Roy Eldridge played in Artie Shaw's band, one piece was to be performed as a duet with the (white) singer Anita O' Day. But, the local authorities insisted that they place themselves at opposite ends of the stage, with two separate microphones. Hence, it is not surprising to find Ornette Coleman's famous cover with the Bill of Rights set afire.

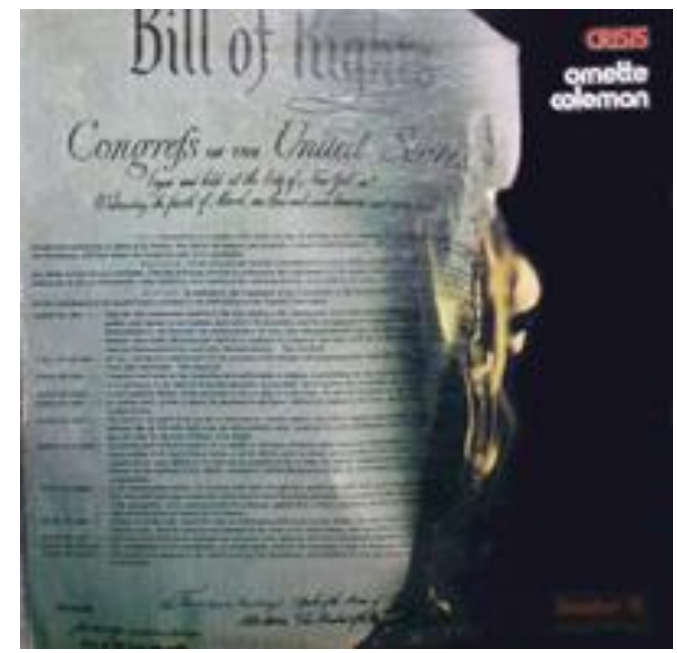

Jaurnal of Crass Cultural Image Studies - Revue d'Études Interculturelles de l'Image Imaginations, I-I, 2010 Copyright (2). Dpen Journal Systems. ISSN - 1918-8439. 
Nor is it surprising, ultimately, that the record has never been re-released by Impulse, and that today it remains impossible to find. Voicing their resistance to this situation, the Afro-Americans organized political rallies where musicians did their own part. The Freedom Riders originated in 1961, a mixed group of people (blacks and whites, young and old, men and women, atheists and believers) proposing to travel from Washington to New Orleans using public transport and distributing themselves spontaneously in different places. "The Freedom Rider" is also the title of a drum solo on Art Blakey's album of the same name (Blue Note, 1961). In 1963, the Sixteenth Street Baptist Church in Birmingham, Alabama, was dynamited, killing four children who were attending their Sunday school lessons. That same year, Coltrane, in "Alabama" mournfully evoked these deaths. The piece "The Funeral" was dedicated by Archie Shepp to the memory of Medgar Evers, Secretary of the NAACP in Mississippi, shot to death in Jackson by a white racist. "Malcom, Malcom - semper Malcolm", also by Shepp, combines music and poetry to evoke the figure of Malcom X. In this piece, based on a poem reproduced in the liner notes of the album Fire Music, Shepp is simultaneously reciting poet and saxophonist, accompanied by the bow of the classically-trained contrabass player David Isenzon and the drumming of J.C. Moses. The trumpeter Lee Morgan composed a piece eloquently titled $\mathrm{Mr}$ Kenyatta, as well as Angela, dedicated to Angela Davis. Around the same time, the singer Nina Simone composed "Mississippi God Damn", which becomes a sort of hymn among the activists during those years. Roach's recording We insist. Freedom Now should have been released in 1963, on the centennial anniversary of the Abolition of Black Slavery. The album's sub-title would become the name of a Black nationalist party (moreover, the use of music as political protest is not exclusive to the 1960s; closer to our times Lester Bowie expressed in The Fire "this" Time his indignation for the farcical proceedings of the Los Angeles police officers who had beaten Rodney King to death. The images of the beating, filmed by an amateur video, circulated throughout the world, and the acquittal triggered the worst riot since World War II).

The creative process

Pertaining to the relationship between images and sounds, there is finally a third, more underground affinity between jazz (improvisation) and - certain - visual arts, centred on the notion of process, action and operation.

A good - historical - starting point is the convergence between surrealism and jazz, with its concern for the conscious/unconscious dimension of the artistic creation. Decades ago in his famous Entretiens, André Breton lingered over the surrealistic practice of automatic writing, directed at opening up an access way to a deep and self-reproductive language revealing itself through the artist. Julio

Journal of Crass Cultural Image Studies - Revue d'Études Interculturelles de l'Image

Imaginations, I-I, 2010 Copyright (2). Dpen Journal Systems. ISSN - 1918-8439. 
Cortázar, in a conference titled "A few aspects of the short story", has declared that the majority of his own short stories were born from unexpected associations and from ill-defined bridges in space and time - that is, they have been "decided" in a latent region, at the margins of his own will, in a non-diurnal area. (1994, p. 1317). Jazz arises from that same psychic region. Cortázar's comparison of improvisation to automatic writing is not unjustified. «Mi sono interessato al jazz perché in quel momento [gli anni Trenta] era la sola musica che si avvicinasse alla nozione di scrittura automatica, di improvvisazione totale della scrittura. Siccome ero stato molto attratto dal surrealismo ed ero immerso nella lettura di autori come Breton, Crevel, e Aragon (...) il jazz mi offriva un equivalente musicale del surrealismo, una musica che faceva a meno dello spartito» (Cortázar 215).

"I became interested in jazz because at that time (the Thirties) it was the only music that came close to automatic writing, writing as total improvisation. Since I had been attracted to surrealism and became immersed in reading authors like Breton, Crevel, and Aragon (...) jazz offered me the musical equivalent of surrealism, music that eschewed a score."

In the figurative arts connected to surrealism, one should remember, on the one hand, the works of Dubuffet, who dedicated at least one work of art explicitly to jazz, Grand Jazz Band (Oil on canvas, 1944, exhibited in New York at the Museum of Modern Art), and, on the other hand, the works by Matta, particularly Jazz 1 and Jarz 2 .

Most of all, the surrealist reflection raises an epistemological question: can one play (create) something that is yet unknown? In her Lectures in America (181), Gertrude Stein wondered if there could be a way of expressing what one knows that did not come about as an outcome of our memory. Let's consider Keith Jarrett's earlier solo improvisations. There is in Jarrett an explicit attempt to make music emerge not as the implementation of a preconceived idea, but in such a way that it reaches expressive areas that the musician only knows in an obtuse way. This attempt especially assumes the form of a negative control: I control myself in such a way that music flows autotelically without being obstructed by the memory of what has been consolidated with the passage of time. Formulated differently, it is a matter of maintaining a state of maximum sensibility without relying upon specific ideas, activating a cognitive style that is not focused, nor fixed, for that matter, on determined models. Rather than being centered on one's ideas, it is necessary to de-center oneself, in order to let the tacit dimension operate. As Jarrett put it in an interview (1995), the jazz musician has to discover a way of starting an improvised performance without any mentally pre-established goals (a specific motif or melody in mind), as if enabling his hands to start the performance without him. It is as if the music - the emerging sounds - were

Jaurnal of Crass Cultural Image Studies - Revue d'Études Interculturelles de I'Image

Imaginations, I-I, 2010 Copyright (2). Open Journal Systems. ISSN - I9I8-8439. 
taking the lead. The modality of which we are speaking does not implicate a refusal of the musician's knowledge. Certainly, the latter proceeds in the light of a determined (and personal) conception of music. But he relaxes his cognitive control over the musical direction. We thus find a paradox: if we try too explicitly to obtain a state of autotelic flow, we obstruct it. Therefore we are back to the mental disposition of which the surrealists spoke: a particular state of vigilance, between relaxation and wakefulness, where the conscious and the unconscious are transitory and reversible. At the heart of the artistic creation, then, there is a sort of immobility, a state of readiness. Not a doing, and even less a non-doing, but a way of letting the music display itself through the artist.

The most relevant visual artist we can evoke in this area is Jackson Pollock, who explicitly invokes surrealism (he was interested in surrealist automatism, the idea of spontaneity in automatic design), as well as jazz. If we analyze Jackson Pollock's method of dripping paint on the canvas as a way to compose a work of art something marked by a formal balance, by a correspondence amongst elements the result is ridiculous: even a child could do it. Moreover, how does one frame this type of art? As a process, not a (finished) product. This can be seen in the famous documentary film on Pollock, shot by the art photographer Hans Namuth between 1950 and 1951: the work of art is primarily the operation, the performative process.

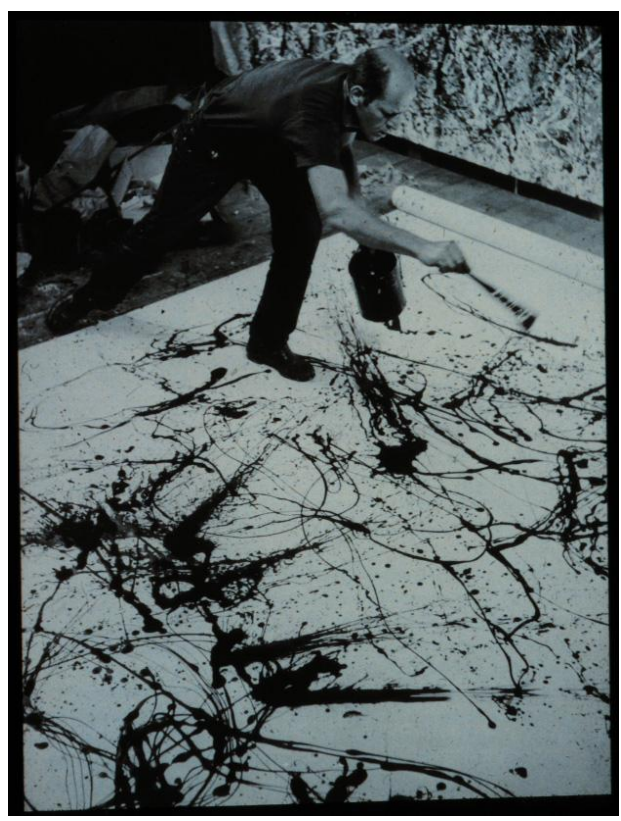

Jaurnal of Crass Cultural Image Studies - Revue d'Études Interculturelles de l'Image Imaginations, I-I, 2010 Copyright (2). Dpen Journal Systems. ISSN - 1918-8439. 


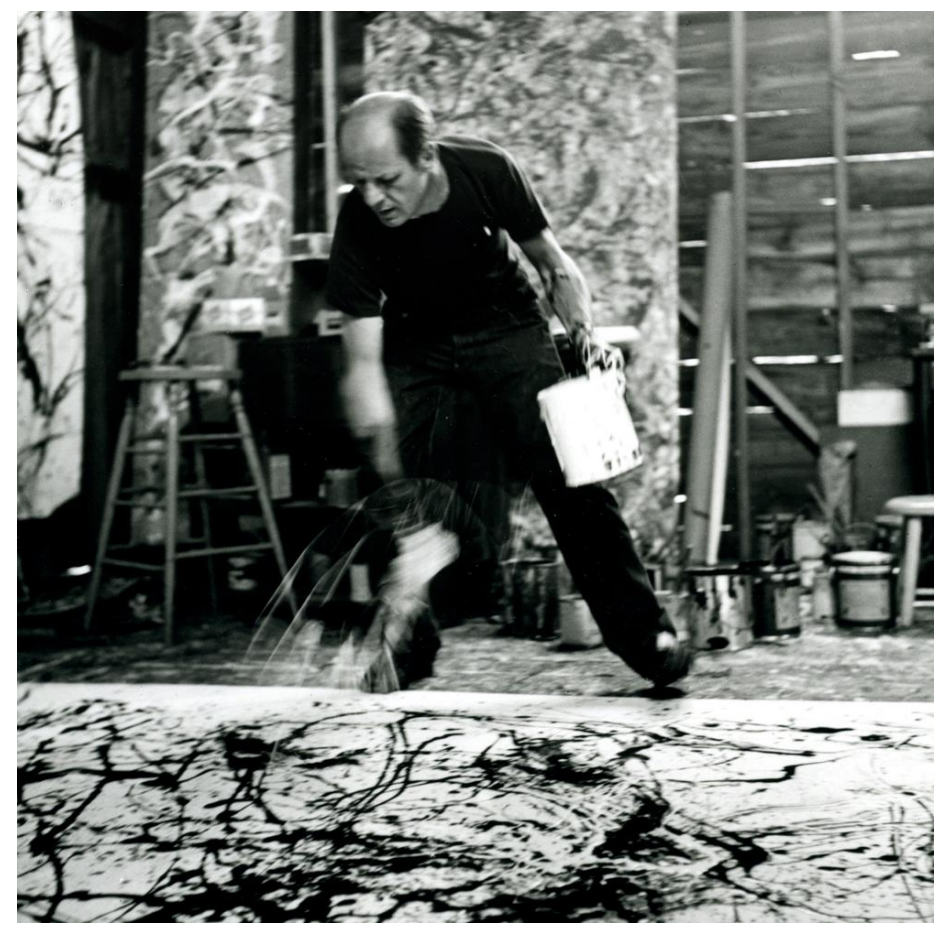

Henceforth the term Action painting, coined in 1952 by Harold Rosenberg (Pollock never defined himself as an action painter). It was only expost, when the process was completed, that his works would be given titles. Although he adhered to an aesthetic, Pollock liberated himself from the category of the pre-designed and finished product (one can also think of the particular case of Calder's mobiles, or of Tinguely's self-destructing kinetic constructions: as of 1960, during an installation in front of New York's Museum of Modern Art, Tinguely fabricated self-destructing "objects", made from iron scraps and pieces of mechanical waste finely soldered together, objects destined to be reduced to dust from friction). In Pollock's case, primary importance is given to the implications of the passage of the canvas resting on the easel - as a representational window - to the canvas laid down on the floor, an arena into which Pollock can enter, crouch down and turn in any direction, facing every bit of space and freeing himself from the tyranny of the horizontal line (it is important to be inside the frame Pollock told the magazine Possibilities, in the winter of 1947). There is no single access door to the painting: you can go in or out anywhere. The margin does not mark the end of the artist's world (and the beginning of the outside, or of reality), but lets it continue, indefinitely. This is valid in an analogous manner for improvisation. By privileging what is in due course, improvisation is, strictly-speaking, endless, notwithstanding 
waning ideas and energy, and concluding narrative cycles. After the flow of music, there is nothing left of the improvisation except a memory - the trace - of something that has already passed. Hence, what remains cannot be represented as the refined, final outcome of a specific intention (cfr. Sparti 2007). It is important to avoid the fallacy of retrospection, which consists in looking at a process from the point of view of a refined product, as if interpreting the process only in function of an anticipated completion.

Thanks to his canvas laid down on the floor, Pollock also has better control over the drippings, so that they are not too randomly scattered (by dripping and mixing paint colors, Pollock is not so much inventing, but rather re-elaborating the technique of dripping which was already current among dadaists and surrealists hence, his nickname "Jack the dripper"). It is not simply a matter of letting loose in an indiscriminate manner but rather of following an additional procedure: Pollock paints "in counterpoint", on successive layers. Again, as in improvisational jazz, what is crucial is the capacity to remain open to the emerging music in such a way as to respond to it creatively. Control and the absence of control alternate in a process that requires the necessary confidence to almost let oneself be led by the changing course of the blobs of color. Which is really the confidence (and the desire) to play, in the musical as well as in the childish sense of the term. It is therefore not by chance that Ornette Coleman chose precisely Jackson Pollock's painting White Light for the cover of his most innovative album: Free Jaz\%:

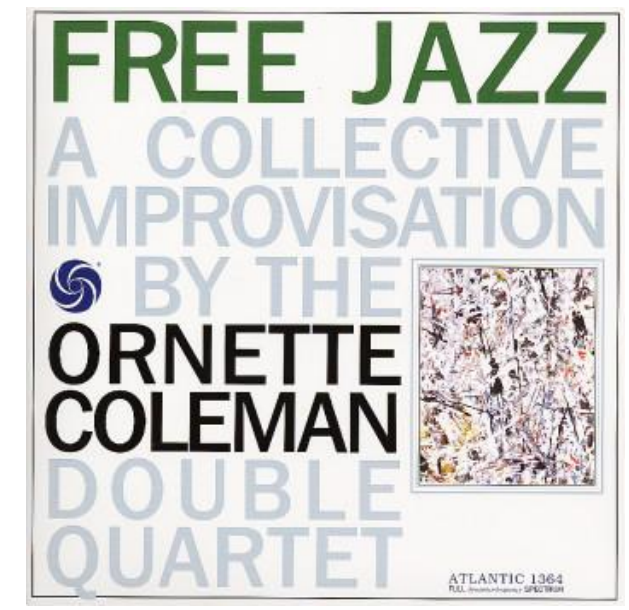

This again evidences the fact that the way in which Pollock played with colors recalls the improvised jazz performance (nor is it by chance that Jane Ira Bloom 
recorded "Chasing Paint", improvising on the soprano saxophone with a visual inspiration provided by Pollock's works).

I would like to conclude this brief analysis with a look at the case of the painter Jeff Schlanger, and his particular visual approach to improvised music. Schlanger transcribes (or better yet, "incorporates") in another artistic medium - the more spatial and "slower" medium of visual arts - the process of dynamic creation of improvised music. His attempt is not one of representing or of capturing a particular moment of the performance, but of witnessing a flow in the course of its execution. For this reason, Schlanger, who simultaneously uses two paintbrushes, starts painting when the performance begins, suspending his actions at the moment the performance ends.

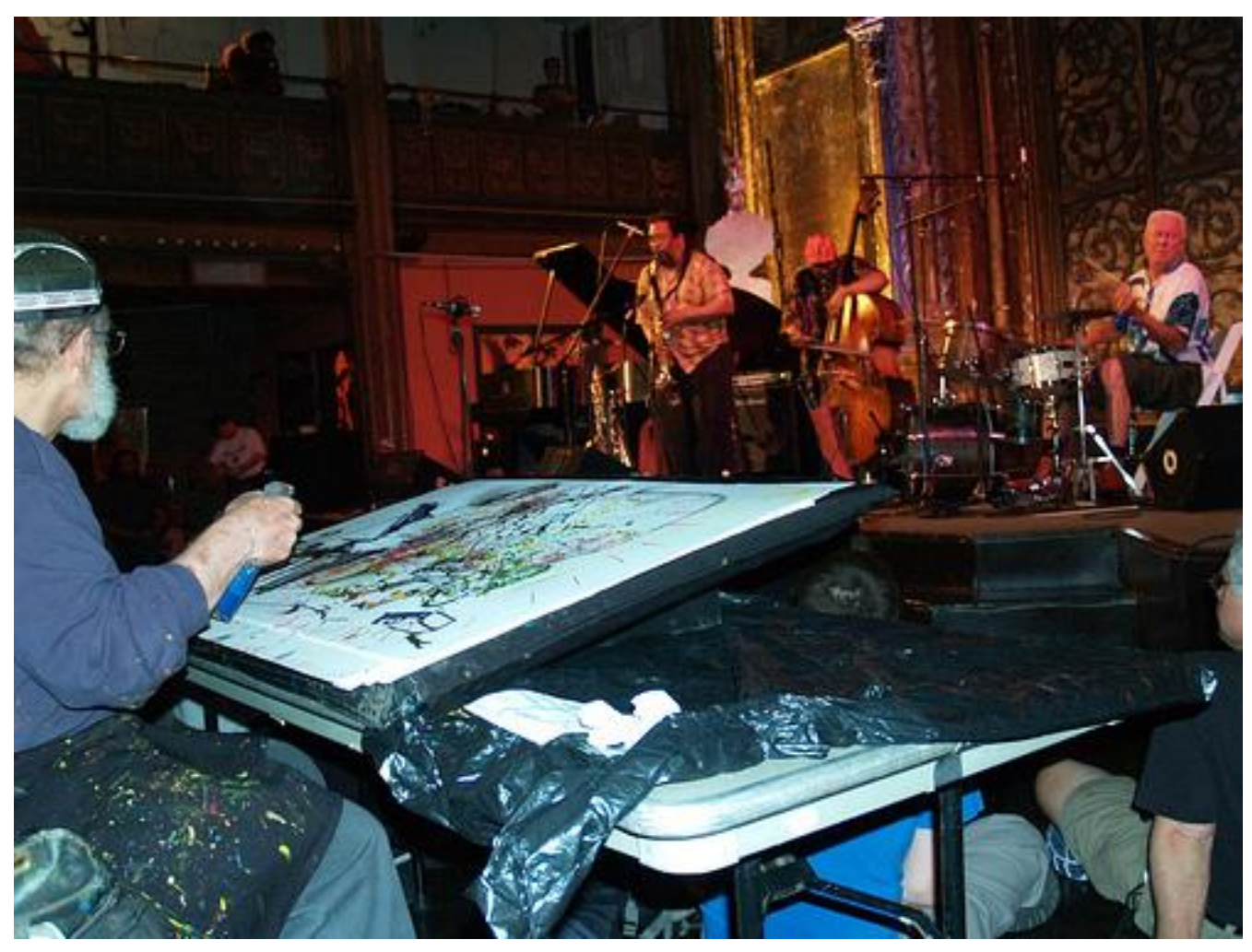

Furthermore, he adapts his assault on the canvas in accordance with the musical progression, more or less intense or aggressive, more or less controlled or splattered. 


\section{Conclusion}

We live in a videocentric age which puts great emphasis on the completed and definitive object, and which has sanctioned the existence of a place of worship for it: the museum. But an improvisation - the verb reveals it better than the noun -is primarily an action, the action of generating music during the course of a performance. By analyzing a solo as a finished product, we risk losing sight of "the phenomenon" itself: the emergence, sound after sound, of a musical sense. In the case of the composer, and especially because he, like many painters, can take all the time he wants to decide what to "express," the process falls into the background and the text that he produces is relevant (also in evaluative terms). The term "composition" still refers to a created product, while the generating process itself appears to be subsidiary. On the contrary, precisely because it is not finalized in an external product (it produces a result, but not a product), improvisation is always an ongoing process, always exposing its own practice. In the improvised solo there is no goal outside the process that might constitute a development toward a conclusive end. And by definition, each process is "in progress" (a completed process is inconceivable). Those who paint or sculpt typically - accumulate objects, solidifying the past, but those who improvise stand alone in the present. Improvisation exists only in its process, exhausting itself as it is produced. Driven by a different logic, a logic situated in, and contingent on, a creation in the present, the jazz musician does not play for eternity, and not even for the following day, but rather for - and in - the specific circumstances in which he finds himself, on this particular evening, with these particular musicians in front of this particular public, situated around him. (Béthune 112).

Although it maintains various relationships with the spatial arts (as we have seen), jazz becomes, all in all, a symbol of that process that always remains on the point of realizing itself, signalling and representing the actual passage of time.

References

Barthes, Roland. Camera Lucida. Reflections on Photography. New York: Hill and Wang, 1982.

Béthune, Christian. Adorno et le jaz:. Analyse d'un déni esthétique. Paris: Klincksieck, 2003.

Cortázar, Julio. Entretiens avec Omar Prego. Paris: Folio/Essais-Inédit, 1986.

---. Gallimard. I racconti. Paris: Einaudi-Gallimard, 1994.

Gentile, Enzo and Francensco Martinelli, eds. Siena Jazz Eye. Catalogo della mostra senese. Milan: Mazzotta, 2008.

Jaurnal of Crass Cultural Image Studies - Revue d'Études Interculturelles de l'Image

Imaginations, I-I, 2010 Copyright (2). Dpen Journal Systems. ISSN - 1918-8439. 
Gitler, Ira. "Il fascino supremo del vinile." Siena Jazz Eye. Catalogo della mostra senese. Eds. Enzo Gentile and Francesco Martinelli. Milan: Mazzotta, 2008. 43-8.

Merlo, Mirco. "How I create." Interview with Keith Jarrett. March 1995. www.keithiarrett.it. Web. 7 Dec. 2010.

Nisenson, Eric. Open Sky. Sonny Rollins and His World of Improvisation. New York: Da Capo Press, 2000.

Sparti, Davide. Il corpo sonoro. Oralità e scrittura nel jazz: Bologna: Il Mulino, 2007. Stein, Gertrud. Lectures in America. New York: Random House, 1935.

Image Notes

Blakey, Art. The Freedom Rider. Blue Note, 1961.

Ira Bloom, Jane. Chasing Paint. Arabesque, 2003.

Bowie, Lester. The Fire «this» Time. In\&Out, 1992.

Coleman, Ornette. Free jaz:. Atlantic, 1960.

---. Crisis. Impulse, 1969.

Coltrane, John. Live at Birdland. Impulse, 1966.

Davis, Miles. Someday my Prince Will Come. Columbia, 1961.

Mead, Dodd. Pollock Painting. New York: Dodd Mead, 1980.

Newman, Joe. Counting Five in Sweden. World Pacific, 1960.

Rogers, John. "Jeff Schlanger." Flicker.

http://www.flickr.com/photos/crayonsemble/679985653/in/set-

72157600581068038/Web. 7 Dec. 2010.

Shepp, Archie. A. Shepp \& the New York Contemporary Five. Storyville, 1963.

---. Fire music. Impulse, 1966.

Simone, Nina. Nina Simone In Concert. Philips, 1964. 


\title{
imaginatinne
}

\section{Publish and Anguish: \\ Reconsidering the Never-Ending Crisis of the Humanities}

\author{
Russell Cabb
}

Bonks discussed in this essay:
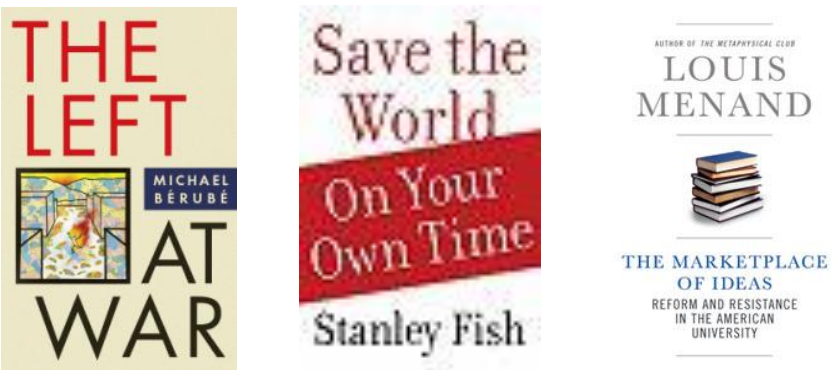

ONE OF THE CENTRAL IRONIES of our times has to be that, in the midst of a deepening existential and financial crisis in humanities departments across North America, a veritable boom in publishing about this crisis has taken place. The number of students majoring in the humanities continues to decline. The trend first began in the 1970s and continues unabated today, along with the decline in new tenure-track positions. ${ }^{1}$ At the same time, however, research in print and online has blossomed, with new online journals being launched all the time. ${ }^{3}$ Many 
of these publications-including the one you're reading now-have sought to address the crisis by appealing to new methodologies and new fields of research. In this context, the word "interdisciplinary" has assumed a sort of magical aura as scholars look for ways to build bridges between their crumbling departments of art, literature, history, and music. New departments, programs, and certificates are created in the hopes that a rebirth of the humanities will inspire a new generation of students and researchers - and maybe, just maybe, lead to an influx of funding. In light of these developments, then, I would like to consider three books by humanities scholars and public intellectuals who come at the crisis from different angles and offer different solutions.

In The Marketplace of Ideas, Louis Menand argues that much of the belly-aching in the liberal arts is the result of a "crisis of legitimation," in which scholars of poststructuralism or Renaissance drama are called upon by politicians, pundits, students, and administrators to justify themselves and their research. It is often a struggle. Because the larger social value of a monograph on the representations of horses in Victorian literature or a journal article on the semiotics of Jennifer Lopez's derriere are not readily apparent to the outside world, academics usually become defensive when asked to explain themselves. "The instinctive response of liberal educators is to pull up the drawbridge, to preserve college's separateness at any price," Menand writes, continuing: "But maybe purity is the disease" (55). Furthermore, academics in the liberal arts disdain their colleagues in professional schools - the Business School, the Law School, etc.—, believing that, "the practical is the enemy of the true" (Menand, 57). Menand may be oversimplifying matters, but anyone who has spent time in a large North American research institution will recognize the problem. Although the original prestige of the university resided in disinterested study of classics, history, and philosophy, the money and jobs are in the professional fields. As the august halls of the English Department crumble, a billion dollar glass house for the study of nanotechnology is erected across campus. Superstar scientists earn millions while salaries in the history department barely keep pace with inflation. How did we get here and what should be the response?

According to Menand, the seeds of the current crisis were sown in the post-Civil War landscape of the state-run university. Before the Civil War, universities still functioned in the mode of the medieval, scholastic institution, with a theological foundation. Students were, in many ways, monastics. The doctrine of in loco parentis meant that the relationship of students to professors resembled a close mentorship, not a professional training. This gave way to the great professionalization of the university, a model which still holds today, despite the recent trend towards a market-based-or even neoliberal-model in which 
educational value is determined by the price the market will bear. While professionalization and secularism freed the 19th century scholar to pursue new lines of inquiry, new methodologies, etc., professionalization is now our central problem, according to Menand. Frustrated by a lack of respect, funding, and interest from the general public, academics try to replicate themselves in a new generation of graduate students who are kept in graduate school for, on average, an entire decade, training for jobs that no longer exist. That institutions rely on these professional students to provide cheap academic labor to undergraduates only makes the situation seems that more intractable.

The result of all this is a stifling homogeneity borne out by statistical research. Menand cites a study of the political leanings of professors in the humanities and social sciences that found that in the 2004 election, 95\% of professors in the humanities at elite universities voted for Kerry, while $0 \%$ voted for Bush. The leftof-center political tendencies of professors is well-known and well-documented, although its causes and effects are still being debated. Conservatives critics have used these kinds of statistics to claim there is a liberal bias shutting out conservative voices in academe. There are mistaken, Menand says. The problem is not political, but professional. Professors seek to clone themselves professionally, and political identity is but one aspect of the creeping homogeneity.

According to others, such as Michael Bérubé (who I will turn to in a moment), the politics of the university are not as one-sided as Menand claims. Bérubé documents in The Left at $W$ ar the divisions within the academic Left since 9/11 have amounted to virtual civil war. Divisions between cultural studies critics, deconstructionists, and gender studies people, Menand seems to argue, do not really constitute the struggle for the soul of the academy so much as they are symptoms of a system in which academics posture to be iconoclasts and nonconformists in a homogeneous culture. In reality, political differences obscure a more pressing reality of sclerosis and professional conformity. Menand wants the professoriate to stop replicating itself when the job prospects for graduates are so dim. He also wants to shorten the time humanities PhDs spend in their apprenticeships. In a recent interview on National Public Radio, Menand contrasted the amount of time the average doctor or lawyer spent in graduate school with the average English PhD:

Now, if you think that you can get a law degree and argue a case before the Supreme Court in three years, get a medical degree and cut somebody open in four years. And there are a number of factors involved in that. One obviously is the job market. Another is the fact of part-time hiring. That is, a lot of 
graduate students teach college students, and they do it quite full time for very little money because they are still enrolled as students in their institutions. ${ }^{2}$

While The Marketplace of Ideas is not a book of solutions, Menand clearly wants two things: to shorten the amount of time required for the degree, and expand the narrow definition of research in the humanities. Insisting on "pure" research is keeping professors from other work that would increase their visibility outside academia.

While I was sympathetic to Menand's argument and applaud some of his solutions, there is something missing from this book. Curiously, it the same thing missing from Stanley Fish's Save the World on Your Own Time: a cogent, clear-headed defense of the humanities. Both writers seem reluctant to defend the humanities while pausing to critique many of the most shopworn explanations. Sure, it may be cliché or trite to defend the humanities as a necessary tool to becoming a critical, aware citizen, or a well-rounded member of society, but what are we to say when politicians, donors, and parents ask us what it is, exactly, we do? Menand contends that universities are in the knowledge business. The job of the university, then, "is simply the production and dissemination of knowledge." Any administrator could do better than this; Menand does not address why or how certain forms of knowledge are in ascendency and some-including the traditional fields of the humanities_-are in decline.

Menand adopts a disinterested and slightly bemused attitude towards The Crisis (he is a New Yorker writer, after all); Bérubé and Fish are grumpy, even vitriolic, at times. Both cast about for culprits and find plenty of blame to go around. The Crisis, however, is slightly different in each formulation. For Fish, the underlying problem is two-fold: on the one hand, academics-especially those in the humanities and social sciences - have forsaken their job-teaching and researchfor a much larger enterprise: that of saving the world. On the other hand, nonacademics - especially politicians looking to shore up populist credentials-have intruded into a world they do not understand and which does not belong to them.

For Fish, academics have brought some of the backlash upon themselves by overreaching beyond the boundaries of their disciplines. Fish boils his thesis down to the following commandment: "Do your job," by which he means: hew closely to the established — although arbitrarily constructed — strictures of your discipline. By the flip side of the same coin, Fish also admonishes faculty to "not let anyone do your job for you," by which he means: don't let administrators, politicians, or parents tell you how to obey those same established-although arbitrarily constructed-strictures of your discipline. 
Fish cites many examples (although they mostly seem to come from English Departments) of scholars turning their métier of teaching and research into student indoctrination. He quotes an English professor at Kent State, Mark Bracher, extensively. He finds Bracher's views on politics and the humanities emblematic of what has gone wrong in academia. Fish quotes Bracher:

Many literature teachers and scholars are committed to promoting social justice through both their teaching and their scholarship...But despite this commitment of critical and pedagogical activity to political and ethical ends, there is little evidence that literary study had made much difference in the injustice that permeates our world. (170)

Fish interrupts this self-critical account of radical pedagogy to make his own evaluation. "To me, that's the good news," Fish says of Bracher's admission that literary studies have not healed the world. Fish summarizes Bracher's position and then demolishes it:

Injustice would be diminished, Bracher believes, if sympathy and compassion for others were increased. And that, he says, should be the work of the classroom...But literary study could have this effect only if it were no longer literary study, that is, if the study of stylistic effects, genres, meters, verse forms...were made instrumental to an end not contemplated by those who either produce the literature or consume it. (171)

What he seems to be arguing for then, is a sort of literary study for literary study's sake doctrine. But why study literature in the first place if it teaches you nothing about what it means to be human? To me, it seems Fish has conflated those who wish to use literature as a didactical tool to politicize students and those who wish to use literature as a critical tool to help students understand what it means to be a human being. The former see literature as a weapon in an ideological struggle and the latter see literature as a mode for self-reflection, criticism, and inspiration, an inexhaustible source for debate about our deepest conflicts and dreams.

Fish, the cranky iconoclast, questions the foundations of even the most banal, feelgood statements about the mission of higher education. He ridicules former Harvard University President Derek Bok for saying that universities should strive to "help develop such virtues as racial tolerance, honesty, and social responsibility" (11-12) Bah! Humbug! says Ebenezer Fish, who, while not advocating a ban on such topics from the classroom, would narrowly restrict them. Debates about social justice, racism, and sexism should always be, in his words, "academicized." 
That is, debates about anything political should be placed within the analytical framework of an established discourse and never be endorsed nor denounced.

Fish, in other words, is in the unenviable - and unpopular-position of sticking up for everything that Menand diagnoses as sclerotic and reactionary about academe. From an intellectual conservative-Allan Bloom, say-Fish's position would be understandable. He is, after all, simply defending the institution to which he has dedicated an entire career. Nevertheless, this is the same Stanley Fish who was at the center of the debate about postmodernity and cultural relativism when the topics first appeared on the scene a few decades ago. This is odd since a younger Fish might have concurred with Menand that debates about disciplinarity, core education, and, indeed, the very purpose of higher education, change all the time. For Fish, however, the job of the English Department has always been, and forever shall be, the study of meter and narratology in Milton and Shakespeare. Fish, whose name was once synonymous with anti-foundationalism, is now asking us to accept the status quo as a fixed, atemporal Truth. Of course, finding the Truth is the self-assigned task most universities seek to achieve. And here we come to one of the defining paradoxes of modern academic life in the humanities and social sciences. Since the 1960s and the waves of post-structuralism, postcolonialism, and post-modernism, Truth-objectively verifiable conclusions we can come to about a text, a culture, an historical event-is increasingly bracketed off by Context. We don't so much seek the Truth so much as we seek to understand the construction of truths, a pursuit perhaps not as noble as Truthseeking but every bit as necessary and much more honest.

Michael Bérubé in the Left at War is not so much concerned about the relationship between academics and the wider world as he is with a certain strand of leftist thinking that, while not exclusively academic, has sought refuge within the doctrine of academic freedom to nurture itself. In a way, Bérubé's book is a bit of an outlier in this debate; it is primarily concerned with the discourse of the Left as a reaction to the policies of the Bush Administration. Bérubé's book is an invaluable and compelling guide to the cultural politics of the academic Left in the past decade or so, but it is as exhausting as it is exhaustive. Furthermore, it is really two books: one about the reaction of what he calls the "Manichean Left" to the policies of the Bush Administration and another about the valuable lessons cultural studies scholar Stuart Hall has to teach U.S. academics about the relationship between the marketplace and cultural production. Yes, Bérubé does valiantly attempt to pull these two themes together, but it is in vain.

There is a certain righteous indignation in the Left at War that becomes tediouseven to someone (such as this writer) who agrees with Bérubé politically. At the

Jaurnal of Crass Cultural Image Studies - Revue d'Études Interculturelles de l'Image Imaginations, I-I, 2010 Copyright (2). Open Journal Systems. ISSN - 1918-8439. 
heart of this indignation is the reaction among the radical left to the attacks of 11 September 2001. Some of the names-Noam Chomsky, Slavoj Žižek-will be familiar, while others are quite obscure. Almost all of them occupy academic positions and Bérubé takes great pains to offer elaborate deconstructions of their arguments. What bothers Bérubé is that the radical Left - the Manichean Left, in his words-fails to distinguish between the neoconservatives of the Bush Administration and moderate, social democratic leftists like himself, who are part of a "loyal opposition." Any attempt to distinguish between the wars in Afghanistan and Iraq, for example, indicates that someone is a lackey for Empire. While some conservative critics have called this faction of the Left the "academic Left," Bérubé points out that many figures associated with this school of thought have "nothing but contempt for the kind of poststructuralist theorizing common to the properly 'academic' left" (7). Robert McChesney, for example, spent much of the 1990s attacking the cultural critic John Fiske, who had claimed that consumers could resist the hegemony of mass media by creating their own meanings in a Madonna song or the space of a shopping mall.

By the time Bérubé cites a Lawrence Grossberg essay called "Cultural Studies vs. Political Economy: Is Anyone Else Bored with This Debate?" my initial enthusiasm had worn off and, indeed, a certain amount of boredom crept in. There were, however, still a few more chapters to go: a few more detailed critiques of Chomsky's Manichean views of U.S. foreign policy, a few more declarations of Bérubé's faithfulness to the core of Leftist values, a few more hand-wringing defenses of the initial invasion of Afghanistan. Bérubé is a wonderful writer who churns out the occasional witticism worthy of The Daily Show. He is more engaging than Menand and more subtle than Fish; still, one is left feeling completely worn out-indeed, bored-with arguments about whether it is possible to resist consumer capitalism or whether any belief in resistance is indicative of false consciousness. And, regardless of what one thinks of the radical Left of Chomsky, et. al., it bears remembering that its influence is so small, so marginal in terms of the larger political debates in the United States, as to be inconsequential. Indeed, the presence of a radical critique of culture and politics would enliven the public sphere. Surely, a social democrat like Bérubé would agree that including voices of anti-capitalist thinkers on cable TV would complicate and enrich discussions about topics like the financial crisis and the state of constant wars. But that would mean doing someone else's job, something that Stanley Fish would rather leave for the Glenn Becks of the world.

\section{References}

Journal of Crass Cultural Image Studies - Revue d'Études Interculturelles de I'Image Imaginations, I-I, 2010 Copyright (2). Open Journal Systems. ISSN - 1918-8439. 
Bauerlein, Mark, Mohamed Gad-el-Hak, Wayne Grody, Bill McKelvey, and Stanley W. Trimble, "We Must Stop the Avalanche of Low-Quality Research," Chronicle of Higher Education, June 13, 2010.

Bérubé, Michael. The Left at War. New York: New York University Press, 2009.

Chase, William. "The Decline of the English Department." American Scholar. Autumn (2009). < http://www.theamericanscholar.org/the-decline-of-theenglish-department/P

Fish, Stanley. Save the World on Your Own Time. Oxford: Oxford University Press, 2008.

Menand, Louis. The Marketplace of Ideas: Reform and Reaction in the American University. New York: W.W. Norton, 2010.

\section{Endnotes}

1 See William Chace: "In one generation, then, the numbers of those majoring in the humanities dropped from a total of 30 percent to a total of less than 16 percent; during that same generation, business majors climbed from 14 percent to 22 percent. Despite last year's debacle on Wall Street, the humanities have not benefited; students are still wagering that business jobs will be there when the economy recovers."

2 See Mark Bauerlein, Mohamed Gad-el-Hak, Wayne Grody, Bill McKelvey, and Stanley W. Trimble.

3 “Author Louis Menand On Reforming U.S. Universities," All Things Considered, NPR, January 18, 2010. 